YOEL RODRIGUEZ PINTO

ECOTOXICIDADE DO COBRE E POSSÍVEIS BIOMARCADORES NO RESERVATÓRIO GUARAPIRANGA

Tese apresentada ao Programa de PósGraduação em Biologia Celular e Tecidual do Instituto de Ciências Biomédicas da Universidade de São Paulo para obtenção do Título de Doutor em Ciências. 
YOEL RODRIGUEZ PINTO

\section{ECOTOXICIDADE DO COBRE E POSSÍVEIS BIOMARCADORES NO RESERVATÓRIO GUARAPIRANGA}

Tese apresentada ao Programa de PósGraduação em Biologia Celular e Tecidual do Instituto de Ciências Biomédicas da Universidade de São Paulo para obtenção do Título de Doutor em Ciências.

Área de concentração: Biologia Celular e Tecidual

Orientador: Professor Dr. José Roberto Machado Cunha da Silva

Versão original 
DADOS DE CATALOGAÇÃO NA PUBLICAÇĀO (CIP)

Serviço de Biblioteca e Informação Biomédica do

Instituto de Cièncias Biomédicas da Universidade de São Paulo

Oreproduçáso total

Pinto, Yoel Rodriguez.

Ecotoxicidade do cobre e possiveis biomarcadores no reservatório Guarapiranga / Yoel Rodriguez Pinto. - São Paulo, 2016.

Orientador. Prof. Dr. José Roberto Machado Cunha da Silva.

Tese (Doutorado) - Universidade de Säo Paulo. Instituto de Ciências Biomédicas. Departamento de Biologia Celular e do Desenvolvimento. Área de concentraçäo: Biologia Celular e Tecidual. Linha de pesquisa: Ecotoxicologia com enfase nos metais pesados, alterações histológicas e estresse oxidativo.

Versäo do título para o inglês: Copper ecotoxicity and possible biomarkers at Guarapiranga reservoir.

1. Tilápia do Nilo 2. Cobre 3. Estresse Oxidativo 4. Alteraç̋̈es histológicas 5. Enzimas I. Silva, Prof. Dr. José Roberto Machado Cunha da II. Universidade de Säo Paulo. Instituto de Ciências Biomédicas. Programa de Pós-Graduaçäo em Biologia Celular e Tecidual III. Título. 
Candidato(a): $\quad$ Yoel Rodriguez Pinto.

Título da Tese: $\quad$ Ecotoxicidade do cobre e possiveis biomarcadores no reservatório Guarapiranga.

Orientador(a):

Prof. Dr. José Roberto Machado Cunha da Silva.

A Comissão Julgadora dos trabalhos de Defesa da Tese de Doutorado, em sessão pública realizada a I. , considerou

( ) Aprovado(a)

( ) Reprovado(a)

\begin{tabular}{|c|c|}
\hline Examinador(a): & $\begin{array}{l}\text { Assinatura: .. } \\
\text { Nome: ......... } \\
\text { Instituição: ... }\end{array}$ \\
\hline Examinador(a): & $\begin{array}{l}\text { Assinatura: . } \\
\text { Nome: ......... } \\
\text { Instituição: ... }\end{array}$ \\
\hline Examinador(a): & $\begin{array}{l}\text { Assinatura: . } \\
\text { Nome: ......... } \\
\text { Instituição: ... }\end{array}$ \\
\hline Examinador(a): & $\begin{array}{l}\text { Assinatura: . } \\
\text { Nome: ........ } \\
\text { Instituição: ... }\end{array}$ \\
\hline Presidente: & $\begin{array}{l}\text { Assinatura: .. } \\
\text { Nome: .......... } \\
\text { Instituição: ... }\end{array}$ \\
\hline
\end{tabular}




\section{Certificado}

Certificamos que o protocolo registrado sob $\mathrm{n}^{\circ} \mathbf{1 1 2}$ nas fls. 108 do livro $\mathbf{0 2}$ para uso de animais em experimentação, sob a responsabilidade do Prof(a) Dr(a)) José Roberto Machado Cunha da Silva, Coordenador (a) da Linha de pesquisa "Importância do fracionamento químico para a ecotoxicologia do cobre no reservatório Guarapiranga" do qual participam o(s) aluno(s) Yoel Rodríguez Pinto , Karina Fernandes Oliveira Rezende e o pesquisador Raúl Bonne Hernández, está de acordo com os Principios Éticos de Experimentação Animal adotado pela Sociedade Brasileira de Ciência de Animais de Laboratório (SBCAL) e foi aprovado pela COMISSÃO DE ÉTICA NO USO DE ANIMAIS (CEUA) em 15.09.2011, com validade de 3 anos.

São Paulo, 22 de setembro de 2011.

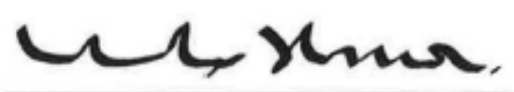

Prof.Dr.Wothan TaVares de LIMA Coordenador CEUA - ICB/USP

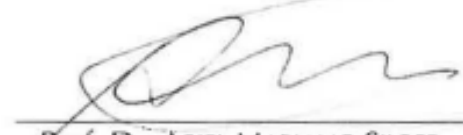

Prof. Dr. ARIel MARIANo SILber Secretário CEUA - ICB/USP 
Q Dedico esta Obra a minha mãe Gladys que me trouxe até aqui. Squeles de quem sou guia as novas gerasâes: Samuel (Camu), meu sobrinho, meu afithado do corasão. As meu fitho. Shatheus mesmo longe levo comigo. 


\section{AGRADECIMENTOS}

Teve algumas entidades divinas e terrenais que fizeram possível eu chegar até este momento e defender a tese do doutorado o terceiro que faço e o primeiro que finalizo.

- Primeiramente muito obrigado a Jeová meu Deus, a Santa Rita mi Santa das causas impossíveis. A minha mãe Gladys Guerra que Deus, a tenha sei que desde lá cuida de mim.

- Obrigado a Bonne e Zé Roberto um por me trazer de volta a este desafio e outro, por me oferecer um ponto de entrada para atingir o objetivo. Ambos os tenho não como orientadores e sim como amigos.

- Muito obrigado ao Breno pelo apoio nas analises químicas e por colocar o laboratório a minha disposição.

- Obrigado o Alexandre da Farmácia pelo apoio nas analises enzimáticas.

- Isabella, ela sempre foi muito insistente para eu não desistir e largar tudo nas muitas horas que senti essa vontade. Muito obrigado.

- Grato a Karina, Débora, Douglas, Tania e o João pela ajuda nos experimentos e coletas.

- Muito Obrigado a Ignácio F. Bencomo pelo apoio e consideração.

- A Cris, que chegou para dar a força final e definitiva sem a sua cooperação tivesse sido bem mais difícil. O apoio, cuidado e amor que me provê são inestimáveis. Por tudo isso muitíssimo obrigado!!

- Agradeço a CAPES pela Bolsa fornecida e a FAPESP pelo auxilio de pesquisa, também a todos os professores e funcionários do Departamento de Biologia Celular e Tecidual e do ICB. 
I Have no Special Talent. Im only

Passionately curious.

$\mathcal{A}$ lbert Finstein 


\section{RESUMO}

RODRIGUEZ PINTO, Y. Ecotoxicidade do cobre e possíveis biomarcadores no reservatório Guarapiranga. 2016. 101 f. Tese (Doutorado em Biologia Celular e Tecidual) Instituto de Ciências Biomédicas, Universidade de São Paulo, São Paulo, 2016.

$\mathrm{Na}$ atualidade, a poluição das águas constitui um dos mais sérios problemas ambientais, sendo os resíduos domésticos, industriais e agrícolas as principais fontes de poluição pela contaminação por metais. $\mathrm{O}$ cobre $(\mathrm{Cu})$ é um íon essencial para as plantas, animais e para a saúde humana devido a sua utilidade em várias funções catalíticas e de transporte nas células vivas e suas organelas, em especial a mitocôndria. Este é um elemento requerido por enzimas oxidativas como superóxido dismutase, catalase, peroxidase e citocromo oxidase na síntese de hemoglobina e está ligado à $\alpha$-globulina no sangue, sendo transportado para rins, coração, sistema nervoso central, ossos e estocado principalmente no fígado. Em elevadas concentrações, este elemento pode ser extremamente tóxico para os organismos. A Tilápia do Nilo (Oreochromis niloticus) é amplamente utilizada na aquicultura como fonte de alimentação, e é comumente sugerida como bioindicador da contaminação das águas. O fracionamento do $\mathrm{Cu}$ no sistema aquático do reservatório de Guarapiranga foi realizado para conhecer a distribuição deste metal e os possíveis riscos ambientais associados, bem como os possíveis biomarcadores e mecanismos de toxicidade do Cu na Tilápia do Nilo (Oreochromis niloticus). Determinação das variáveis físico - químicas da água, índice do estado trófico, alterações histológicas, o índice hepatosomático, bioacumulação do $\mathrm{Cu}$ nos tecidos branquial e hepático e marcadores de estresse oxidativo como superóxido dismutase (SOD), catalase (CAT), glutationa peroxidase (GPx) nos fígados foram realizados. Os resultados mostraram que as maiores concentrações estavam na fração $\mathrm{Cu}$ dissolvido, no período chuvoso, provavelmente ao aumento que as chuvas provocam na dinâmica das águas na represa e ao grande aporte de águas de lixiviação. A exposição a maiores concentrações de $\mathrm{Cu}$ provocou alterações como, descolamento do epitélio basal das lamelas, aneurismas, fusão lamelar entre outros nas brânquias, vacuolização e necroses no fígado. Os fígados mostraram-se grandes acumuladores do metal, por outro lado, o índice hepatosomático apresentou uma diminuição em relação ao aumento do $\mathrm{Cu}$. Esta diminuição pode estar relacionada com o aumento do gasto energético como resposta à exposição ao $\mathrm{Cu}$. As atividades enzimáticas não apresentaram diferenças significativas, com exceção da CAT. Mas de forma geral, as atividades das enzimas 
antioxidantes CAT, SOD e GPX, apresentaram alterações após 120 horas de exposição ao Cu, proveniente dos 4 pontos de coleta da Represa Guarapiranga.

Palavras-chave - Tilápia do Nilo. Reservatório. Contaminação por metais. ROS. IHS. IAH. Cobre. Estresse oxidativo. 


\begin{abstract}
RODRIGUEZ PINTO, Y. Copper ecotoxicity and possible biomarkers at Guarapiranga reservoir. 2016. 101 p. Ph. D. Thesis (Cell and Tissue Biology) - Instituto de Ciências Biomédicas, Universidade de São Paulo, São Paulo, 2016.

The water pollution is one of the most serious environmental problems now a day. The contamination of water is caused mainly for the human activities in the form of domestic and industrial waste, been the two last ones the main cause of the aquatic environment contamination with metals. Copper is an essential ion for plants, animals and for human health, due to its function in several catalytic functions and transport in the cell, specially in mitochondria. This element, is also required by the antioxidant enzymes like, catalase, superoxide dismutase, peroxidase, cytochrome oxidase and is used in hemoglobin synthesis. Although the crucial role of $\mathrm{Cu}$ in several enzymatic processes, this heavy metal can exert adverse toxicological effects, when present in high concentrations in water. In fact, it is potentially toxic when the internal available concentration exceeds the capacity of physiological detoxification processes. The Nile Tilapia (Oreochromis niloticus) a widely used species in aquaculture for food supply and has been suggested as a bio indicator of water contamination. The main purpose of this study is to determine the effects of copper exposure from natural sources in the liver and gills of Nile Tilapia. $\mathrm{Cu}$ fractioning in the aquatic system of the reservoir was done to know the metal distribution and the possible risk associated as well as the possible biomarkers and toxic mechanism of $\mathrm{Cu}$ in the Nile Tilapia. The determination of water's physic - chemistry parameters, trophic index, histological alterations, hepatosomatic index, $\mathrm{Cu}$ bioaccumulation in livers and gills and oxidative stress enzymes like, CAT, SOD and GPX were done. Our results show that the higher values of $\mathrm{Cu}$ concentration were in the dissolved $\mathrm{Cu}$ and in the rainy season, probably due to the increase in water dynamics and the great intake of water in the reservoir that comes with many dissolved matter from surround fields. The exposition o the fishes to a higher $\mathrm{Cu}$ concentrations altered the gills; aneurism, lamellar fusion, basal epithelium lifting. In the liver the alterations were, vacuolization and necrosis among others. The $\mathrm{Cu}$ bioaccumulation was more significate in the rainy season, where the higher $\mathrm{Cu}$ concentrations were found and in the livers that were the greatest bioaccumulation organs, and the other hand the hepatosomatic index decreased with higher $\mathrm{Cu}$ concentrations, this phenomenon could be related with the increase of energy consumption caused by the exposition to $\mathrm{Cu}$ high concentrations. There was no significant difference in the enzyme activities with the exception of CAT that increased with $\mathrm{Cu}$ increase,
\end{abstract}


nevertheless in general, the enzyme activities of SOD, CAT and GPx were altered some how after 120 hours of $\mathrm{Cu}$ treatment, with water sample from 4 points located at Guarapiranga Reservoir.

Keywords - Nile Tilapia. Reservoir. Metal contamination. Copper. ROS. HAI. HIS. Oxidative stress. 


\section{LISTA DE FIGURAS}

Figura 1 - Represa Guarapiranga mapeamento de pontos de amostragem........................................... 34

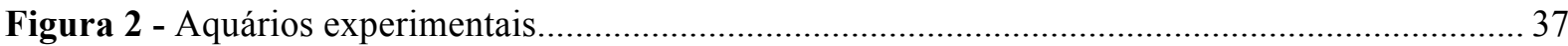

Figura 3 - Quatro maiores alterações histológicas (a) controle, (b) edema, (c) lifting de epitélio,

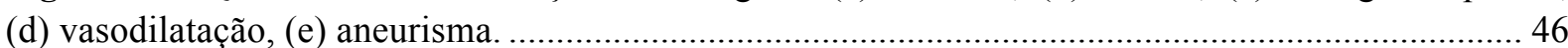

Figura 4 - Microfotografia mostrando cortes de $5 \mu \mathrm{m}$ de brânquias coradas com H\&E..................... 47

Figura 5 - Microfotografia mostrando cortes de $5 \mu \mathrm{m}$ de fígado, corados com H\&E........................ 48 


\section{LISTA DE GRÁFICOS}

Gráfico 1 - IAH das brânquias por grupo de tratamento no período seco (média e desvio padrão)..... 49 Gráfico 2 - IAH por grupo de tratamento nos fígados para o período seco (média e desvio padrão). . 51 Gráfico 3 - Comprimento da lamela por grupo de tratamento e controle em micrómetros no período seco.

Gráfico 4 - Área das células de muco por grupo de tratamento e controle em micrómetros quadrados no período seco.

Gráfico 5 - IAH por grupo de tratamento para as brânquias no período chuvoso (média e desvio padrão).

Gráfico 6 - IAH por grupo de tratamento para os fígados, período chuvoso (média e desvio padrão). 55

Gráfico 7 - Comprimento da lamela por grupo de tratamento e controles em micrómetros no período chuvoso (média e desvio padrão)...

Gráfico 8 - Área das células de muco por grupo de tratamento e controles em micrómetros quadrados no período chuvoso (média e desvio padrão). 56

Gráfico 9 - Comparação das médias do IAH Branquial no período de Seca vs Chuva. .57

Gráfico 10 - Comparação das médias do IAH Fígado no período de Seca vs Chuva.

Gráfico 11 - Médias de bioacumulação com os desvios padrões na brânquia para o período chuvoso.

Gráfico 12 - Médias de bioacumulação com os desvios padrões no fígado para o período chuvoso... 59

Gráfico 13 - Médias de bioacumulação de $\mathrm{Cu}$ com os desvios padrões nas brânquias no período seco.

Gráfico 14 - Médias de bioacumulação de $\mathrm{Cu}$ com os desvios padrões nos fígados no período seco . 61

Gráfico 15 - Médias de bioacumulação de $\mathrm{Cu}$ com os desvios padrões nas brânquias nos períodos Seca vs Chuva..

Gráfico 16 - Médias de bioacumulação de $\mathrm{Cu}$ com os desvios padrões nos fígados nos períodos Seca vs Chuva.

Gráfico 17 - Médias do fator de bioacumulação para as brânquias nos períodos seco e chuvoso. ....... 62

Gráfico 18 - Médias do fator de bioacumulação para fígados nos períodos seco e chuvoso.

Gráfico 19 - Médias do fator de bioacumulação para as brânquias e fígados no período chuvoso....... 63

Gráfico 20 - Médias do fator de bioacumulação para as brânquias e fígados no período de seca......... 63

Gráfico 21 - Médias de IHS com os desvios padrões por grupo de tratamento no período seco. ......... 66

Gráfico 22 - Médias de IHS com os desvios padrões por grupo de tratamento no período chuvoso... 66

Gráfico 23 - Comparação das médias de IHS no período de Seca vs Chuva.

Gráfico 24 - Média da atividade da catalase $(\mathrm{U} / \mathrm{mL})$ no período da seca.

Gráfico 25 - Média da atividade da catalase $(\mathrm{U} / \mathrm{mL})$ no período chuvoso. 
Gráfico 26 - Média da atividade da Catalase $(\mathrm{U} / \mathrm{mL})$ no período chuvoso e seco. 70

Gráfico 27 - Média da atividade SOD $(\mathrm{U} / \mathrm{mL})$ no período seco........................................................ 71

Gráfico 28 - Média da atividade SOD (U/mL) no período chuvoso.................................................... 72

Gráfico 29 - Média da atividade SOD $(\mathrm{U} / \mathrm{mL})$ no período chuvoso vs seco....................................... 72

Gráfico 30 - Média da atividade GPx (U/L) no período seco................................................................. 74

Gráfico 31 - Média da atividade GPx (U/L) no período chuvoso........................................................ 75

Gráfico 32 - Média da atividade GPx (U/L) no período seco vs chuvoso............................................ 75 


\section{LISTA DE TABELAS}

Tabela 1 - Pontos de amostragem e descrição.

Tabela 2 - Dados das medições insitu na Represa Guarapiranga no período seco.

Tabela 3 - Dados das medições insitu na Represa Guarapiranga no período chuvoso...................... 41

Tabela 4 - Dados das variáveis físico - químicas no período seco........................................... 42

Tabela 5 - Dados das variáveis físico - químicas no período chuvoso......................................... 42

Tabela 6 - Índice de Estado Trófico nos períodos seco e chuvoso. .................................................43

Tabela 7 - Concentrações de Cu por fração na Represa Guarapiranga período seco (mg/L)............. 44

Tabela 8 - Concentrações de Cu por fração na Represa Guarapiranga período chuvoso (mg/L)........ 44

Tabela 9 - IAH das brânquias por indivíduo e grupo de tratamento período seco. ...........................49

Tabela 10 - Índices de Alterações Histológicas para brânquias no período seco. ...............................50

Tabela 11 - IAH por indivíduo e grupo de tratamento para os fígados período seco.......................50

Tabela 12 - Índices de Alterações Histológicas para fígados no período seco................................51

Tabela 13 - IAH por indivíduo e grupo de tratamento para as brânquias no período chuvoso. ...........53

Tabela 14 - Índices de Alterações Histológicas para brânquias no período chuvoso..........................54

Tabela 15 - IAH por indivíduo e grupo de tratamento para os fígados no período chuvoso...............55

Tabela 16 - Índices de Alterações Histológicas para fígados no período chuvoso.............................55

Tabela 17 - Bioacumulação de $\mathrm{Cu}$ nas brânquias $(\mathrm{mg} / \mathrm{L})$ no período chuvoso. ................................. 58

Tabela 18 - Bioacumulação de $\mathrm{Cu}$ nos fígados $(\mathrm{mg} / \mathrm{L})$ no período chuvoso...................................58

Tabela 19 - Bioacumulação de $\mathrm{Cu}$ nas brânquias $(\mathrm{mg} / \mathrm{L})$ no período seco......................................60

Tabela 20 - Bioacumulação de $\mathrm{Cu}$ nos fígados $(\mathrm{mg} / \mathrm{L})$ no período seco. ......................................60

Tabela 21 - Valores em \% dos IHS para os peixes por tratamento no período seco. ........................64

Tabela 22 - Valores em \% dos IHS para os peixes por tratamento no período chuvoso....................65

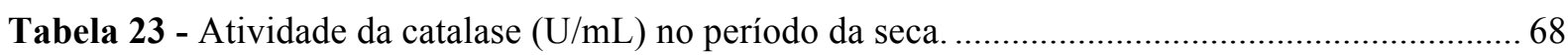

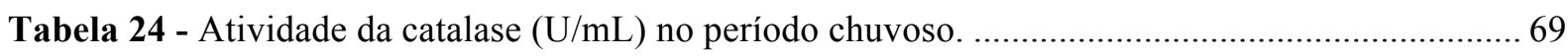

Tabela 25 - Atividade SOD $(\mathrm{U} / \mathrm{mL})$ no período seco. ..................................................... 70

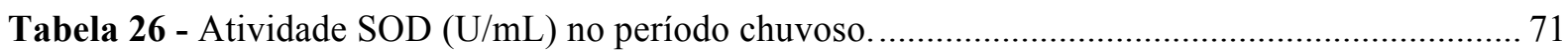

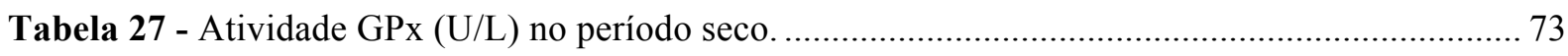

Tabela 28 - Atividade GPx (U/L) no período chuvoso.................................................. 74 


\section{LISTA DE ABREVIATURAS, SIGLAS E SÍMBOLOS}

APPs - Áreas de Preservação Permanente

CAT - Catalase

CETESB - Companhia Ambiental do Estado de São Paulo

$\mathrm{Cu}-$ Cobre

$\mathrm{Cu}^{+}$- Íon Cuproso

$\mathrm{Cu}^{2+}$ - Íon Cúprico

$\mathrm{CuO}$ - Óxido de cobre

$\mathrm{CuSO}_{4}$ - Sulfato de cobre

FB - fator de bioacumulação

GPx - Glutationa peroxidase

GSH - Glutationa

$\mathrm{H}_{2} \mathrm{O}_{2}$ - Peróxido de Hidrogênio

IAH - Índice de Alterações Histológicas

IET - Índice de estado trófico

IET - Índices de Estado Trófico

IHS - Índice Hepatosomático

MDA - Malondialdeído

$\mathrm{O}_{1}$ - Oxigênio Simples

$\mathrm{O}_{2}{ }^{-}$- Íon Superóxido

-OH - Radical Hidroxilo

PFOA - Ácido perfluorooctanóico

PFOS - Ácido perfluoro-octanossulfônico

RMSP - Região Metropolitana de São Paulo

ROS - Espécies reativas de oxigênio

SABESP - Companhia de Saneamento Básico do Estado de São Paulo

SOD - Superóxido Dismutase 


\section{SUMÁRIO}

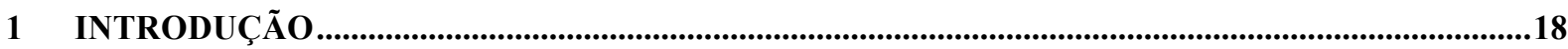

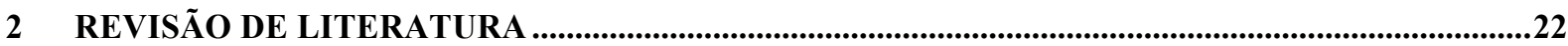

2.1 Aporte de metais em águas...................................................................................................................23

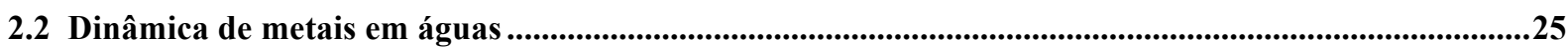

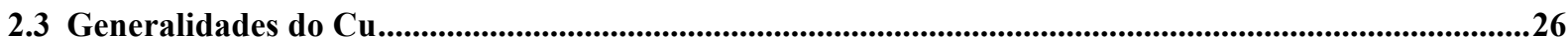

2.4 Efeitos do $\mathrm{Cu}$ em tecidos e órgãos.........................................................................................................26

2.5 Toxicidade do $\mathrm{Cu}$..........................................................................................................................................28

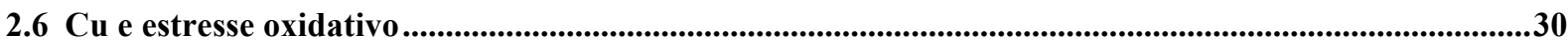

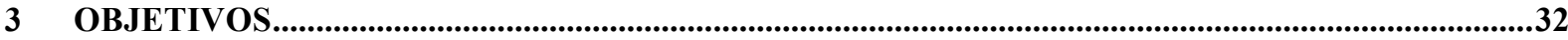

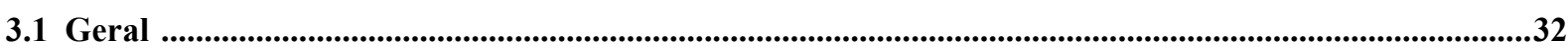

3.2 Específicos..............................................................................................................................................32

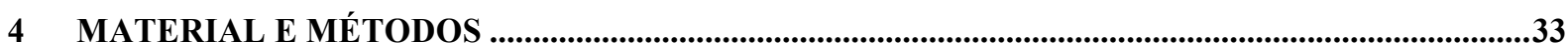

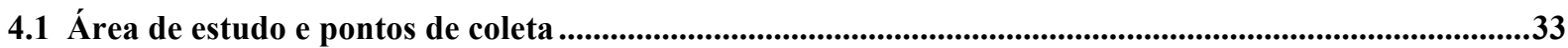

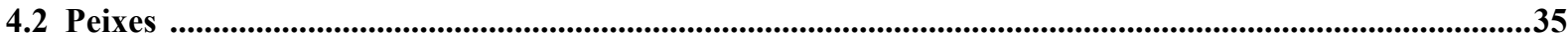

4.3 Determinação das variáveis físico-químicas na água da Represa ...............................................................35

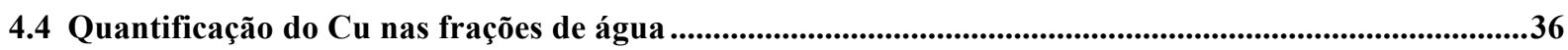

4.5 Tratamento agudo de $\mathbf{1 2 0}$ horas das Tilápias com amostras da água da Represa ....................................36

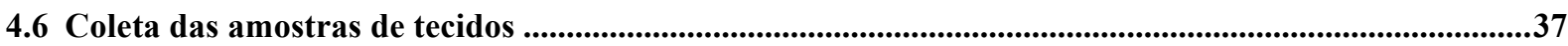

4.7 Análise biomarcadores e mecanismos de toxicidade do $\mathrm{Cu}$ em função das diferentes frações na água 38

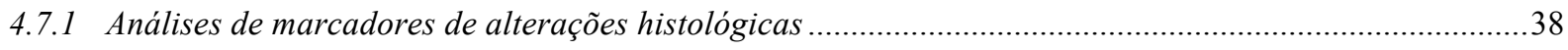

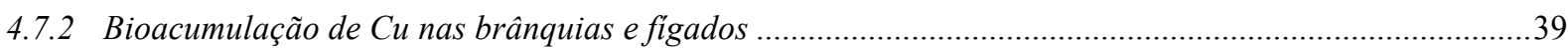

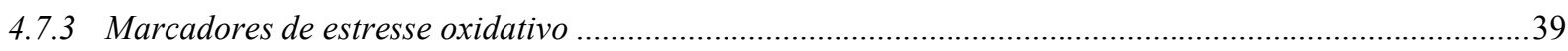

4.8 Análise estatística .................................................................................................................................................40

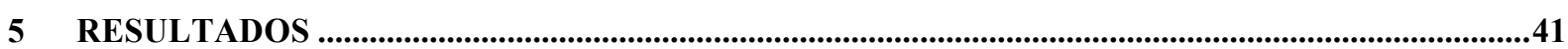

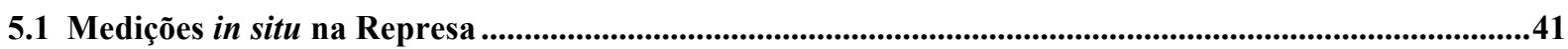

5.2 Variáveis físico - químicas das amostras da água da represa e o IET calculado ……………………….....42

5.3 Concentrações do $\mathrm{Cu}$ por frações determinadas nas amostras da água ...................................................44

5.4 Alterações histológicas nos tecidos branquial e hepático ................................................................................45

5.5 Índice de alterações histológicas nas brânquias e fígados .......................................................................49

5.6 Bioacumulação de Cu nas Brânquias e Fígado, Cálculo Fator de Bioacumulação ....................................58

5.7 Cálculo do Índice Hepatosomático (IHS).........................................................................................................64

5.8 Marcadores de estresse oxidativo: Catalase (CAT), Superóxido dismutase (SOD) e Glutationa

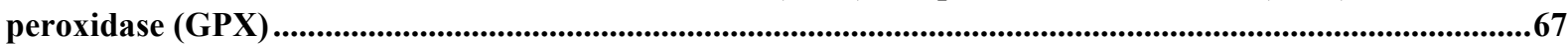

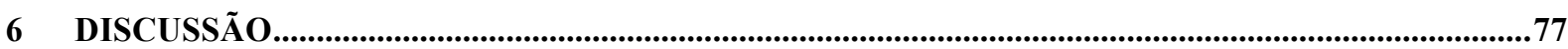

7 CONCLUSÃO

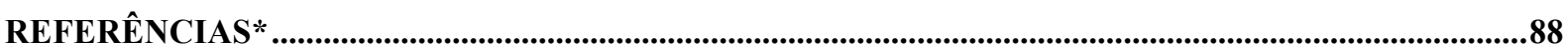




\section{INTRODUÇÃO}

A poluição das águas constitui um dos mais sérios problemas ambientais da atualidade. As fontes de poluição das águas decorrem, sobretudo, da atividade humana na forma de resíduos domésticos, industriais (JARDIM, 1992) e agrícolas, principais responsáveis pela contaminação dos ambientes aquáticos por metais (HOLT, 2000). A contaminação dos ecossistemas aquáticos com metais nos últimos tempos tem recebido a atenção mundial, especialmente nos países em desenvolvimento, como o Brasil. Metais e metaloides provenientes de fontes naturais ou antropogênicas podem entrar no ambiente aquático e provocar sérias ameaças devido a sua toxicidade, longa persistência, bioacumulação e biomagnificação na cadeia alimentar (ISLAM et al., 2015). Estudos tem demonstrado que o desenvolvimento urbano e industriais contribuem com a contaminação por metais no ambiente e organismos aquáticos (TAO et al., 2012).

O cobre $(\mathrm{Cu})$ é um elemento essencial para o crescimento e desenvolvimento de todo organismo vivo, incluindo as plantas. E também funciona como cofator em várias enzimas, principalmente nas que participam da cadeia de transporte de elétrons na fotossíntese e no processo de respiração (BURKHEAD et al., 2009). O Cu é um íon essencial para as plantas, animais e para a saúde humana devido a sua utilidade em várias funções catalíticas e de transporte nas células vivas e suas organelas, em especial a mitocôndria (MEHTA; TEMPLETON; O’BRIEN, 2006). Este elemento também é requerido por enzimas oxidativas como superóxido dismutase, catalase, peroxidase e citocromo oxidase na síntese de hemoglobina e está ligado à $\alpha$-globulina (ceruloplasmina) do sangue, sendo transportado para rins, coração, sistema nervoso central, ossos e estocado principalmente no fígado (SORENSEN, 1991). Em elevadas concentrações pode ser extremamente tóxico para os organismos (HEATH, 1995). Uma vez que o $\mathrm{Cu}$ é liberado no ambiente, um complexo conjunto de reações químicas ocorrem em função de diversos parâmetros químicos da água, os quais, por sua vez, podem variar em função da hidrodinâmica local. As concentrações de metais associados ao material em suspensão dependem das variações de $\mathrm{pH}$, salinidade e das características do material. Sendo assim, diversos fatores químicos da água, tais como matéria orgânica dissolvida, $\mathrm{pH}$, dureza e composição iônica podem modificar a toxicidade do $\mathrm{Cu}$.

Aproximadamente 30 enzimas que utilizam o $\mathrm{Cu}$ como componente são conhecidas. Nos crustáceos, por exemplo, o $\mathrm{Cu}$ é integrante do pigmento respiratório hemocianina. Na maioria dos sistemas aquáticos os íons livres de $\mathrm{Cu}$ representam menos de $1 \%$ da quantidade total de 
$\mathrm{Cu}$. A adição total anual de $\mathrm{Cu}$ em áreas marinhas e rios é estimada em 2,5 milhões de toneladas das quais dois terços são retidas no sedimento dos estuários e áreas costeiras.

Uma vez no ambiente aquático, os poluentes podem ser absorvidos pelos teleósteos por quatro vias: alimentação, brânquias, ingestão de água e pele, sendo que alimentação e via branquial são as principais. Uma vez incorporados, os poluentes podem ser acumulados nas brânquias, no fígado, nos rins, no intestino e músculo. Uma boa parte desses poluentes são transferidas para o fígado e rins onde são biotransformados, por meio de enzimas, para se tornarem hidrossolúveis. E então, serem excretadas na pele pelo muco; no intestino pelas fezes; nos rins pela urina; ou pelas brânquias (HEATH, 1995).

De acordo com Ozcelik e Uzun (2009), a acumulação excessiva de Cu (1 g/L na água) diminui a atividade do superóxido dismutase e os níveis de Glutationa (GSH) e as concentrações de malondialdeído (MDA) aumentam nos tecidos cerebrais.

A exposição ao excesso de $\mathrm{Cu}$ pode danificar as células e os órgãos, porque os íons do $\mathrm{Cu}$ e seus complexos podem induzir a formação de espécies reativas de oxigênio danificando biomoléculas como lipídeos, proteínas e DNA (FEDELI; CARLONI; FALCIONI, 2010). Larvas de anfíbios expostas ao sulfato de cobre $\left(\mathrm{CuSO}_{4}\right)$ diminuíram o crescimento em até $30 \%$, quando comparadas a exemplares não expostos (GARCÍA-MUÑOZ; GUERRERO; PARRA, 2010). Nas algas, o excesso de $\mathrm{Cu}$ reprime o crescimento celular, fotossínteses, síntese de clorofila e mobilidade mediante diversos mecanismos de toxicidade, como substituição de metais essenciais, inibição de enzimas e dano oxidativo (KNAUERT; KNAUER, 2008).

O Reservatório Guarapiranga na bacia Cotia - Guarapiranga, o segundo maior da região metropolitana de São Paulo, abastece quatro milhões de pessoas residentes na zona sudoeste da capital Paulista, incluindo as regiões de Santo Amaro, Morumbi, Pinheiros e Butantã. Além desses usos, apresenta diversos outros tais como lançamento de esgoto doméstico, abastecimento e lança-mento de efluentes industriais, pesca e preservação da vida aquática (CETESB, 2005).

É também o mais ameaçado entre todos os que abastecem a RMSP. A população que vive ao redor da represa aumentou em cerca de 40\% entre 1991 e 2000 e foi estimada em aproximadamente 800 mil pessoas.

Foi construída no início do século passado, entre 1906 a 1908, com a construção da barragem no rio Guarapiranga e seus afluentes, a fim de regularizar as vazões contribuintes e ampliar a produção de energia elétrica em Santana de Parnaíba (CETESB, 1991). O lago fícou 
com um perímetro de $85 \mathrm{~km}$, inundando uma área de $34 \mathrm{~km}^{2}$, a profundidade perto da barragem era de 13 metros e de 6 metros no restante do reservatório.

Em 1928, a Represa se converteu na principal fonte de água para o abastecimento público de São Paulo, mediante o fornecimento de 86,4 milhões de litros de água/ dia (WHATELY; CUNHA, 2006). O reservatório foi classificado como eutrófico em 1960, em função da descarga de esgoto urbano (ROCHA, 1976; WHATELY; CUNHA, 2006). A diminuição da qualidade da água da Represa Guarapiranga começou a ficar evidente na década de 70. No final da década de 80, o custo de produtos químicos lançados na represa para controle das florações de algas era da ordem de US\$ 1.000.000,00 ao ano. O gasto aumentou para US\$ 8.400.000,00 (BEYRUTH, 1996; WHATELY; CUNHA, 2006).

Este reservatório apresenta regime semilótico, com menor tempo de residência das águas devido ao grande volume captado para abastecimento (tempo de residência entre 40 e 200 dias, aproximadamente). Desde agosto de 2000, passou a receber as águas eutróficas do Reservatório Billings (braço do Taquacetuba), via várzea do rio Parelheiros, a fim de manter volume suficiente para o abastecimento público. Esta transposição de águas, associada aos baixos volumes do reservatório no período seco (o que aumenta a concentração de nutrientes), tem promovido alterações na qualidade de suas águas, como o aumento do grau de trofia. (CETESB, 2002).

Em 2003, mais da metade da área da Bacia Hidrográfica da Guarapiranga encontrava-se alterada por atividades humanas. Parte destas alterações (16\%) estão relacionadas aos usos urbanos, e o restante a usos diversos como agricultura, mineração e solo exposto. As áreas com vegetação remanescente de Mata Atlântica, essenciais para a manutenção da capacidade de produção hídrica e para o equilíbrio ambiental da região ocupavam em 2003, apenas 37\% da área da bacia (WHATELY; CUNHA, 2006). Entre 1989 e 2003, as áreas urbanas aumentaram em 19\%, e mais da metade deste crescimento ocorreu em áreas com severas restrições à ocupação. A situação é tão grave e descontrolada que nem as Áreas de Preservação Permanente (APPs) - protegidas por leis federal e estadual por serem áreas ambientalmente mais frágeis como o entorno de rios e nascentes, foram poupadas. Parcela significativa destas áreas $(37,6 \%)$ encontram-se ocupadas por usos humanos, com sérias consequências para o abastecimento de água (WHATELY; CUNHA, 2006). De acordo com dados da CETESB (2008) nos anos de 2006 e 2007 foram encontradas concentrações de cobre dissolvido, acima do permitido pela CONAMA 357/05, de 0,009 mg/L, provavelmente decorrente da aplicação de sulfato de cobre para o controle das algas que se desenvolvem em grandes concentrações no reservatório. Segundo a CETESB (2008), a aplicação de algicidas (sulfato de cobre e peróxido de 
hidrogênio) durante o ano de 2006 foi maior do que a do ano anterior, com valores entre 12 e 62 toneladas.

Considerando os aspectos elencados, nos levantamos a hipóteses de que a determinação das frações de cobre e possíveis biomarcadores da contaminação por este metal, devem contribuir para aumentar o conhecimento da distribuição e os efeitos deste metal no ecossistema aquático do reservatório Guarapiranga. 


\section{REVISÃO DE LITERATURA}

Os ecossistemas aquáticos são os últimos recipientes de quase todas as sustâncias incluindo os metais pesados, que são moléculas de gravidade especifica $>5.0$ e não são biodegradáveis. A poluição com metais pesados nos ecossistemas aquáticos está crescendo a um ritmo alarmante e tem se convertido em um sério problema ambiental para o mundo todo (MALIK et al., 2010). Os metais pesados que podem induzir problemas na saúde dos peixes incluem cadmio $(\mathrm{Cd})$ e Cobre $(\mathrm{Cu})$. Estes podem ser introduzidos no meio aquático mediante resíduos industriais ou agrícola (MACINTYRE et al., 2008; MAZON; CERQUEIRA; FERNANDES, 2002), pelas estações de esgoto (ATSDR, 1990). E também como agente quimioterápico no controle de algas em estações de abastecimento de água e de piscicultura (MENEZES, 2005). Níveis elevados de metais podem induzir estresse oxidativo gerando ROS (Reactive Oxygen Species). Como por exemplo, o peróxido de hidrogênio $\left(\mathrm{H}_{2} \mathrm{O}_{2}\right)$, radical superóxido e hidroxila via reações Haber - Weiss e Fenton que podem oxidar proteínas, lipídios e ácidos nucleicos podendo danificar a célula até a morte (CAO et al., 2010; DEWEZ et al., 2005). A presença de metais pesados nos ecossistemas aquáticos podem exercer efeitos negativos nas enzimas digestivas dos peixes e dos invertebrados, pois inibem a proteinase (BIDINOTTO; MORAES; SOUZA, 1997; BOUGATEF et al., 2007).

$\mathrm{O} \mathrm{Cu}$ funciona como co-fator em várias enzimas, em especial as que participam da cadeia de transporte de elétrons na fotossíntese e no processo de respiração (BURKHEAD et al., 2009). O Cu é requerido por enzimas oxidativas como superóxido dismutase, catalase, peroxidase e citocromo oxidase (NELSON; COX; LENNINGER, 2000) na síntese de hemoglobina. E está ligado à $\alpha$-globulina (ceruloplasmina) do sangue, sendo transportado para rins, coração, sistema nervoso central, ossos e estocado principalmente no fígado (SORENSEN, 1991). Entretanto, em elevadas concentrações, este elemento pode ser extremamente tóxico para os organismos (HEATH, 1995). Quando o $\mathrm{Cu}$ é liberado no ambiente, um complexo conjunto de reações químicas ocorrem em função de diversos parâmetros químicos da água, os quais, por sua vez, podem variar em função da hidrodinâmica local. As concentrações de metais associados ao material em suspensão dependem das variações de $\mathrm{pH}$, salinidade e das características do material em suspensão. Sendo assim, diversos fatores químicos da água, tais como matéria orgânica dissolvida, $\mathrm{pH}$, dureza e composição iônica, podem modificar a toxicidade do $\mathrm{Cu}$. Em estudos realizado por Khangarot e Das (2010), todos os embriões do molusco Lymnaea luteola (L.) morreram quando submetidos às concentrações de $100-320 \mu \mathrm{g} / \mathrm{L}$ de $\mathrm{Cu}$, em um período de $168 \mathrm{~h}$. As 
consequências foram más formações detectadas como enfraquecimento dos pés e olhos, formação incompleta da concha, retardo do crescimento e rotação lenta do embrião dentro da cápsula dos ovos quando comparados aos controles.

Jo et al. (2010) verificaram que o aumento do pH, dureza e DOC (Carbono Orgânico Dissolvido), provocaram uma diminuição da toxicidade da mistura $\mathrm{Cu}$ (II) e $\mathrm{Cr}$ (VI), pela redução das concentrações de espécies tóxicas como o $\mathrm{Cu}^{2+}$ e $\mathrm{HCrO}_{4}$. No entanto, os pesquisadores Atli e Canli (2010a) relataram que as enzimas antioxidantes são muito sensíveis aos metais, sendo suas atividades alteradas significativamente. Isto sugere que estas podem ajudar na predição da toxicidade sub letais dos metais e serem úteis como uma ferramenta nos estudos de monitoramento natural.

\subsection{Aporte de metais em águas}

Metais pesados aportam em sistemas aquáticos por meio de fontes pontuais e difusas. As fontes pontuais são facilmente identificadas e diagnosticadas. Por este motivo, é possível estabelecer medidas de controle ou, em alguns casos ações que visam punir os responsáveis pelo descarte de resíduos que não se enquadram à legislação vigente. Fontes pontuais estão, geralmente, associadas ao descarte de efluentes a partir estações de tratamento industriais, domésticos e fossas sépticas. Os pesquisadores Markich e Brown (1998), avaliaram a qualidade das águas em rios da Austrália e observaram que as concentrações de nutrientes, carbono orgânico e metais pesados aumentaram em função das atividades antrópicas, particularmente, por meio de fontes pontuais.

Ao contrário das fontes pontuais, as fontes difusas de poluentes não podem ser facilmente identificadas, ocorrem em extensas áreas, associadas à chuva e ao escoamento que dela resultam e chegam aos corpos d'água de forma intermitente (BUNCE, 1994). Devido à estas características, a identificação destas fontes constitui um grande desafio em estudos ambientais. Nos Estados Unidos, por exemplo, a ocorrência de fontes difusas são os principais motivos pelo qual, cerca de $40 \%$ dos rios, lagos e estuários não se encontram com qualidade suficiente para pesca e recreação (USEPA, 2005). As principais fontes que contribuem para o aporte de contaminantes de maneira difusa são a deposição atmosférica úmida e seca (WU et al., 1992), a lixiviação de compostos do solo e a drenagem de águas pluviais em ambientes rurais e urbanos (MITCHELL, 2005). Em áreas rurais, as cargas difusas podem surgir a partir de atividades agrícolas por meio da contaminação por fertilizantes ou pesticidas aplicados nas culturas (GONÇALVES; LUCHESE; LENZI, 2000). Em regiões urbanas, as águas de 
drenagem podem conter uma grande variedade de espécies potencialmente tóxicas para corpos aquáticos receptores. Além disso, devido à elevada impermeabilização em alguns tipos de solo, a taxa de infiltração da água é reduzida e consequentemente o escoamento na superfície tornase maior. De acordo com Taebi e Droste (2004), o escoamento das águas de drenagem em áreas urbanas podem ser responsáveis pela aceleração da erosão das margens dos rios, pelo aumento das taxas de eutrofização em ambientes lacustres e pela diminuição na qualidade da água dos corpos receptores à jusante, ou mesmo dentro de áreas urbanas. Em países desenvolvidos o maior problema relacionado à poluição de corpos aquáticos naturais, reside no controle das fontes difusas (D'ARCY; FROST, 2001).

Conforme Davis; Shokouhian e Ni, (2001) os teores de metais encontrados nas águas avaliadas foram maiores para o Zinco com valores da ordem de 20 a $5.000 \mu \mathrm{g} / \mathrm{L}$; seguido do chumbo e do $\mathrm{Cu}$, com níveis na faixa de 5 a $200 \mu \mathrm{g} / \mathrm{L}$; e do cádmio, com concentrações menores que $12 \mu \mathrm{g} / \mathrm{L}$.

A descarga de metais em águas naturais a partir de fontes difusas ou pontuais podem promover alterações significativas nos comportamentos físico, químico e biológico, tanto do corpo receptor (VEGA et al., 1998) como do próprio metal (VELASQUEZ; JACINTO; VALERA, 2002). Essas alterações podem ser divididas em duas categorias: (i) efeito do ambiente sobre o metal e (ii) efeito do metal sobre o ambiente. A primeira categoria enfatiza condições nas quais as águas receptoras podem influenciar a especiação e a toxicidade dos metais. Tais condições incluem a distinção da entrada de material antropogênico e geoquímico, qualidade dos efluentes industriais, concentração de ligantes e os teores de sólidos suspensos. O efeito do metal na resposta biológica é enfatizado na segunda categoria. Dependendo das condições ambientais, o metal pode alterar a densidade, a diversidade, a estrutura da comunidade e a composição das espécies de populações. O grau de variação dependerá da concentração de metais na água e, igualmente, no sedimento. As mudanças nas características do meio aquático pelo aporte de metais de fontes antropogênicas podem provocar efeitos deletérios à biota aquática. Considerando as interdependências entre organismos aquáticos, estas modificações podem proporcionar desequilíbrios ambientais (HUDSON, 1998). 


\subsection{Dinâmica de metais em águas}

A distribuição, o transporte e a biodisponibilidade de metais em ambientes aquáticos são primariamente controlados pelo sedimento e pela coluna de água. A mobilização de metais depende da textura física e da natureza química do sedimento, na qual sua variação determinará a quantidade e a força de ligação do metal (BENOIT; ROZAN, 1999). A composição físicoquímica da coluna de água determina os mecanismos de associação do metal, tais como na forma particulada, coloidal, iônica dissolvida e complexada dissolvida. Frequentemente, metais encontram-se associados a diversos tipos de ligantes naturais ou antropogênicos que podem governar a distribuição e a especiação das espécies metálicas em corpos aquáticos. A separação destas frações é arbitrária e dependente de condições operacionais (BENOIT; ROZAN, 1999). Considera-se como dissolvida toda espécie que foi separada de uma amostra de água natural por meio da filtração em uma membrana de $0,45 \mu \mathrm{m}$ de porosidade (TEMPLETON et al., 2000). Conforme Allen; Luther e Garrison (1997), partículas orgânicas maiores que $0,45 \mu$ m podem surgir a partir da decomposição de organismos aquáticos ou por meio dos produtos de degradação. Além disso, fitoplânctons, algas e bactérias, também podem interagir com o $\mathrm{Cu}$ nesta fração pela absorção do metal ou ainda pela formação de complexos em grupos funcionais presentes na superfície proteica celular (ALLEN; LUTHER; GARRISON, 1997). Dependendo das condições naturais, algas e fitoplânctons podem regular a concentração de íons metálicos na coluna de água (BRULAND; DONAT; HUTCHINS, 1991). A capacidade de absorção de bactérias frente a vários metais depende dos tipos e da concentração dos grupos funcionais presentes na parede celular (WARREN; HAACK, 2001). Grupos carboxílicos e fosfatos com pKa de 4-6 e 7, conferem à parede celular uma rede de cargas aniônicas na maioria dos ambientes aquáticos naturais e contribuem para a interação com cátions metálicos.

Não existe uma definição clara a respeito da composição química e estrutural da matéria orgânica dissolvida. Devido à composição heterogênea apresentar variações com relação à massa molar, grupos funcionais, presença e tipos de radicais livres tornando difícil a caracterização de sua estrutura química (HAN; THOMPSON, 1999). As formas de carbono associadas a estas substâncias apresentam variações de região para região devido à natureza heterogênea do material de origem (UNSAL; SOZUDOGRU OK, 2001). Uma característica importante da matéria orgânica dissolvida é a sua capacidade de formar complexos estáveis com íons metálicos. Diversos autores têm demonstrado que a complexidade do $\mathrm{Cu}$ pela matéria orgânica em águas naturais podem ser influenciadas pela concentração e pelos tipos de grupos 
funcionais presentes (KIPTON; POWELL; FENTON, 1996; LU; ALLEN, 2002; MASINI et al., 1998), bem como pelo tamanho das moléculas (SARGENTINI JUNIOR et al., 2001).

\subsection{Generalidades do $\mathrm{Cu}$}

$\mathrm{O} \mathrm{Cu}$ em estado puro é um metal de cor marrom - avermelhado com alta ductilidade e maleabilidade. O peso atômico é de 63,54; o número atômico é de 29 e a densidade de $8,94 \mathrm{~g} / \mathrm{cm}^{3}$. Possui dois isótopos estáveis de massa 63 e 65 com abundância natural de 69,2\% e 30,8\%, respectivamente (GEORGOPOULOS et al., 2001). A solubilidade em água do sulfato de cobre $\left(\mathrm{CuSO}_{4}\right)$ (II) é de $143 \mathrm{~g} / \mathrm{L}$ a $0{ }^{\circ} \mathrm{C}$, porém o óxido de $\mathrm{Cu}$ (I) e o Cu são praticamente insolúveis na água (WHO, 1998).

\subsection{Efeitos do Cu em tecidos e órgãos}

Uma vez no ambiente aquático, os poluentes podem ser absorvidos pelos teleósteos por quatro vias: alimentação, brânquias, ingestão de água e pela pele. A alimentação e a via branquial são as principais. Uma vez incorporados, os poluentes podem ser acumulados nas brânquias, no fígado, nos rins, no intestino e no músculo. Uma boa parte desses poluentes são transferidos para o fígado e rins para serem biotransformados por meio de enzimas, tornandose hidrossolúveis e então serem excretados pela pele por meio do muco; pelo intestino nas fezes; pelos rins por meio da urina; ou pelas brânquias (HEATH, 1995).

Conforme relatado por Ozcelik e Uzun (2009), a acumulação excessiva de $\mathrm{Cu}$ (1 g/L na água) diminui a atividade da superóxido dismutase e os níveis da Glutationa (GSH) e aumentam as concentrações de malondialdeído (MDA) nos tecidos cerebrais dos ratos testados.

As brânquias são órgãos alvo na toxicidade do $\mathrm{Cu}$ para os peixes, devido a sua extensa área de superfície em contato direto com o ambiente aquático (CERQUEIRA; FERNANDES, 2002). As brânquias estão envolvidas nas trocas gasosas, no balanço ácido-base e no transporte e excreção de compostos nitrogenados (PERRY, 1997). Todos ou quase todos os estressores afetam a estrutura branquial e também, direta ou indiretamente o balanço hidromineral que é uma das principais razões para a vulnerabilidade dos peixes em águas poluídas (QUABIUS; BALM; WENDELAAR BONGA, 1997).

As brânquias exercem funções vitais nos teleósteos, tais como respiração, osmoregulação e excreção. Desempenham um papel fundamental no balanço hidro-eletrolítico e ainda constituem o sítio de tomada e depuração de contaminantes onde a desintoxicação e os metabolismos destes agentes tóxicos ocorrem. Consequentemente, alterações morfológicas podem ocorrer em razão da introdução de poluentes na água e, portanto, estas alterações podem 
ser utilizadas como parâmetros para o monitoramento ambiental (COOMBS et al., 2011; SCHWAIGER et al., 1997). Estes órgãos também estão implicados na excreção de $\mathrm{Cu}$ (ÇOĞUN; KARGIN, 2004). Conforme o período de exposição e as concentrações de Cu impostas, podem ocorrer alterações nos intermediários metabólicos os quais permitem verificar o ajuste no metabolismo energético (HEATH, 1995). A estimulação do metabolismo pode ser claramente refletida nas mudanças do consumo de $\mathrm{O}_{2}$ durante exposição ao $\mathrm{Cu}$ (MCGEER et al., 2000) ou pelo aumento de excretas metabólicas como, por exemplo, a amônia (TAYLOR et al., 1996).

No âmbito bioquímico, estas excretas podem refletir nas mudanças das enzimas envolvidas no metabolismo e nas funções críticas para a sobrevivência da célula, como a regulação iônica e atividade da $\mathrm{Na}^{+} / \mathrm{K}^{+-}$ATPase (MCGEER et al., 2000). Estes órgãos podem acumular altas concentrações de metais (ÇOĞUN; YÜZEREROĞLU; KARGIN, 2003). O Cu liga-se aos sítios ativos da $\mathrm{Na}^{+} / \mathrm{K}^{+-}$ATPase resultando em uma diminuição na sua atividade, desestabilizando o equilíbrio iônico e/ou osmótico do animal (GROSELL; NIELSEN; BIANCHINI, 2002).

Alguns estudos como de Abdel-Moneim; Al-Kahtani e Elmenshawy (2012) mostraram que as principais alterações encontradas nas brânquias dos peixes capturados nos pontos de amostragem foram: aneurismas, congestão sanguínea nos vasos lamelares, hemorragia, hiperplasia, hipertrofia, elevação do epitélio, entre outras. No entanto, Song et al. (2015) encontraram alterações nas brânquias de trutas como proliferação e descolamento das células epiteliais na base das lamelas secundárias, quando expostas a $1 \mathrm{mg} / \mathrm{L}$ e $0.5 \mathrm{mg} / \mathrm{L}$ de $\mathrm{Cu}$.

O fígado é um órgão chave quando se considera a ação dos poluentes químicos sobre os peixes. É o primeiro órgão na biotransformação dos xenobióticos e provavelmente também para excreção de metais. Assim, muitos metais e outros xenobióticos se acumulam no fígado, de modo que suas células ficam expostas a um nível elevado de agentes químicos que podem estar presentes no meio ambiente (HEATH, 1995). O fígado tem recebido atenção especial em estudos toxicológicos relacionados à contaminação de diferentes espécies de peixes por agentes químicos orgânicos e inorgânicos.

Metais provocam alterações na integridade dos mecanismos fisiológicos e bioquímicos dos peixes, que são componentes importantes nos ecossistemas-e também utilizados como alimentos (ATLI; CANLI, 2007, 2008). Os tecidos dos peixes, especificamente o fígado, estão providos de um sistema de proteção antioxidante, que os protege do estresse oxidativo causado por metais (ATLI; CANLI, 2008; ATLI et al., 2006). 


\subsection{Toxicidade do $\mathrm{Cu}$}

$\mathrm{O} \mathrm{Cu}$ é altamente tóxico para os organismos aquáticos e pode provocar danos irreversíveis em concentrações maiores que as requeridas para o crescimento e reprodução (ABDEL-KHALEK et al., 2015; BALDWIN et al., 2003). Como um elemento essencial para a vida, o $\mathrm{Cu}$ em altas concentrações é toxico para os organismos de água doce (ABDELKHALEK et al., 2015).

A exposição ao excesso de $\mathrm{Cu}$ pode danificar as células e os órgãos, porque os íons do $\mathrm{Cu}$ e seus complexos podem induzir a formação de espécies reativas de oxigênio danificando biomoléculas como lipídeos, proteínas e DNA (FEDELI; CARLONI; FALCIONI, 2010). Larvas de anfíbios expostas ao $\mathrm{CuSO}_{4}$ diminuíram o seu crescimento em até $30 \%$ quando comparadas ao grupo controle (GARCÍA-MUÑOZ; GUERRERO; PARRA, 2010). Nas algas, o excesso de $\mathrm{Cu}$ reprime o crescimento celular, fotossínteses, sínteses de clorofila e mobilidade mediante diversos mecanismos de toxicidade, inibição de enzimas e dano oxidativo (KNAUERT; KNAUER, 2008).

Existem complexos em que o $\mathrm{Cu}$ pode ser muito tóxico, por exemplo, transporte acidental com ligantes fisiológicos (aminoácidos e citrato) (WENGER; TANDY; NOWACK, 2005). Em espécies de peixes como Lúcio (Esox lucius) a influência do Cu reduziu o nível da atividade da proteolítica estomacal a $20{ }^{\circ} \mathrm{C}$, enquanto que o $\mathrm{pH} 3.0$ aumentou até 2 vezes (KUZ'MINA; USHAKOVA, 2010). $\mathrm{O} \mathrm{CuSO}_{4}$ pode ter efeitos colaterais nos peixes induzindo a ruptura das cadeias de DNA e genotoxicidade nos tecidos de forma específica em cada espécie (OLIVEIRA et al., 2008). Os pesquisadores Sikorska e Wolnicki (2010), encontraram um alto efeito tóxico do cádmio $\left(0.1 \mathrm{mg} / \mathrm{dm}^{3}\right)$ e $\mathrm{Cu}\left(0.3 \mathrm{mg} / \mathrm{dm}^{3}\right)$ no começo do processo de inflação da câmara posterior da bexiga natatória em larvas de tenca (Tinca tinca L.).

Nos peixes, antes de ser transportado pelas brânquias, o $\mathrm{Cu}^{2+}$ (íon cúprico) é aparentemente reduzido a $\mathrm{Cu}^{+}$(íon cuproso), sugerindo que esta forma seria a verdadeira responsável pelo efeito tóxico do metal (GROSELL; WOOD, 2002). Os peixes podem acumular o $\mathrm{Cu}$ em diversos órgãos e tecidos de forma direta, a partir da água, ou indireta, por alimentos (SEYMORE DU PREEZ; VAN VUREN, 1996). Este acúmulo pode resultar em alterações nos processos fisiológicos e bioquímicos do organismo. Com a finalidade de atenuar os efeitos ocasionados pela presença de metais (HEATH, 1995) os organismos podem, por exemplo, hiper secretar muco nas brânquias e pele (TAO, 2002). O Cu causa alterações nos mecanismos de regulação iônica, iniciando uma rápida diminuição nos eletrólitos plasmáticos devido à inibição do influxo de $\mathrm{Na}^{+}$, e consequentemente a inibição da enzima $\mathrm{Na}^{+} / \mathrm{K}^{+-}$ATPase 
nas brânquias (LI et al., 1998). Em concentrações mais elevadas, o Cu também atua na permeabilidade das junções paracelulares ao causar o deslocamento do cálcio (principal íon responsável pelo controle da permeabilidade branquial), favorecendo o efluxo dos íons (LAUREN; MCDONALD, 1987).

A inibição do influxo de íons $\mathrm{Na}^{+}$e $\mathrm{Cl}^{-}$branquiais, juntamente com o aumento do efluxo de $\mathrm{Na}^{+}$ocasionam a diminuição desses íons plasmáticos. Como consequência, a água presente no plasma flui para os tecidos, tornando o sangue concentrado, o que é agravado pela liberação de eritrócitos por contração do baço. A alta viscosidade sanguínea causam falhas no sistema circulatório do peixe, podendo levá-lo à morte (WILSON; TAYLOR, 1993). Em altas concentrações o $\mathrm{Cu}$ provoca alterações na homeostase do $\mathrm{Na}^{+}$e o $\mathrm{Cl}^{-}$. $\mathrm{Na}$ osmoregulação altera o nível de metabolitos nitrogenados e induz estresse respiratório (DE BOECK et al., 2007). Os íons cúpricos influenciam de forma diferente o estado oxidativo de dois componentes da hemoglobina da truta (Oncorhynchus mykiss), os componentes I e IV (HbI e HbIV) mudando suas propriedades funcionais e estruturais (FEDELI; CARLONI; FALCIONI, 2010).

Além dos distúrbios vistos anteriormente, peixes expostos ao $\mathrm{Cu}$ podem apresentar alterações no sistema imunológico e efeitos citotóxicos (ROMÉO et al., 2000) e genotóxicos, com a formação de micronúcleos e outras anormalidades nos núcleos dos eritrócitos (CAVAS; GARANKO; ARKHIPCHUK, 2005). Os pesquisadores Oliveira et al. (2008) expuseram a espécie Colossoma macropomum à $367 \mu \mathrm{g} / \mathrm{L}$ de $\mathrm{Cu}$ por 96 horas e observaram desequilíbrio iônico, aumento nos níveis de glicose, redução nos níveis de lactato e danos hepáticos. Além desses efeitos, foi comprovado a característica genotóxica deste metal com o aumento no percentual de anormalidades nucleares eritrocíticas. Desta forma, foi observado que a exposição ao $\mathrm{Cu}$ acarretou sérios efeitos sobre a espécie estudada.

As propriedades do $\mathrm{Cu}$ que o fazem elemento essencial para os sistemas biológicos, também contribuem para a sua toxicidade quando em excesso (HARRISON et al., 2000). O ciclo redox que ocorre entre $\mathrm{Cu}$ (II) e $\mathrm{Cu}$ (I) podem catalisar a produção do radical hidroxila, que é altamente tóxico para a célula (MALMSTRÖM; LECKNER, 1998). Em presença de redutores celulares disponíveis, o ferro e o $\mathrm{Cu}$ ligados com moléculas de baixo peso molecular podem atuar como catalisadores na formação de radicais livres, comprometendo os processos fisiológicos e a integridade das células (BRITTON, 1996). As reações em cadeia de um radical com um não radical, levam a formação de outros radicais diferentes. Esta cadeia de reações se amplificam e inúmeras moléculas podem ser oxidadas no processo (FRIDOVICH, 1998). Isto ocorre com proteínas, carboidratos, ácidos nucléicos e principalmente com lipídeos polinsaturados, abundantes nas membranas celulares (BRITTON, 1996). 
Alguns complexos do $\mathrm{Cu}$ (II) reagem com redutores celulares (ácido ascórbico, glutationa, acetilcisteína, entre outros) gerando radical hidroxila em condições aeróbias, causando quebras no DNA (UEDA et al., 1998). Misturas de $\mathrm{Cu}$ (II) e $\mathrm{H}_{2} \mathrm{O}_{2}$ em pH 7.4, provocaram dano maior às bases do DNA que os causados por misturas de $\mathrm{Fe}$ (III)/ $\mathrm{H}_{2} \mathrm{O}_{2}$. Os produtos da reação, são típicos resultantes do ataque dos radicais hidroxila sobre as bases de DNA, tais como glicóis da citosina e timina, 8-hidroxiadenina e especialmente 8hidroxiguanina (ARUOMA et al., 1991). A formação de 8-hidroxi-2-deoxiguanosina em DNA de esperma de salmão e quebras de fita simples e duplas em plasmídeo pBluescript $\mathrm{K}^{+}$foram detectadas como resultado de reações do tipo Fenton, após exposição ao peróxido de hidrogênio $\left(\mathrm{H}_{2} \mathrm{O}_{2}\right)$ e $\mathrm{Cu}$ (II) (LLOYD; CARMICHAEL; PHILLIPS, 1998). Dano oxidativo às bases do DNA resultando em indução de apoptose foram observados em cultura de células humanas após tratamento com nitriloacetato de $\mathrm{Cu}$ (MA et al., 1998). Foi demonstrado que o $\mathrm{Cu}$ adicionado ao meio em quaisquer concentrações alteram a expressão gênica. Muitos genes que pertencem a família de genes funcionais foram modulados pelo $\mathrm{Cu}$, alguns dependentes da dosagem, como por exemplo as Metalotioneinas (MT1A e MT2A) que foram fortemente expressadas, quando expostos ao $\mathrm{Cu}$ (BIGAGLI et al., 2010).

\subsection{Cu e estresse oxidativo}

Diferentes formas do $\mathrm{Cu}$ podem induzir estresse oxidativo, porque este catalisa a formação de espécies reativas de oxigênio via reações de Fenton (PROUSEK, 2007). O íon positivo $\mathrm{Cu}^{2+}$ pode agir diretamente se ligando ao grupo carregado negativamente - $\mathrm{SH}$ das proteínas e provocar a desnaturalização das enzimas, ou indiretamente via geração de ROS e como consequência causar o estresse oxidativo (AHMAD et al., 2005; BOPP; ABICHT; KNAUER, 2008).

As análises de parâmetros bioquímicos podem ajudar na identificação de órgãos alvos da toxicidade, assim como o estado geral de saúde dos animais, e ainda indicar sinais de alerta em organismos estressados (DAVID et al., 2010; PRASHANTH, 2012). Para Carvalho; Aline e Narciso (2015), a exposição de curimbata (Prochilodus lineatus) ao $\mathrm{Cu}$, resultou no aumento da atividade das enzimas, com algumas exceções. A atividade da SOD diminuiu 54\%, porém GPX, CAT, GR e GST aumentaram em 30 - 60\%, quando comparado aos grupos controles.

A atividade da $\mathrm{Na}, \mathrm{K}$ - ATPase no intestino e brânquias da Tilápia do Nilo, diminuíram quando exposta ao Cu (ATLI; CANLI, 2007). Grosell et al. (2004) observaram que a elevação da atividade da $\mathrm{Na}, \mathrm{K}$ - ATPase devido a exposição ao $\mathrm{Cu}$ no intestino de Opsanus beta, que 
estava associado a um aumento da absorção de fluído no intestino, a modo compensatório. Para o peixe neotropical Prochilodus lineatus não foi observado diferenças significativas para CAT, GST e GPX quando exposto ao $\mathrm{Cu}$, porém a SOD aumentaram 87,5 e 81,8\% nos fígados dos peixes expostos a 9 e $20 \mu \mathrm{g} / \mathrm{L}$ (SIMONATO et al., 2016). Em estudo realizado no rio Mekong por Bui et al. (2016) foi concluído que o $\mathrm{Cu}$ em baixas concentrações provocam alterações nos organismos do rio. 


\section{OBJETIVOS}

\subsection{Geral}

- Determinar a ecotoxicidade do cobre no reservatório Guarapiranga.

\subsection{Específicos}

- Desenvolver um esquema de fracionamento do cobre no sistema aquático do reservatório Guarapiranga, assim como avaliar as variáveis físico - químicas da água e o índice de trofia;

- Caracterizar as alterações histológicas nas tilápias do Nilo expostas ao cobre do reservatório Guarapiranga,

- Determinar possíveis biomarcadores e mecanismos de toxicidade do cobre in vivo em função da sua biodisponibilidade. 


\section{MATERIAL E MÉTODOS}

\section{1 Área de estudo e pontos de coleta}

A Represa Guarapiranga é uma sub-bacia do Alto Tiete e está ligada pelo canal do rio Pinheiros. Está localizada a $23^{\circ} 43^{\prime} \mathrm{S}$ e $46^{0} 32^{\prime} \mathrm{W}$ a uma altitude de $742 \mathrm{~m}$, é um dos principais mananciais da Região Metropolitana de São Paulo (RMSP) e abrange uma área de drenagem de $631 \mathrm{Km}^{2}$.

Na Represa Guarapiranga foram selecionados 4 pontos de coleta (Tabela 1) que são parte da UGRHI 6 - Alto Tietê (Figura 1) (CETESB, 2002, 2005, 2008). Estes pontos de amostragem foram selecionados seguindo 2 critérios fundamentais: 1) pontos onde as medidas da CETESB ofereceram sinais de afetação e 2) pela posição geográfica em áreas de uso pela população ou áreas de incorporação de afluentes (CETESB, 2008).

Tabela 1 - Pontos de amostragem e descrição.

\begin{tabular}{|c|c|c|}
\hline Pontos & Coordenada geográfica & Locais de referência \\
\hline GUAR 00071 & $\begin{array}{l}\mathrm{S} 23^{\circ} 44^{\prime} 42^{\prime \prime} \\
\text { W } 46^{\circ} 46^{\prime} 09^{\prime \prime}\end{array}$ & $\begin{array}{l}\text { Praia na Associação dos Funcionários } \\
\text { Públicos do Estado de São Paulo }\end{array}$ \\
\hline GUAR 00100 & $\begin{array}{l}\mathrm{S} 23^{\circ} 45^{\prime} 15^{\prime \prime} \\
\mathrm{W} 46^{\circ} 43^{\prime} 37^{\prime \prime}\end{array}$ & $\begin{array}{l}\text { Região central do Rio Parelheiros, bairro } \\
\text { Balneário São José }\end{array}$ \\
\hline GUAR 00900 & $\begin{array}{l}\text { S } 23^{\circ} 41^{\prime} 22^{\prime \prime} \\
\text { W } 46^{\circ} 43^{\prime} 35^{\prime \prime}\end{array}$ & $\begin{array}{l}\text { A } 2 \mathrm{~km} \text { da barragem (corpo central), } \\
\text { jusante dos braços dos rios M'Boi-Mirim, } \\
\text { Parelheiros, Embu-Guaçu e Itupu. }\end{array}$ \\
\hline GUAR 00901 & $\begin{array}{l}\mathrm{S} 23^{\circ} 40^{\prime} 30^{\prime \prime} \\
\mathrm{W} 46^{\circ} 43^{\prime} 51^{\prime \prime}\end{array}$ & $\begin{array}{l}\text { Prainha do Parque Municipal } \\
\text { Guarapiranga }\end{array}$ \\
\hline
\end{tabular}

Amostras de água foram coletadas no período seco e chuvoso. Em cada ponto de amostragem foram coletados 50 litros de água e mantidos em galões de polietileno até a chegada ao laboratório, onde foram colocadas nos respectivos aquários para os tratamentos experimentais dos peixes. As amostras de água para fracionamento e determinação de variáveis físico-químicas foram coletadas na zona fótica, aproximadamente $30 \mathrm{~cm}$ de profundidade, com o auxílio de um amostrador de PVC e imediatamente conservadas em garrafas de polietileno de $1 \mathrm{~L}$ sob gelo a temperatura de $4{ }^{0} \mathrm{C}$. Os coletores foram previamente lavados com ácido nítrico $10 \%$ e água milli-Q, para minimizar a contaminação das amostras. Todas as amostras foram armazenadas em sacolas plásticas no gelo $\left(4{ }^{\circ} \mathrm{C}\right)$ e transportadas ao laboratório para as análises imediatas, e com o intuito de evitar ou minimizar alterações no fracionamento do $\mathrm{Cu}$. Medidas de $\mathrm{pH}$, temperatura, dureza total, fosfato total foram medidas insitu (BONNE HERNÁNDEZ; OLIVEIRA; ESPÓSITO, 2009). 
Figura 1 - Represa Guarapiranga mapeamento de pontos de amostragem.

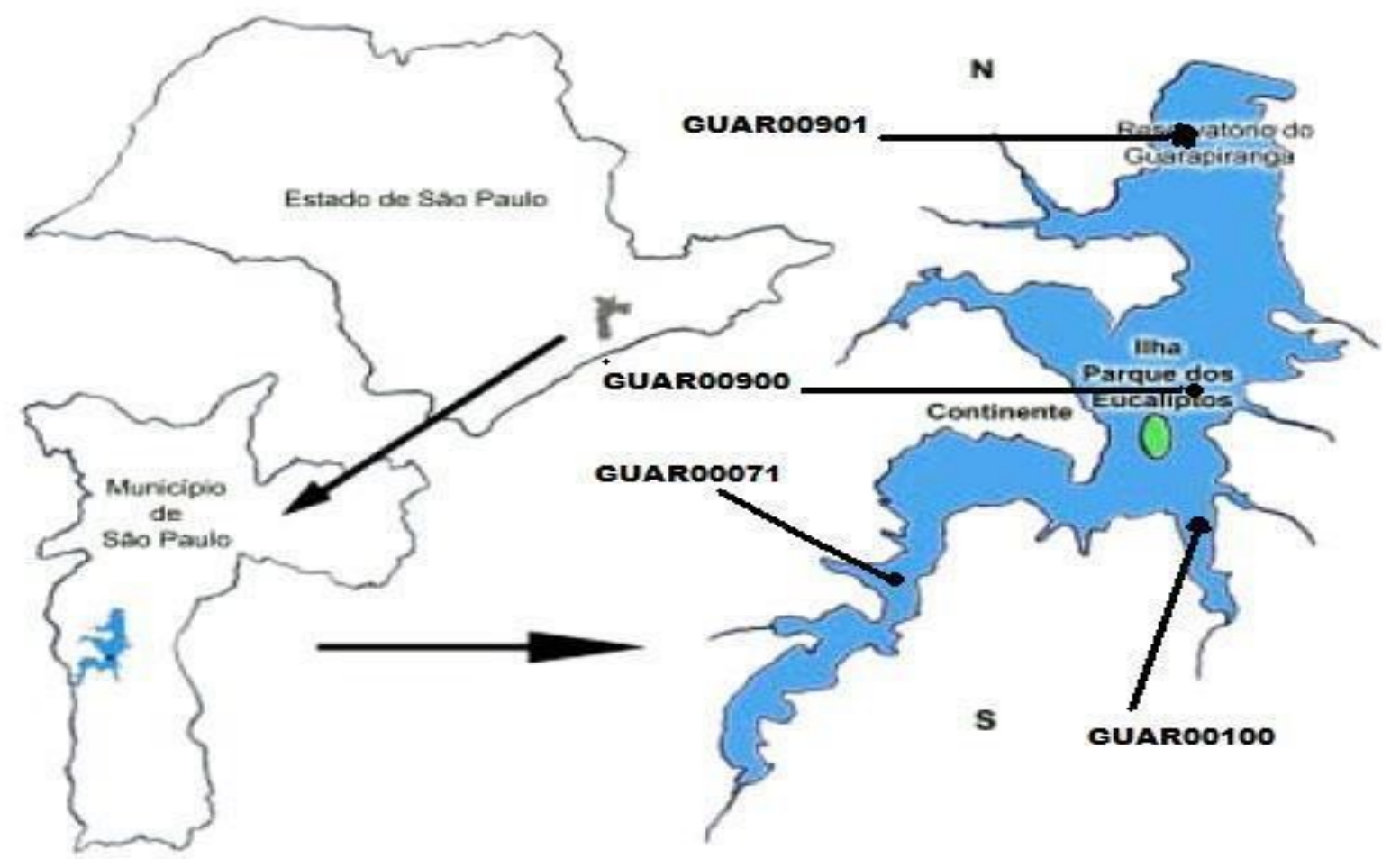

Figura 1a - Situação de coleta e disposição de esgotos nos municípios inseridos na Bacia da Guarapiranga, em 2000.

\begin{tabular}{l|c|c|c|c|}
\hline Municipio & $\begin{array}{c}\text { Domicilios } \\
\text { atendidos por } \\
\text { rede de esgotos } \\
\text { (na Bacia da } \\
\text { Guarapiranga) }\end{array}$ & $\begin{array}{c}\text { Destino do } \\
\text { esgoto } \\
\text { coletado }\end{array}$ & \multicolumn{2}{|c}{$\begin{array}{c}\text { Destino do } \\
\text { restante do } \\
\text { esgoto }\end{array}$} \\
\hline Embu & $4.493(30,1 \%)$ & $\begin{array}{c}\text { Rio Embu-Mirim } \\
\text { e afluentes }\end{array}$ & 4.940 & 5.345 \\
d'água
\end{tabular}




\subsection{Peixes}

Foram utilizados duzentos alevinos de Tilápias (Orecochromis niloticus) certificados por cada experimento. Estes alevinos foram obtidos por doação da piscicultura Rio Doce. Na chegada ao laboratório foram mantidos em 3 aquários de 300 litros com temperatura entre 26 $-28{ }^{\circ} \mathrm{C}$, com água bem oxigenada e filtragem constante, num regime de foto periocidade de 14/10 horas luz/escuridão por 15 dias para aclimatação. As Tilápias foram alimentadas 2 vezes por dia com ração comercial Koi Royal até 72 horas antes dos experimentos.

\subsection{Determinação das variáveis físico-químicas na água da Represa}

No local de amostragem, foram realizadas medidas de $\mathrm{pH}$ e de temperatura com um $\mathrm{pH}-$ metro portátil (Marconi, Brasil); dureza total e fosfato, usando kits comerciais de ensaios colorimétricos (Red Sea e Tropic Marin). Com as amostras de água coletadas nas garrafas de $1 \mathrm{~L}$ que foram mantidas a $4{ }^{\circ} \mathrm{C}$, se determinaram as seguintes variáveis físico - químicas: alcalinidade total (SMEWW 21a. Ed. 2005, mét. 2320 B), clorofila a (SMEWW 21a. Ed. 2005, mét. $10200 \mathrm{H}$ ), dureza total (SMEWW 21a. Ed. 2005, mét. 2340 C), fosfato total (SMEWW 21a. Ed. 2005, mét. 4500-P B e E), fósforo total (SMEWW 21a. Ed. 2005, mét. 4500-P B e E), nitrogênio amoniacal (SMEWW 21a. Ed. 2005, mét. 4500- $\mathrm{NH}_{3} \mathrm{~B}$ e C), nitrogênio nitrato (ABNT NBR 12620:1992 Determinação de Nitrato), nitrogênio nitrito (SMEWW 21a. Ed. 2005, mét. $4500 \mathrm{NO}_{2} \mathrm{~B}$ ), nitrogênio total (SMEWW 21a. Ed. 2005, mét. 4500 Norg B).

Com os valores da clorofila-a e do fósforo total obtidos em cada ponto, foi calculado o Índice de Estado Trófico. O Índice do Estado Trófico tem por finalidade classificar corpos d'água em diferentes graus de trofia, ou seja, avaliar a qualidade da água quanto ao enriquecimento por nutrientes orgânicos e inorgânicos, como fosfatos e clorofila a, e seu efeito no ecossistema.

$$
I E T=\frac{I E T(P T)+I E T(C l)}{2}
$$

Onde:

IET (PT): Índice do estado trófico para o fósforo;

IET $(\mathrm{Cl})$ : Índice do estado trófico para a clorofila;

$\mathrm{PT}=$ concentração de fósforo total medida à superfície da água, em $\mu \mathrm{g} / \mathrm{L}$.

$\mathrm{CL}=$ concentração de clorofila a medida à superfície da água, em $\mu \mathrm{g} / \mathrm{L}$. 


\subsection{Quantificação do Cu nas frações de água}

Quatro frações de água (Iw - IVw) foram obtidas de cada amostra a partir de filtrações e extrações com quelantes (BONNE HERNÁNDEZ; OLIVEIRA; ESPÓSITO, 2009), com modificações. Os procedimentos do fracionamento do $\mathrm{Cu}$ nas amostras de águas foram:

a) $\mathrm{Cu}$ total (Iw): uma alíquota de $100 \mathrm{~mL}$ de amostra acidificada com $2 \mathrm{~mL}$ de $\mathrm{HNO}_{3} \mathrm{e}$ $5 \mathrm{~mL}$ de $\mathrm{HCl}$, ambos concentrados, foram submetidas a digestão $\left(95 \pm 1{ }^{\circ} \mathrm{C}\right)$ até o volume ser reduzido a 15-20 mL. O volume final foi ajustado para $25 \mathrm{~mL}$, com água milli-Q, e analisado em duplicata por ICP-OES.

b) $\mathrm{Cu}$ Particulado (IIw): amostras de água não tratadas foram filtradas por membranas de acetato $(0,45 \mu \mathrm{m})$ aproximadamente três horas após a coleta em campo. Uma alíquota de $100 \mathrm{~mL}$ foi tratada e analisada como no item (a).

c) $\mathrm{Cu}$ Dissolvido (IIIw): amostras de água não tratadas foram filtradas por membranas de acetato $(0,22 \mu \mathrm{m})$ aproximadamente três horas após a coleta em campo. Uma alíquota de $100 \mathrm{~mL}$ foi tratada e analisada como descrito no item (a).

d) Cu não lábil (IVwa): uma alíquota do filtrado (c) foi agitada por duas horas em contato com a resina ChelexTM-100 (ensaio de troca iônica) a pH natural (6,5-8), resultando em duas frações de $\mathrm{Cu}$ : IVwa (complexos metálicos não lábeis de origem orgânica e inorgânica e/ou metal não lábil adsorvido em material orgânico e/ou inorgânico), que não foi retida na resina; e IVwb (complexos lábeis de metal de origem orgânica e inorgânica e/ou metal adsorvido em material orgânico e/ou inorgânico), que é retida na resina. A fração IVwa foi tratada e analisada como descrito no item (a). A fração IVwb não foi analisada.

Para todas as medições das amostras o equipamento utilizado foi o Espectrômetro Ótico de Emissão Atômica com Plasma Indutivamente Acoplado (ICP OES, Radial) da marca Spectro, modelo Arcos. Linha de emissão do Cu: 324,754 nm.

\subsection{Tratamento agudo de 120 horas das Tilápias com amostras da água da Represa}

Água coletada em cada ponto de amostragem da Represa, foi preservada em galões de 50 litros sem incidência da luz solar direta até a chegada no laboratório. Posteriormente foram colocados em quatro aquários, sendo um aquário para cada ponto de coleta e outros dois aquários como controle e controle positivo. No controle positivo foi adicionado uma solução de $\mathrm{CuSO}_{4}$ penta hidratado com uma concentração de $0.5 \mathrm{mg} / 1$. 
Em cada aquário foram colocados 18 indivíduos juvenis de Oreochromis niloticus com peso médio de $12.5 \mathrm{~g}$ e $10 \mathrm{~cm}$ de comprimento. Estes indivíduos foram mantidos em sala isolada com controle de foto período de 14/10 horas luz/escuridão, com oxigenação constante e temperaturas entre $26-28^{\circ} \mathrm{C}$ por 120 horas (Figura 2).

\subsection{Coleta das amostras de tecidos}

Após 120 horas as Tilápias foram anestesiadas com solução de 100 mg/l de Benzocaína e em seguida foram decapitadas e pesadas. Foram coletadas amostras de brânquias e fígado para posterior análises sendo: análise de marcadores de alterações histológicas, bioacumulação de Cu nas brânquias e fígados, marcadores de estresse oxidativo (Análise Enzimática).

Cada fígado foi pesado e junto com o peso dos peixes foram calculados o Índice hepatosomático (IHS). As amostras para análise enzimática foram preservadas em freezer a $80{ }^{\circ} \mathrm{C}$. Todos procedimentos para coleta das amostras de tecido para análise enzimática foram realizados em bandejas com gelo seco e imediatamente inseridos em nitrogênio líquido até sua colocação nos freezers. Estes procedimentos foram realizados para o período de seca e de chuva.

Figura 2 - Aquários experimentais.

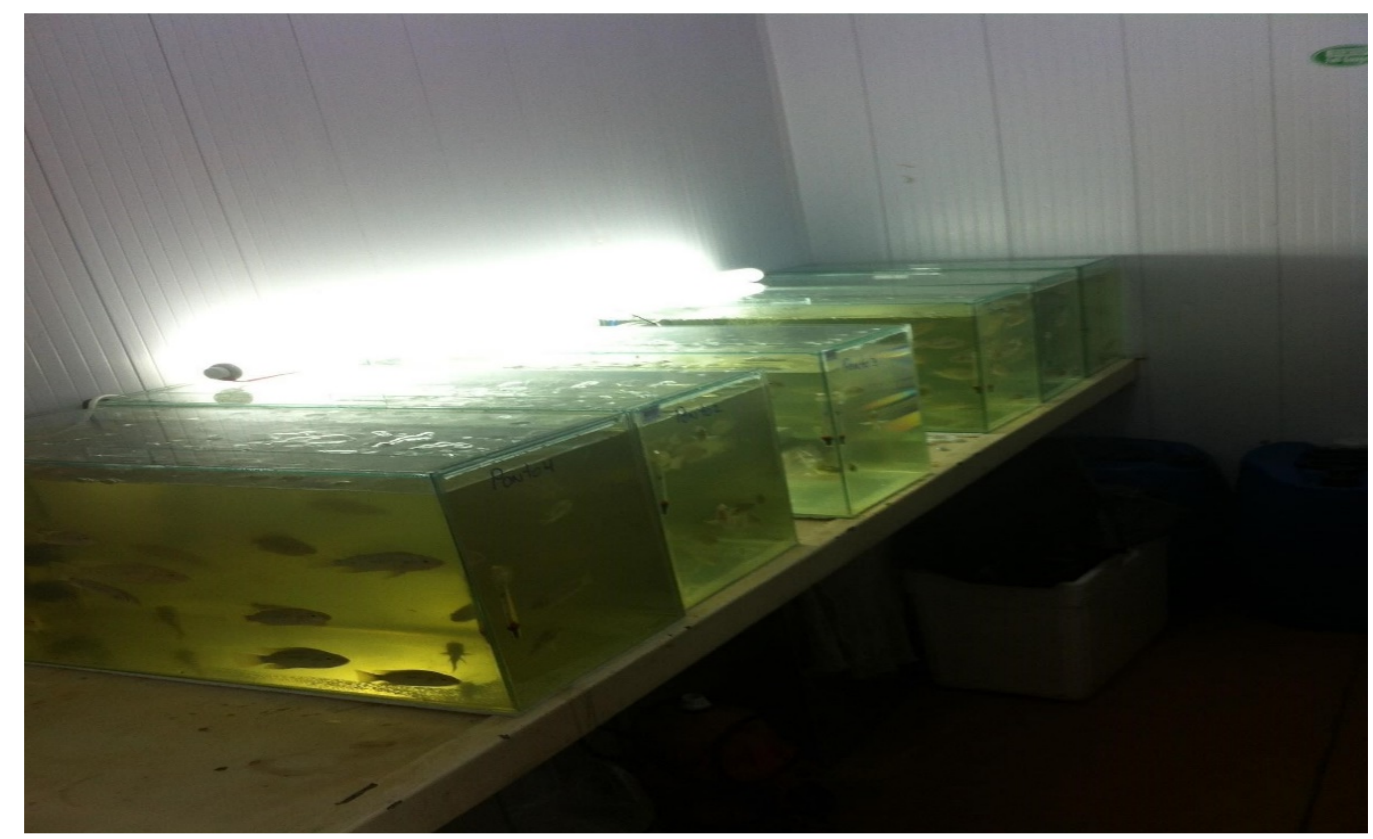




\subsection{Análise biomarcadores e mecanismos de toxicidade do $\mathrm{Cu}$ em função das diferentes frações na água}

\subsubsection{Análises de marcadores de alterações histológicas}

O penúltimo e antepenúltimo arco branquial do lado direito e o fígado de cada peixe foram coletados e colocados em cassete histológico devidamente identificados. Posteriormente, foram colocados no fixador Metacarn, desidratado em bateria crescente de álcoois e incluídas em parafina. Cortes de 5 micrômetros foram realizados e colocados nas lâminas para coloração com H\&E e PAS.

Estas lâminas foram observadas com microscopia de luz com aumento de 400x (Microscópio Carl Zeiss). Para cada peixe foram tiradas cinco fotos (AXIOCAM HRC Carl Zeiss) por corte, sendo quatro cortes por peixe para um total de 20 fotos analisadas, para cada tecido.

As alterações foram avaliadas semi-quantitativamente, pelo cálculo do Índice de Alterações Histológicas (IAH), baseado na seriedade da lesão observada. As alterações foram classificadas em estágios progressivos do dano tecidual:

- Estágio I, que não afeta o funcionamento do órgão;

- Estágio II, mais severo e prejudica o funcionamento normal do órgão;

- Estágio III, muito grave e irreversível.

Para cada peixe o IAH foi calculado usando a fórmula:

$$
\mathrm{IAH}=\left(1 \mathrm{x} \sum \mathrm{I}\right)+\left(10 \mathrm{x} \sum \mathrm{II}\right)+\left(100 \mathrm{x} \sum \mathrm{III}\right),
$$

onde I, II e III correspondem ao número de alterações de estágio I, II e III.

A média de IAH foi dividida em 5 categorias:

a) $0-10=$ funcionamento normal do órgão;

b) $11-20=$ menor a moderado;

c) $21-50=$ moderado a grave;

d) $51-100=$ alterações graves;

e) $\geq 100=$ alteração irreversível.

As alterações observadas foram qualificadas e tabeladas para o cálculo do Índice de Alterações Histológicas (IAH) (POLEKSIC; MITROVIC-TUTUNDZIC, 1994), com modificações. 
Nas brânquias foram quantificadas as áreas das células de muco presentes e os comprimentos das lamelas em cada imagem e calculado a média para cada peixe para verificar as possíveis diferenças entre os tratamentos e o tratamento controle.

\subsubsection{Bioacumulação de Cu nas brânquias e fígados}

Após a dissecção, as amostras de brânquias e fígados foram pesadas (aproximadamente $1 \mathrm{~g})$ e mantidas em estufa $\left(60^{\circ} \mathrm{C}\right)$ para a determinação do peso seco até peso constante. Foram adicionados ao tecido $10 \mathrm{~mL}$ de $\mathrm{H}_{2} \mathrm{SO}_{4}$. Um volume de $50 \mathrm{~mL}$ de água destilada foi adicionado e posteriormente analisado por espectrofotometria de absorção atômica (NEDER, 2006).

\section{- Fator de Bioacumulação (FBA)}

O fator de bioacumulação se define como a relação da concentração do metal no organismo com a concentração do metal na água durante o estado de equilíbrio (OPPERHUIZEN, 1991). A incorporação de metais pode ser diferente em cada organismo, pois eles seguem uma difusão passiva análoga a absorção de oxigênio (VAN DER OOST et al., 2003). O FBA se calcula aplicando a fórmula: BA = concentração do metal no peixe/concentração do metal na água. Neste estudo se aplicou a concentração do metal no tecido/concentração do $\mathrm{Cu}$ dissolvido na água vezes $100\left(\mathrm{FBA}=\left(\mathrm{C}_{\text {fígado }} / \mathrm{C}_{\text {água }}\right)\right)$.

\subsubsection{Marcadores de estresse oxidativo}

Para analisar a defesa antioxidante pela exposição ao $\mathrm{Cu}$ nas amostras de fígado, foram determinadas as atividades das enzimas catalase (CAT), $\mathrm{Cu} / \mathrm{Zn}$ - superóxido dismutase $(\mathrm{Cu} / \mathrm{Zn}$ - SOD) e glutationa peroxidasse (GPX). Para estes, foram seguidas as orientações definidas pelo fabricante nos KITs, sendo CAT (EnzyChromTM Catalase Assay Kit (ECAT-100)), SOD (EnzyChromTM Superoxide Dismutase Assay Kit (ESOD-100)), GPX (EnzyChromTM Glutathione Peroxidase Assay Kit (EGPX-100)). Todos os kits foram do fornecedor Bioassay (BioAssay Systems · 3191 Corporate Place, Hayward, CA 94545, USA).

A CAT é uma enzima antioxidante que catalisa a decomposição do peróxido de hidrogênio $\left(\mathrm{H}_{2} \mathrm{O}_{2}\right)$ em água e oxigênio.

$$
2 \mathrm{H}_{2} \mathrm{O}_{2} \stackrel{\text { catalase }}{\longrightarrow} \mathrm{O}_{2}+2 \mathrm{H}_{2} \mathrm{O}
$$


Mediante a prevenção da formação excessiva de $\mathrm{H}_{2} \mathrm{O}_{2}$, a CAT permite o correto funcionamento de diversos processos celulares, que tem como subproduto a produção de $\mathrm{H}_{2} \mathrm{O}_{2}$. Neste ensaio, foram medidos diretamente a degradação do $\mathrm{H}_{2} \mathrm{O}_{2}$ pela CAT, utilizando um corante redox. A mudança na intensidade da cor a $570 \mathrm{~nm}$ é diretamente proporcional a atividade da CAT na amostra analisada (EnzyChromTM Catalase Assay Kit (ECAT-100)).

$\mathrm{O} \mathrm{Cu} / \mathrm{Zn}$ - SOD, é parte do grupo da superóxido dismutase, são enzimas que catalisam a dismutação do superóxido em $\mathrm{O}_{2}$ e $\mathrm{H}_{2} \mathrm{O}$.

O GPX, representa uma família de enzimas com atividade peroxidase, com a principal função de proteger o organismo do dano oxidativo. Esta enzima ajuda a prevenir a oxidação lipídica da membrana celular pela remoção do peróxido livre na célula. GPX catalisa a seguinte reação com a glutationa reductase (GR):

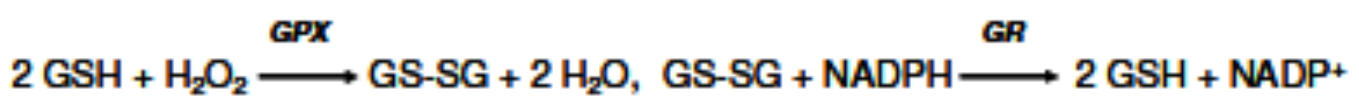

Este ensaio mede diretamente o consumo de NADPH, nas reações acopladas da enzima. A diminuição medida em densidade ótica a $340 \mathrm{~nm}$ é diretamente proporcional a atividade enzimática na amostra (EnzyChromTM Glutathione Peroxidase Assay Kit (EGPX-100)).

\subsection{Análise estatística}

Análises do teste t, teste Dunn e Kruskall - Wallis se aplicaram para determinar diferenças entre os índices de alterações histológicas, assim como a análise de variância, seguida dos testes de Tukey e Bonferroni para relacionar os índices hepatosomáticos, as bioacumulações e também os fatores de bioacumulação nas brânquias e fígados e a relação entre estes nos animais dos diferentes grupos e co controle.

Os resultados (médias +/- DP) das atividades enzimáticas (CAT, SOD e GPx) obtidos para os animais de cada local estudado foram comparados entre si utilizando-se teste ANOVA seguido de Bonferroni ou Bartlett. As análises estatísticas foram realizadas com o software GraphPad Prisma (GraphPad 4,0 softwares Inc, San Diego, CA, EUA). 


\section{RESULTADOS}

\subsection{Medições in situ na Represa}

As medidas de $\mathrm{pH}$, temperatura, dureza total, fosfato total e nitrato foram realizadas insitu e estão descritas na Tabela 2 e Tabela 3.

Tabela 2 - Dados das medições insitu na Represa Guarapiranga no período seco.

\begin{tabular}{|c|c|c|c|c|c|c|}
\hline \multicolumn{7}{|c|}{ Medições em Campo - 22/10/2012 } \\
\hline & Localização & Hora & Temperatura & Dureza T & PH & Fosfato \\
\hline Ponto 1 & 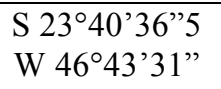 & 08:57 & $18^{\circ} \mathrm{C}$ & Mole & 6.5 & $0.2 \mathrm{mg} / \mathrm{L}$ \\
\hline Ponto 2 & $\begin{array}{l}\text { S 2343'24"5 } \\
\text { W } 46^{\circ} 43^{\prime} 44^{\prime \prime}\end{array}$ & 10:02 & $23{ }^{\circ} \mathrm{C}$ & Mole & 7.0 & $0.5 \mathrm{mg} / \mathrm{L}$ \\
\hline Ponto 3 & $\begin{array}{l}\text { S 23⒋'41" } 5 \\
\text { W } 46^{\circ} 44^{\prime} 49^{\prime \prime}\end{array}$ & $10: 30$ & $19^{\circ} \mathrm{C}$ & Mole & 7.0 & $0.5 \mathrm{mg} / \mathrm{L}$ \\
\hline Ponto 4 & $\begin{array}{l}\text { S } 23^{\circ} 44^{\prime} 25^{\prime \prime} 5 \\
\text { W } 46^{\circ} 45^{\prime} 56^{\prime \prime}\end{array}$ & $11: 10$ & $22{ }^{\circ} \mathrm{C}$ & $\begin{array}{c}\text { Levemente } \\
\text { Dura }\end{array}$ & 6.5 & $0.2 \mathrm{mg} / \mathrm{L}$ \\
\hline
\end{tabular}

Tabela 3 - Dados das medições insitu na Represa Guarapiranga no período chuvoso.

\begin{tabular}{|c|c|c|c|c|c|c|}
\hline \multicolumn{7}{|c|}{ Medições em Campo - 18/03/2013 } \\
\hline & Localização & Hora & Temperatura & Dureza T & PH & Fosfato \\
\hline Ponto 1 & $\begin{array}{l}\text { S 2340'36"5 } \\
\text { W } 46^{\circ} 43^{\prime} 31^{\prime \prime}\end{array}$ & $10: 35$ & $22{ }^{\circ} \mathrm{C}$ & Muito Mole & 8.5 & $0.25 \mathrm{mg} / \mathrm{L}$ \\
\hline Ponto 2 & $\begin{array}{l}\text { S } 23^{\circ} 43^{\prime} 24^{\prime \prime} 5 \\
\text { W } 46^{\circ} 43^{\prime} 44^{\prime \prime}\end{array}$ & 11:02 & $22{ }^{\circ} \mathrm{C}$ & Mole & 7.9 & $0.2 \mathrm{mg} / \mathrm{L}$ \\
\hline Ponto 3 & $\begin{array}{l}\text { S } 23^{\circ} 44^{\prime} 41^{\prime \prime} 5 \\
\text { W } 46^{\circ} 44^{\prime} 49^{\prime \prime}\end{array}$ & $11: 30$ & $22{ }^{\circ} \mathrm{C}$ & Mole & 8.0 & $0.1 \mathrm{mg} / \mathrm{L}$ \\
\hline Ponto 4 & $\begin{array}{l}\text { S } 23^{\circ} 44^{\prime} 25^{\prime \prime} 5 \\
\text { W } 46^{\circ} 45^{\prime} 56^{\prime \prime}\end{array}$ & $11: 55$ & $22{ }^{\circ} \mathrm{C}$ & Mole & 8.0 & $0.2 \mathrm{mg} / \mathrm{L}$ \\
\hline
\end{tabular}

As medidas realizadas insitu de variáveis físico - químicas, como $\mathrm{pH}$, temperatura, dureza total, fosfato total e nitrato, mostraram que a temperatura na coleta do período de seca oscilou entre 18 e $23{ }^{\circ} \mathrm{C}$ (Tabela 2). No entanto, na coleta do período chuvoso, a temperatura se manteve estável em $22{ }^{\circ} \mathrm{C}$. Já os valores de $\mathrm{pH}$ no período seco foram de neutro a ligeiramente ácido e no período chuvoso foram mais básicos (Tabela 3). Por outro lado, os valores de fosfato mostraram uma maior concentração deste íon no período seco. No comparativo entre os diferentes pontos de coleta, os valores se mantiveram muito próximos em todos os casos. 


\subsection{Variáveis físico - químicas das amostras da água da represa e o IET calculado}

Na tabela 4 e 5 podemos observar os valores das variáveis físico - químicas determinadas nas amostras coletadas nos períodos seco e chuvoso. Com os valores da clorofila-a e o fosfato se calculou o Índice do Estado Trófico (IET) (Tabela 6).

Tabela 4 - Dados das variáveis físico - químicas no período seco.

\begin{tabular}{lcccr}
\hline Variáveis Analisadas & Ponto 1 & Ponto 2 & Ponto 3 & Ponto 4 \\
\hline Alcalinidade Total mg/L(CaCO 3$)$ & 45,00 & 50,00 & $<1,00$ & 86,00 \\
Clorofila-a (ug/L) & 32,20 & 51,90 & 19,80 & 10,00 \\
Dureza Total (mg/L) $\left(\mathrm{CaCO}_{3}\right)$ & 28,00 & 31,00 & 28,00 & 26,00 \\
Fosfato Total (mg/L) & 0,09 & 0,09 & 0,06 & 0,09 \\
Fósforo Total (mg/L) & $<0,05$ & $<0,05$ & $<0,05$ & $<0,05$ \\
Nitrogênio Amoniacal (mg/L) & 0,27 & 0,99 & 0,64 & 0,94 \\
Nitrogênio Nitrato (mg/L) & 1,12 & 0,90 & 0,10 & 0,97 \\
Nitrogênio Nitrito (mg/L) & 0,72 & 0,94 & 0,01 & 0,14 \\
Nitrogênio Total (mg/L) & 2,00 & 3,30 & 2,80 & 4,50 \\
\hline
\end{tabular}

Tabela 5 - Dados das variáveis físico - químicas no período chuvoso.

\begin{tabular}{lrrrr}
\hline Variáveis Analisadas & Ponto 1 & Ponto 2 & Ponto 3 & Ponto 4 \\
\hline Alcalinidade Total mg/L(CaCO 3$)$ & 31,00 & 31,00 & 32,00 & 30,00 \\
Clorofila-a (ug/L) & 21,90 & 16,90 & 24,10 & 21,80 \\
Dureza Total (mg/L) $\left(\mathrm{caCO}_{3}\right)$ & 38,00 & 33,00 & 35,00 & 36,00 \\
Fosfato Total (mg/L) & 0,21 & 0,18 & 0,18 & 0,18 \\
Fósforo Total (mg/L) & 0,07 & 0,06 & 0,06 & 0,06 \\
Nitrogênio Amoniacal (mg/L) & $<0,07$ & $<0,07$ & $<0,07$ & $<0,07$ \\
Nitrogênio Nitrato (mg/L) & $<0,10$ & 0,24 & $<0,10$ & 0,18 \\
Nitrogênio Nitrito (mg/L) & 0,06 & 0,18 & 0,07 & 0,20 \\
Nitrogênio Total (mg/L) & 0,30 & 0,50 & 0,10 & 0,30 \\
\hline
\end{tabular}

Os valores das variáveis físico químicas analisadas nas amostras da água de cada ponto de coleta, apresentaram uma grande variação entre os diferentes pontos, assim como entre os dois períodos do ano. No caso da clorofila-a, foi observado que o ponto 2 no período da seca apresentou valores mais elevados, já no período da chuva isto ocorreu no ponto 3. Contudo, os valores do período chuvoso foram bem menores que no período seco. 
Outro elemento de importância que teve variação foi o fósforo total, que entre os diferentes pontos manteve um valor quase constante, porém foi mais elevado no período chuvoso.

No caso da clorofila-a, os valores mais altos foram no período da seca, corroborando com os Relatórios da CETESB $(2012,2013)$, pois é no período da estiagem que ocorrem os florescimentos de algas e com ela o aumento da clorofila-a.

Os valores de fósforo total para sistemas lênticos, no período de seca, estão dentro dos valores permitidos. No entanto, no período da chuva os valores de fósforo total estão acima do valor máximo permitido pela Resolução CONAMA nº 357, de 17 de março de 2005.

Com os dados de clorofila-a e fósforo total foram calculados os índices de estado trófico por cada ponto, com a fórmula:

$$
I E T=\frac{I E T(P T)+I E T(C l)}{2}
$$

Onde:

IET(PT): Índice do estado trófico para o fósforo;

IET(Cl): Índice do estado trófico para a clorofila;

Tabela 6 - Índice de Estado Trófico nos períodos seco e chuvoso.

\begin{tabular}{lcc}
\hline & Período Seco & Período Chuvoso \\
\hline Ponto 1 & 62,81 & IET \\
Ponto 2 & 63,98 & 40,15 \\
Ponto 3 & 61,61 & 38,91 \\
Ponto 4 & 59,94 & 39,78 \\
\hline
\end{tabular}

Os valores de IET do período chuvoso foram consideravelmente menores que os obtidos para o período seco. Contudo, entre os diferentes pontos de coleta dentro da Represa, estes se mantiveram com valores muito próximos. As maiores diferenças entre os pontos ocorreram no período seco. No período de chuva, todos os pontos podem ser classificados como ultraoligotróficos. Já no período seco os pontos 1, 3 e 4 se classificam de Eutróficos e o ponto 2 como super-eutrófico. 


\subsection{Concentrações do $\mathrm{Cu}$ por frações determinadas nas amostras da água}

Os resultados das concentrações de $\mathrm{Cu}$ por diferentes frações nas amostras coletadas no período seco e chuvoso, estão descritos nas tabelas 7 e 8 .

As concentrações de $\mathrm{Cu}$ no período chuvoso foram maiores que no período seco, em todas frações e pontos de coleta. Foi observado que em ambos os períodos, os valores da fração de $\mathrm{Cu}$ dissolvido apresentaram maiores concentrações nos 4 pontos comparando com o particulado (Tabela 7 e 8). O ponto 1 apresentou a maior concentração de $\mathrm{Cu}$ em ambos períodos analisados. Os valores obtidos mostram também, que o Cu na Represa se encontra na grande maioria em estado dissolvido. Isto beneficia a sua assimilação pelos organismos vivos como a Tilápia do Nilo, nossa espécie em estudo.

Tabela 7 - Concentrações de Cu por fração na Represa Guarapiranga período seco (mg/L).

\begin{tabular}{lcccr}
\hline \multirow{2}{*}{ Período Seco } & CuT & Dissolvido & Particulado & Não Lábil \\
\cline { 2 - 4 } & \multicolumn{4}{c}{ Concentrações em $\mathrm{mg} / \mathrm{L}$} \\
\hline Ponto 1 & $\mathbf{0 , 0 1 1 3}$ & $\mathbf{0 , 0 0 6 4}$ & 0,0015 & 0,0034 \\
Ponto 2 & 0,0096 & 0,0053 & 0,0001 & 0,0042 \\
Ponto 3 & 0,0037 & 0,0010 & 0,0014 & 0,0013 \\
Ponto 4 & 0,0064 & 0,0014 & 0,0046 & 0,0004 \\
\hline
\end{tabular}

Tabela 8 - Concentrações de Cu por fração na Represa Guarapiranga período chuvoso (mg/L).

\begin{tabular}{lcccr}
\hline \multirow{2}{*}{ Período Chuvoso } & CuT & Dissolvido & Particulado & Não Lábil \\
\cline { 2 - 5 } & \multicolumn{4}{c}{ Concentrações em mg/L } \\
\hline Ponto 1 & 2,5130 & 2,2430 & 0,1550 & 0,1150 \\
Ponto 2 & 1,0450 & 0,7840 & 0,1570 & 0,1040 \\
Ponto 3 & 1,1690 & 0,4110 & 0,6780 & 0,0800 \\
Ponto 4 & 1,3870 & 1,2230 & 0,0280 & 0,1360 \\
\hline
\end{tabular}

As concentrações de $\mathrm{Cu}$ nas diferentes frações, como no $\mathrm{Cu}$ particulado $(0,45)$ e dissolvido $(0,22)$ estão dentro do permitido pela Resolução CONAMA nº 357, de 17 de março de 2005 (0,009 mg/L) nas medições realizadas no período de seca, para o Cu total os valores estão acima do permitido nos pontos 1 e 2. Já na coleta do período de chuva, estes valores em todos os casos estão bem acima do limite permitido pela legislação. 


\subsection{Alterações histológicas nos tecidos branquial e hepático}

A figura 3, esquematiza as alterações mais, mais comuns nas brânquias com seus graus de severidade. Na figura 4, podemos observar a ausência de alterações acentuadas nas brânquias do peixe controle. Já na figura 4, o peixe exposto em um dos aquários com água da represa, apresentou várias alterações como: proliferação do epitélio interlamelar e lamelar, descolamento do epitélio da lamela secundária, edema intersticial. $\mathrm{Na}$ análise de todas as amostras foram observadas hiperplasia das células epiteliais, desarranjo dos capilares. Estas alterações também ocorreram no controle. Já alterações como aneurismas e hiperplasia/hipertrofia das células mucosas, só ocorreram nos grupos de tratamento no período de chuva. Os resultados das alterações verificadas no período seco foram bastante similares. No entanto, a congestão vascular ocorreu nos tratamentos do período seco com mais frequência que no chuvoso.

Nos fígados foram observadas alterações como vacuolização, necroses, núcleos picnóticos e aparente aumento do tamanho dos hepatócitos, quando comparados com o controle (Figura 5). No período chuvoso, os grupos de tratamentos apresentaram desarranjo dos cordões hepáticos, perda ou atipía do contorno celular e nuclear, degeneração citoplasmática e aumento da frequência relativa dos vasos sanguíneos. Estas mesmas alterações foram observadas nas análises das amostras do período seco. 
Figura 3 - Quatro maiores alterações histológicas (a) controle, (b) edema, (c) lifting de epitélio, (d) vasodilatação, (e) aneurisma.

(a)

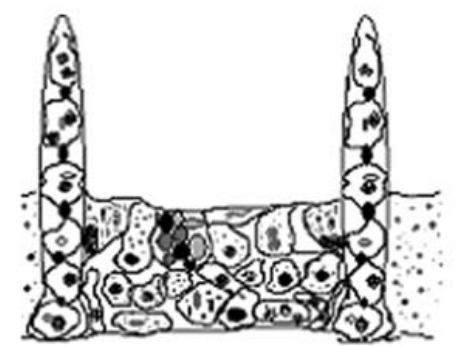

(b)
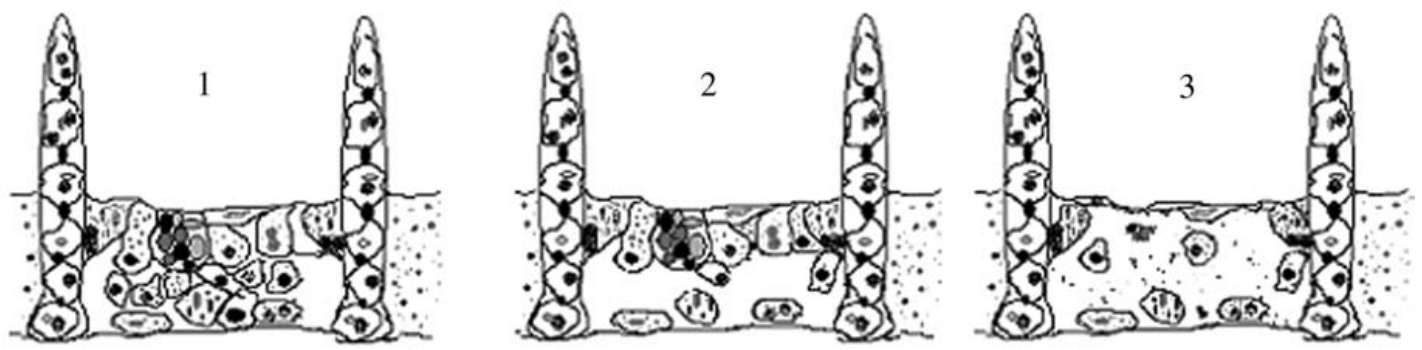

(c)

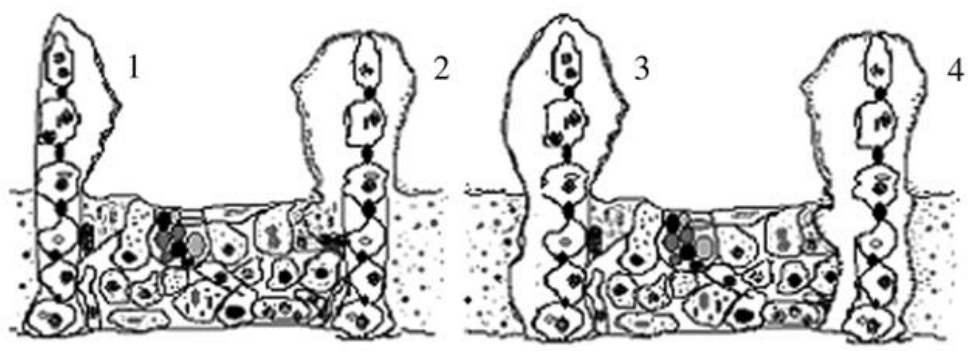

(d)

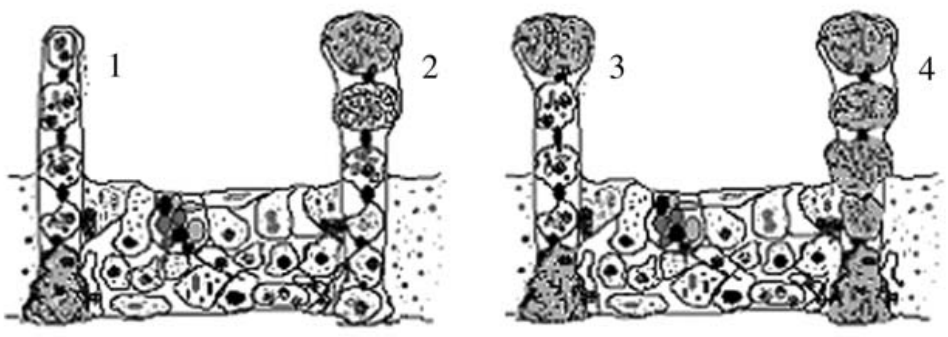

(e)

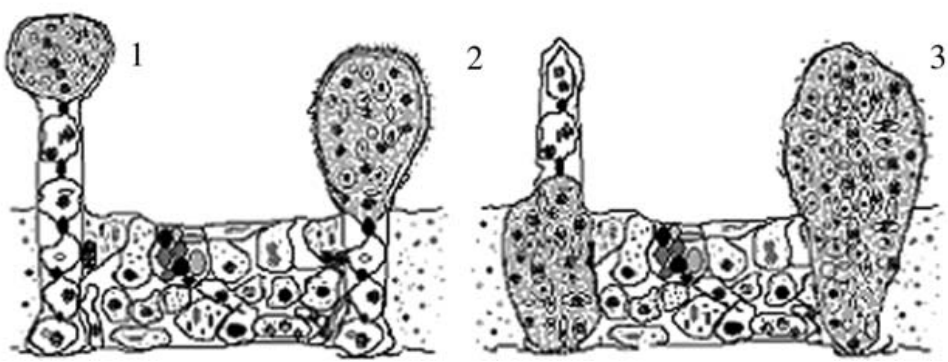

Fonte: Monteiro et al. (2008). 
Figura 4 - Microfotografia mostrando cortes de $5 \mu \mathrm{m}$ de brânquias coradas com H\&E.
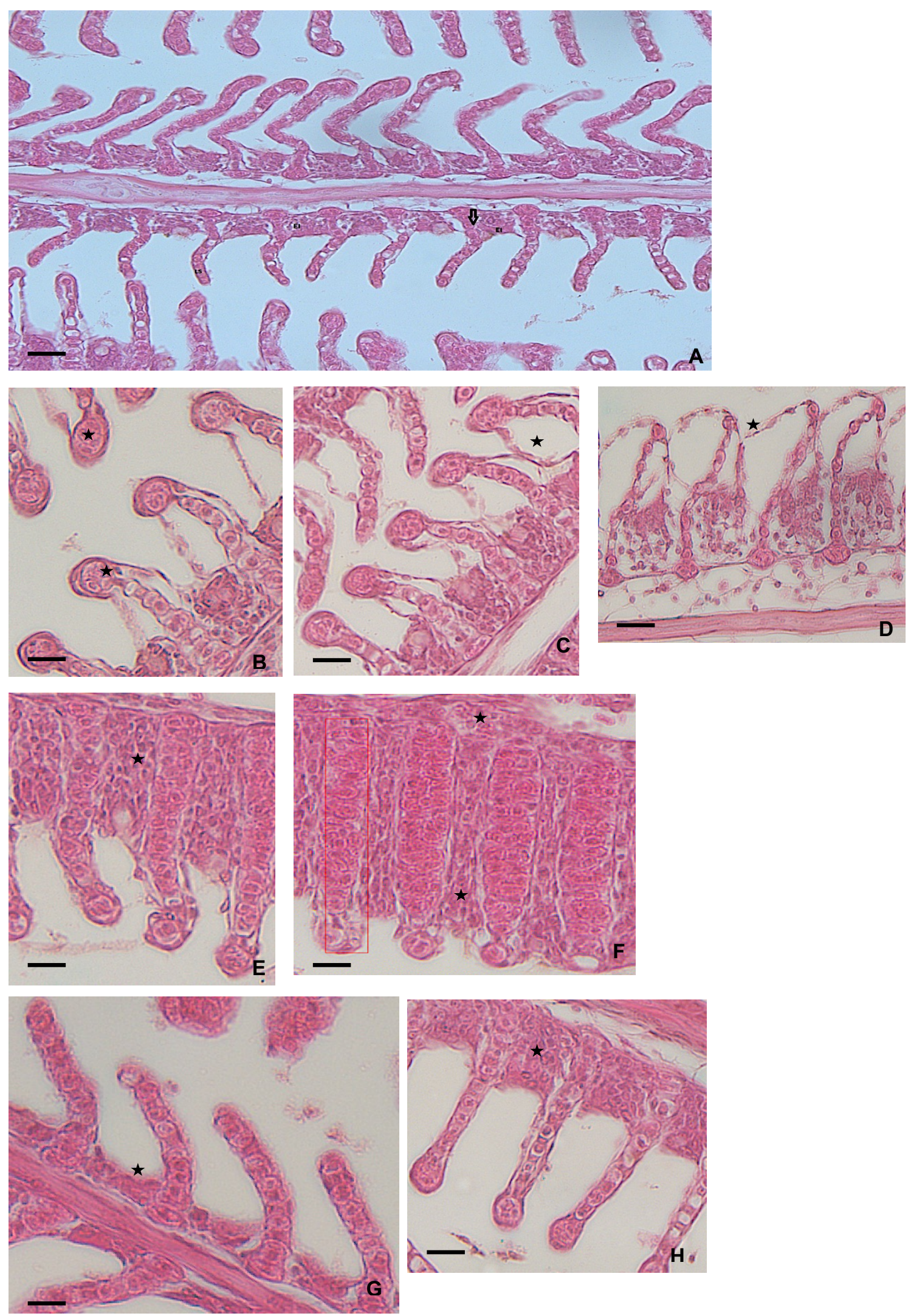

( * ) marca as alterações. (A) Controle, LS (Lamela), EI (Epitélio Interlamelar), seta (eritrócito), (B) Aneurismas, (C -D) Descolamento epitelial, edema e necrose), (E-F) Fusão lamelar, (G-H) Diminuição e Aumento do epitélio filamentar. Barra de escala $=10 \mu \mathrm{m}$. 
Figura 5 - Microfotografia mostrando cortes de $5 \mu \mathrm{m}$ de fígado, corados com H\&E.
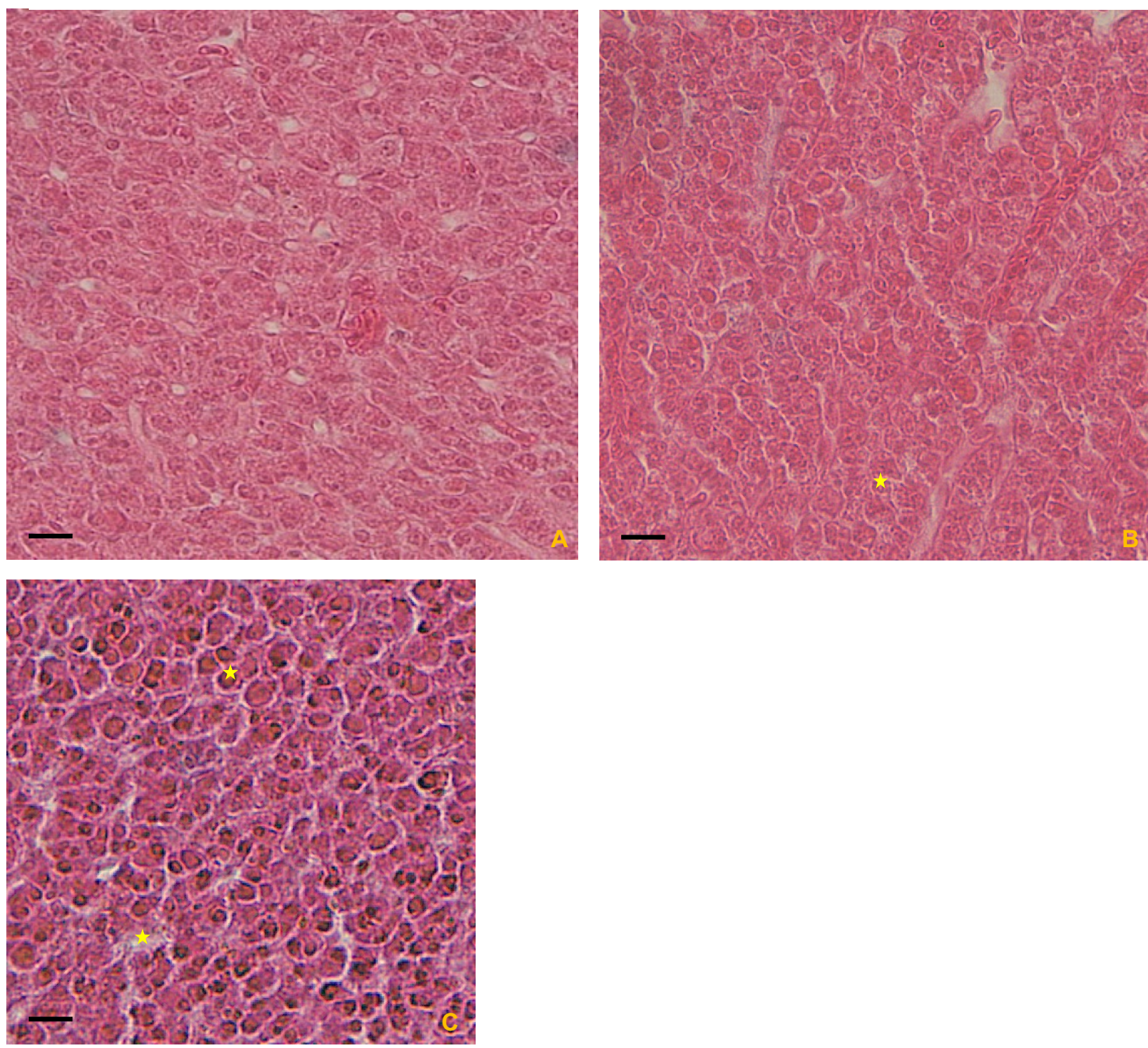

. (* ) marca as alterações. (A) Controle, (B) desarranjo dos cordões hepáticos, aumento de células sanguíneas, vacuolização, (C) núcleos picnóticos, necrose, citoplasma denso, perda ou atipía do contorno celular e nuclear. 


\section{5 Índice de alterações histológicas nas brânquias e fígados}

Este subitem detalha-se os resultados do Índice de Alterações Histológicas (IAH) nos tecidos de brânquias e fígados nos grupos controle e nos tratamentos. O índice foi calculado conforme Poleksic e Mitrovic-Tutundzic (1994), com modificações.

Nas tabelas 9 e 11 e nos gráficos 1 e 2 são apresentados os resultados obtidos para o IAH nas brânquias e fígado do período seco, assim como as médias e o desvio padrão. Após o cálculo dos IAH para cada peixe por grupo de tratamento e os grupos controles, a determinação das médias e a classificação do estado dos órgãos foram realizadas conforme tabela proposta por Poleksic e Mitrovic-Tutundzic (1994) (Tabelas 10, 12).

Tabela 9 - IAH das brânquias por indivíduo e grupo de tratamento período seco.

\begin{tabular}{crrrrrr}
\hline \multicolumn{7}{c}{ IAH BRANQUIAL SECA } \\
\hline PEIXES & HBC- & HBC+ & HBI & HBII & HBIII & HBIV \\
\hline 1 & 4 & 5 & 6 & 6 & 17 & 17 \\
2 & 15 & 5 & 16 & 8 & 8 & 7 \\
3 & 4 & 6 & 7 & 8 & 8 & 18 \\
4 & 5 & 4 & 16 & 8 & 17 & 18 \\
5 & 5 & 4 & 16 & 5 & 7 & 7 \\
6 & 4 & 6 & 5 & 7 & 6 & 8 \\
\hline MÉDIA & $\mathbf{6}$ & $\mathbf{5}$ & $\mathbf{1 1}$ & $\mathbf{7}$ & $\mathbf{1 1}$ & $\mathbf{1 3}$ \\
\hline DESV.PAD. & $\mathbf{4}$ & $\mathbf{1}$ & $\mathbf{6}$ & $\mathbf{1}$ & $\mathbf{5}$ & $\mathbf{6}$ \\
\hline
\end{tabular}

Gráfico 1 - IAH das brânquias por grupo de tratamento no período seco (média e desvio padrão).

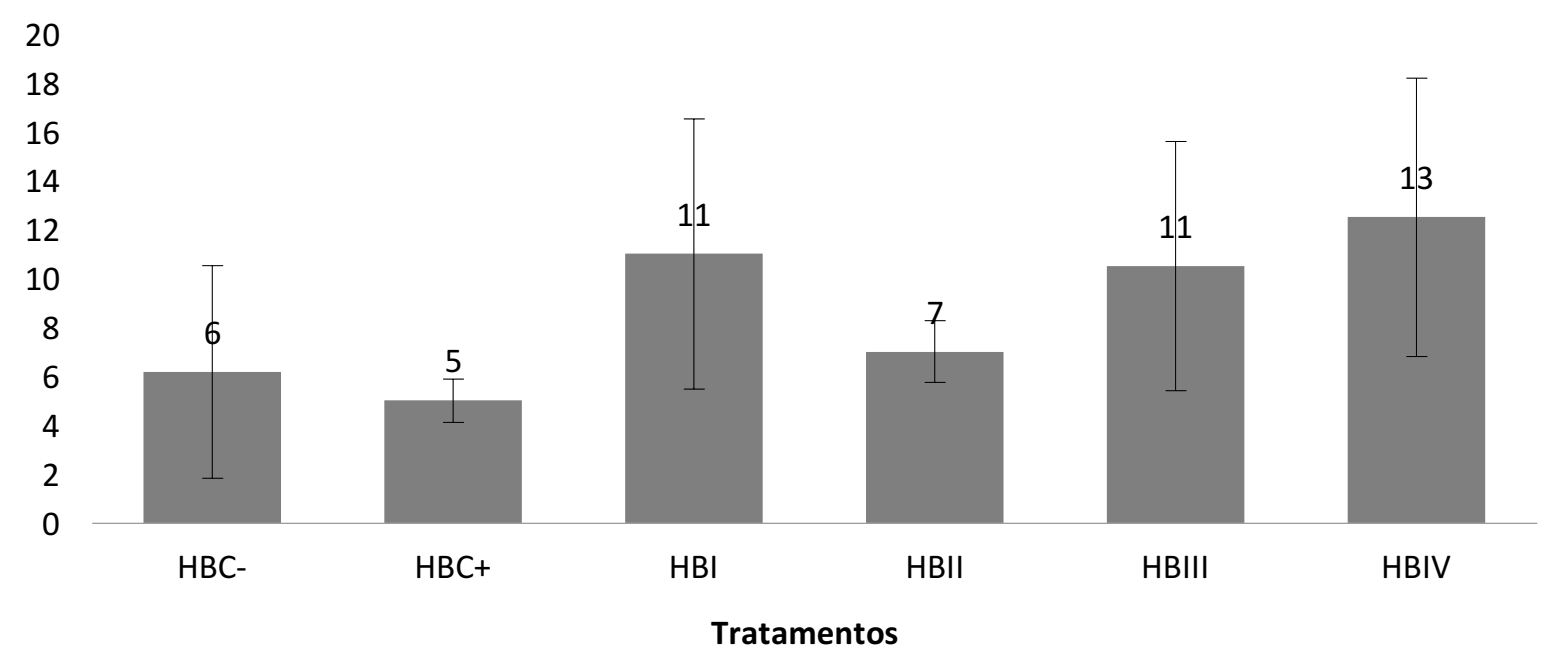


Tabela 10 - Índices de Alterações Histológicas para brânquias no período seco.

\begin{tabular}{ll}
\hline Sigla & Definição \\
\hline HBC- & Órgão funcionalmente normal \\
HBC+ + & Órgão funcionalmente normal \\
HBI & Órgão com alterações de leves a moderadas \\
HBII & Órgão funcionalmente normal \\
HBIII & Órgão com alterações de leves a moderadas \\
HBIV & Órgão com alterações de leves a moderadas \\
\hline
\end{tabular}

Os resultados de IAH para as brânquias no período seco apresentaram diferenças significativas entre as medianas dos grupos, conforme análises com Kruskal - Wallis $(\mathrm{P}<0,05)$. $\mathrm{Na}$ comparação entre os diferentes grupos de tratamento e controle, o teste de comparação múltipla de Dunn apresentou diferença significativa $(\mathrm{P}<0,05)$ com aproximação gaussiana entre o grupo controle (HBC-) e o grupo 4 (HBIV); entre o controle positivo (HBC+) e o grupo 4. No gráfico 1 é possível observar que o ponto HBIV obteve a maior média de IAH, considerando o desvio padrão. Apesar de verificar diferenças numéricas entre os grupos, o teste-t não apresentou diferenças significativas entre as médias $(\mathrm{P}<0,05)$.

Segundo a classificação Poleksic e Mitrovic-Tutundzic (1994) com modificações, nos resultados de IAH foram verificados órgãos com alterações moderadas nos grupos HBI, HBIII e HBIV (Tabela 10).

Tabela 11 - IAH por indivíduo e grupo de tratamento para os fígados período seco.

\begin{tabular}{ccccccc}
\hline \multicolumn{7}{c}{ IAH HEPÁTICA SECA } \\
\hline PEIXES & HFC- & HFC+ & HFI & HFII & HFIII & HFIV \\
\hline $\mathbf{1}$ & 0 & 14 & 24 & 14 & 24 & 14 \\
$\mathbf{2}$ & 0 & 24 & 24 & 24 & 24 & 24 \\
$\mathbf{3}$ & 0 & 14 & 14 & 14 & 24 & 14 \\
$\mathbf{4}$ & 0 & 13 & 14 & 24 & 24 & 24 \\
$\mathbf{5}$ & 0 & 24 & 14 & 24 & 14 & 14 \\
$\mathbf{6}$ & 0 & 24 & 24 & 24 & 14 & 24 \\
\hline MÉDIA & $\mathbf{0}$ & $\mathbf{1 9}$ & $\mathbf{1 9}$ & $\mathbf{2 1}$ & $\mathbf{2 1}$ & $\mathbf{1 9}$ \\
\hline DESV.PAD. & $\mathbf{0}$ & $\mathbf{6}$ & $\mathbf{5}$ & $\mathbf{5}$ & $\mathbf{5}$ & $\mathbf{5}$ \\
\hline
\end{tabular}


Gráfico 2 - IAH por grupo de tratamento nos fígados para o período seco (média e desvio padrão).

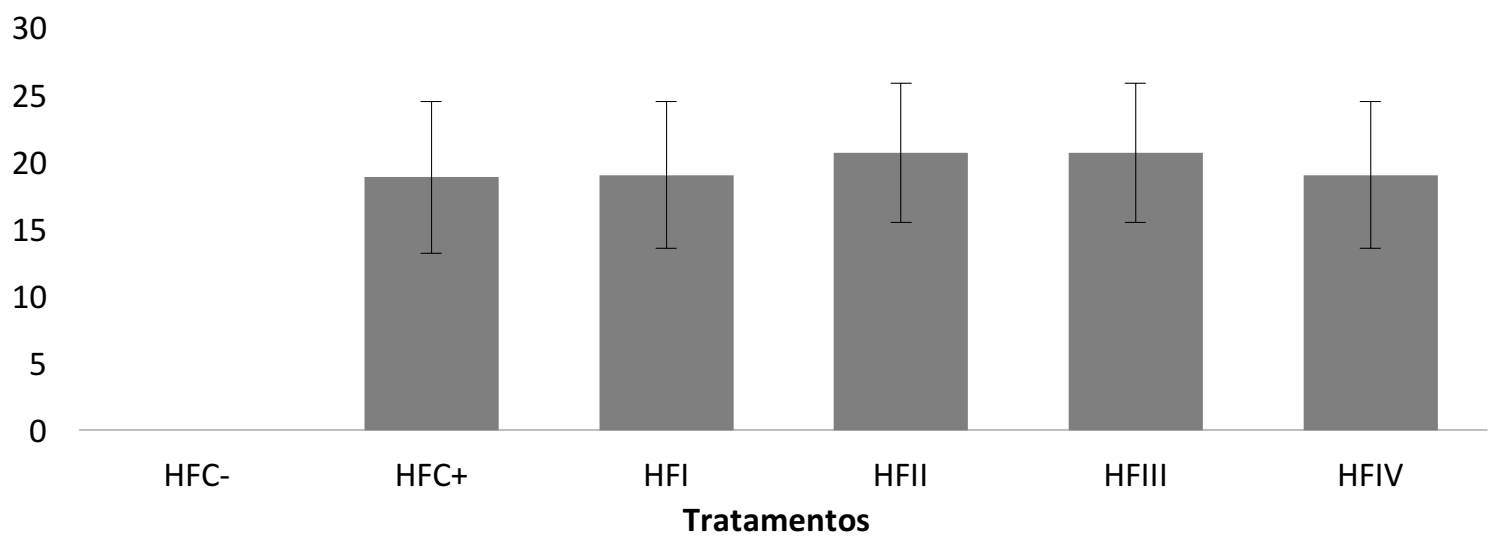

A análise estatística dos IAH para o fígado no período seco apresentou diferenças significativas entre as medianas dos grupos, na comparação entre os valores de IAH de cada grupo, conforme o teste de Kruskal-Wallis. No teste de comparação múltipla de Dunn, também foi encontrado diferenças significativas entre o controle e todos os grupos de tratamento $(\mathrm{P}<0,05)$. Este resultado pode ser visualizado no gráfico 2 para as médias analisadas com o teste-t com $\mathrm{P}(<0,05)$. Todos os grupos, exceto o controle, mostraram órgãos com alterações, sendo os casos mais graves nos grupos HFII e HFIII (Tabela 12).

Tabela 12 - Índices de Alterações Histológicas para fígados no período seco.

\begin{tabular}{ll}
\hline Sigla & Definição \\
\hline HFC- & Órgão funcionalmente normal \\
HFC+ & Órgão com alterações de leves a moderadas \\
HFI & Órgão com alterações de leves a moderadas \\
HFII & Órgão com alterações de moderadas a graves \\
HFIII & Orgão com alterações de moderadas a graves \\
HFIV & Orgão com alterações de leves a moderadas \\
\hline
\end{tabular}

No processamento das alterações histológicas também foram quantificadas o comprimento das lamelas e a área da célula de muco por cada indivíduo nos diferentes tratamentos, assim como nos controles. Com estes valores se determinaram as médias e os desvios padrões para cada grupo de tratamento. Na sequência os dados foram processados para verificar se existiam diferenças significativas entre cada grupo e os controles, para isto foi utilizado ANOVA seguido de teste de comparações múltiplas Turkey $(\mathrm{P}<0,05)$. Os resultados do período seco para o comprimento da lamela apresentaram diferenças significativas entre o controle e o grupo $\mathrm{HBI}$; entre o controle positivo $\mathrm{HBC}+$ e o grupo $\mathrm{HBI}$; entre o grupo $\mathrm{HBI}$ e o 
grupo HBIV. Para a área das células de muco só houve diferença significativa entre os valores do grupo HBI e o HBIV.

No período chuvoso, nos testes do comprimento das lamelas, não foram observadas diferenças significativas entre nenhum dos grupos analisados. A área das células de muco apresentou diferenças significativas entre o controle HBC- e os 4 grupos de tratamento (HBI, HBII, HBIII, HBIV) e entre o controle positivo HBC+ e os grupos HBII, HBIII e HBIV. Os resultados das médias e desvio padrão para cada grupo são expressados nos gráficos 3 e 4 para o período de seca e nos gráficos 7 e 8 para período chuvoso.

Gráfico 3 - Comprimento da lamela por grupo de tratamento e controle em micrómetros no período seco.

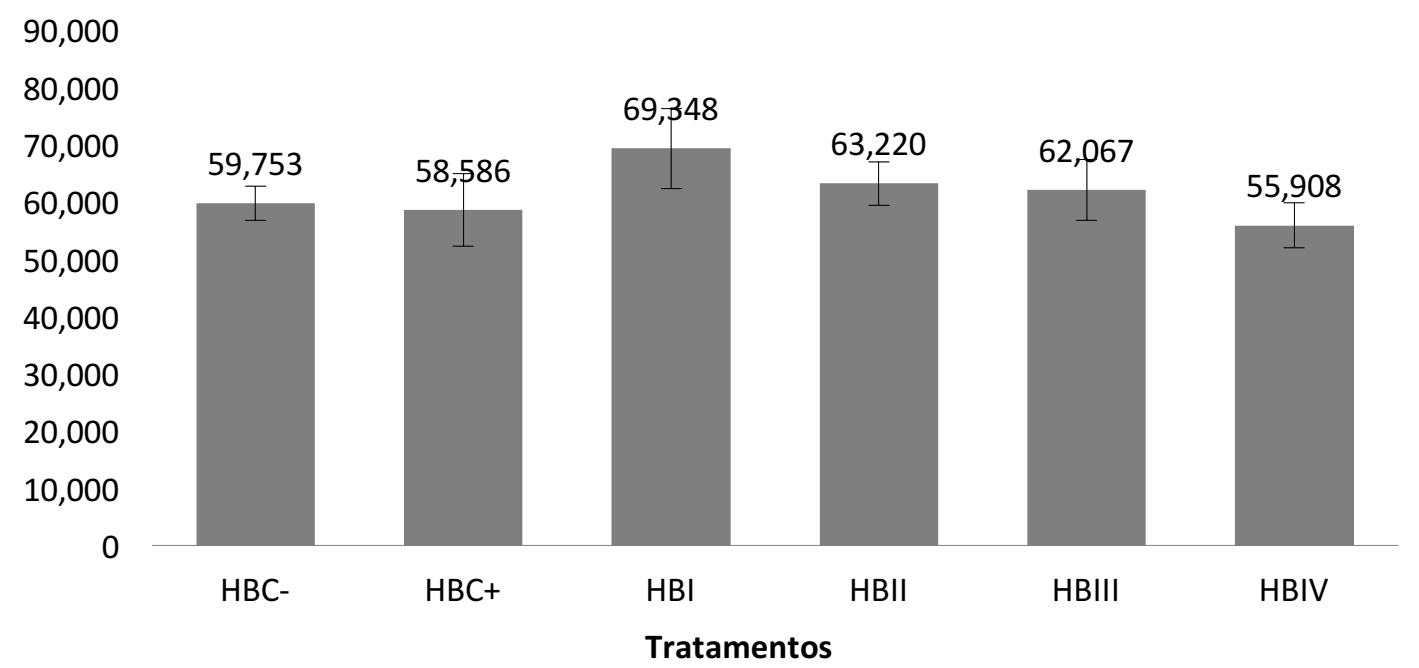


Gráfico 4 - Área das células de muco por grupo de tratamento e controle em micrómetros quadrados no período seco.

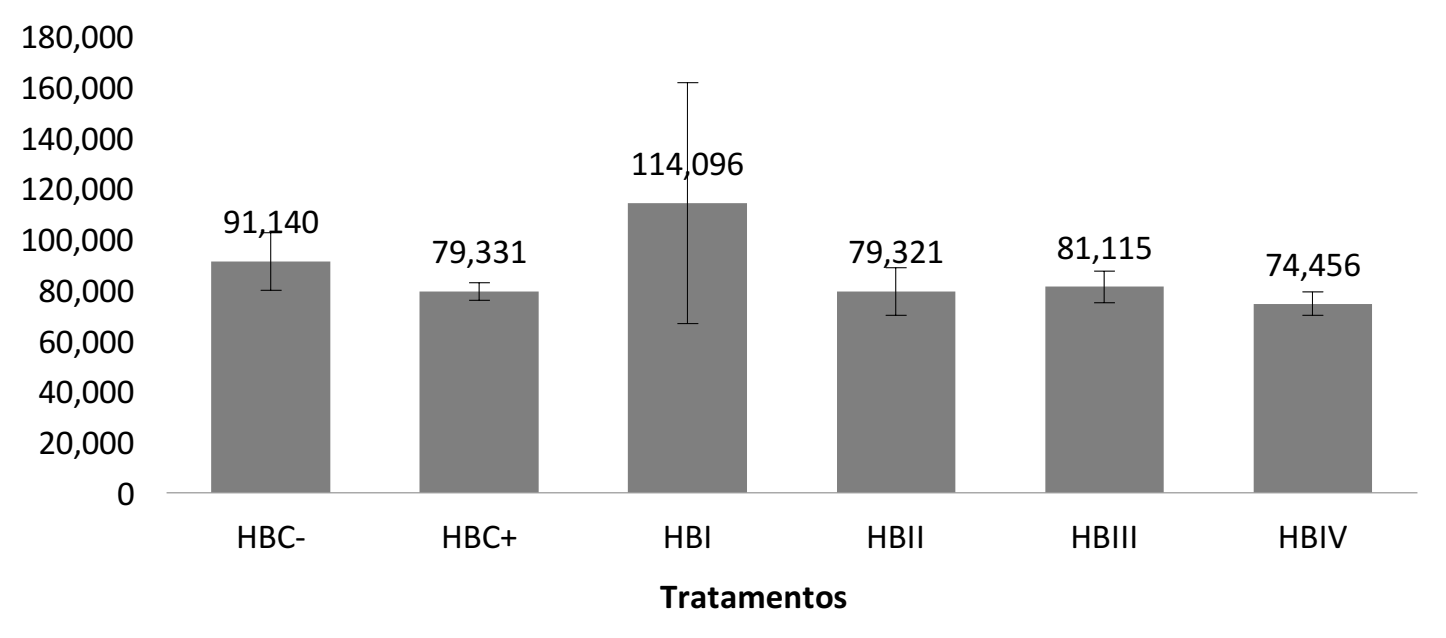

Igualmente ao período seco no chuvoso foram calculados os IAH para brânquias e fígados, assim como as médias e desvio padrão por grupo de tratamento e controles. Estes resultados estão listados nas Tabelas 13 e 15 e os gráficos 5 e 6 . A classificação do estado funcional dos órgãos foi determinada para o período chuvoso e seco (Tabelas 14 e 16).

Tabela 13 - IAH por indivíduo e grupo de tratamento para as brânquias no período chuvoso.

\begin{tabular}{ccccccc}
\hline & \multicolumn{7}{c}{ IAH BRANQUIAL } & HBI & HBII & HBIII & HBIV \\
\hline PEIXES & HBC- & HBC + & HBI & 17 & 17 \\
2 & 2 & 16 & 17 & 6 & 8 & 7 \\
3 & 2 & 5 & 6 & 7 & 6 & 7 \\
4 & 2 & 6 & 8 & 7 & 6 & 8 \\
5 & 2 & 7 & 14 & 19 & 7 & 17 \\
6 & 3 & 6 & 19 & 7 & 11 & 12 \\
\hline MÉDIA & 2 & 7 & 6 & 9 & 6 & 5 \\
\hline DESV.PAD. & 2 & 8 & 12 & 5 & & 17 \\
\hline
\end{tabular}


Gráfico 5 - IAH por grupo de tratamento para as brânquias no período chuvoso (média e desvio padrão).

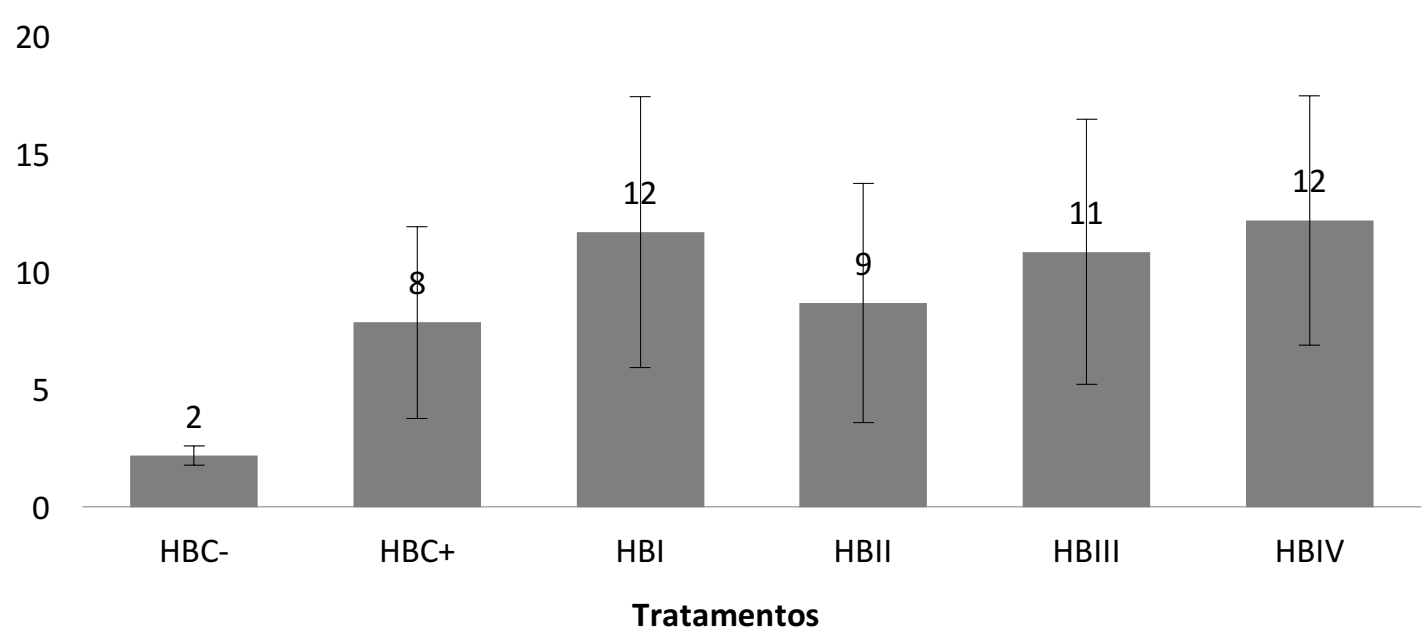

Tabela 14 - Índices de Alterações Histológicas para brânquias no período chuvoso.

\begin{tabular}{ll}
\hline Sigla & Definição \\
\hline HBC- & Órgão funcionalmente normal \\
HBC+ + & Órgão funcionalmente normal \\
HBI & Órgão com alterações de leves a moderadas \\
HBII & Órgão funcionalmente normal \\
HBIII & Órgão com alterações de leves a moderadas \\
HBIV & Órgão com alterações de leves a moderadas \\
\hline
\end{tabular}

Para o período de chuva os resultados foram similares ao período seco conforme o teste de Kruskal-Wallis, seguido pelo teste de comparações múltiplas de Dunn com $(\mathrm{P}<0,05)$ que apresentaram diferenças significativas para as medianas e entre o grupo controle HBC- e o grupo HBI, HBIII e HBIV. Os resultados do teste-t apresentaram diferenças significativas entre as médias do controle e todos os tratamentos (Gráfico 6).

As classificações dos danos nos órgãos mostraram alterações leves a moderadas nos grupos HBI, HBIII e HBIV, correspondendo com os resultados dos testes estatísticos (Tabela 14). 
Tabela 15 - IAH por indivíduo e grupo de tratamento para os fígados no período chuvoso.

\begin{tabular}{ccccccc}
\hline & \multicolumn{7}{c}{ IAH HEPÁTICA } & & & \\
\hline PEIXES & HFC- & HFC + & HFI & HFII & HFIII & HFIV \\
\hline 1 & 0 & 14 & 14 & 14 & 25 & 14 \\
2 & 0 & 24 & 14 & 14 & 14 & 14 \\
3 & 0 & 14 & 14 & 14 & 14 & 24 \\
4 & 0 & 14 & 14 & 24 & 14 & 24 \\
5 & 0 & 24 & 24 & 24 & 24 & 24 \\
6 & 0 & 14 & 24 & 14 & 14 & 14 \\
\hline MÉDIA & 0 & 17 & 17 & 17 & 18 & 19 \\
\hline DESV.PAD. & 0 & 5 & 5 & 5 & 5 & 5 \\
\hline
\end{tabular}

Gráfico 6 - IAH por grupo de tratamento para os fígados, período chuvoso (média e desvio padrão).

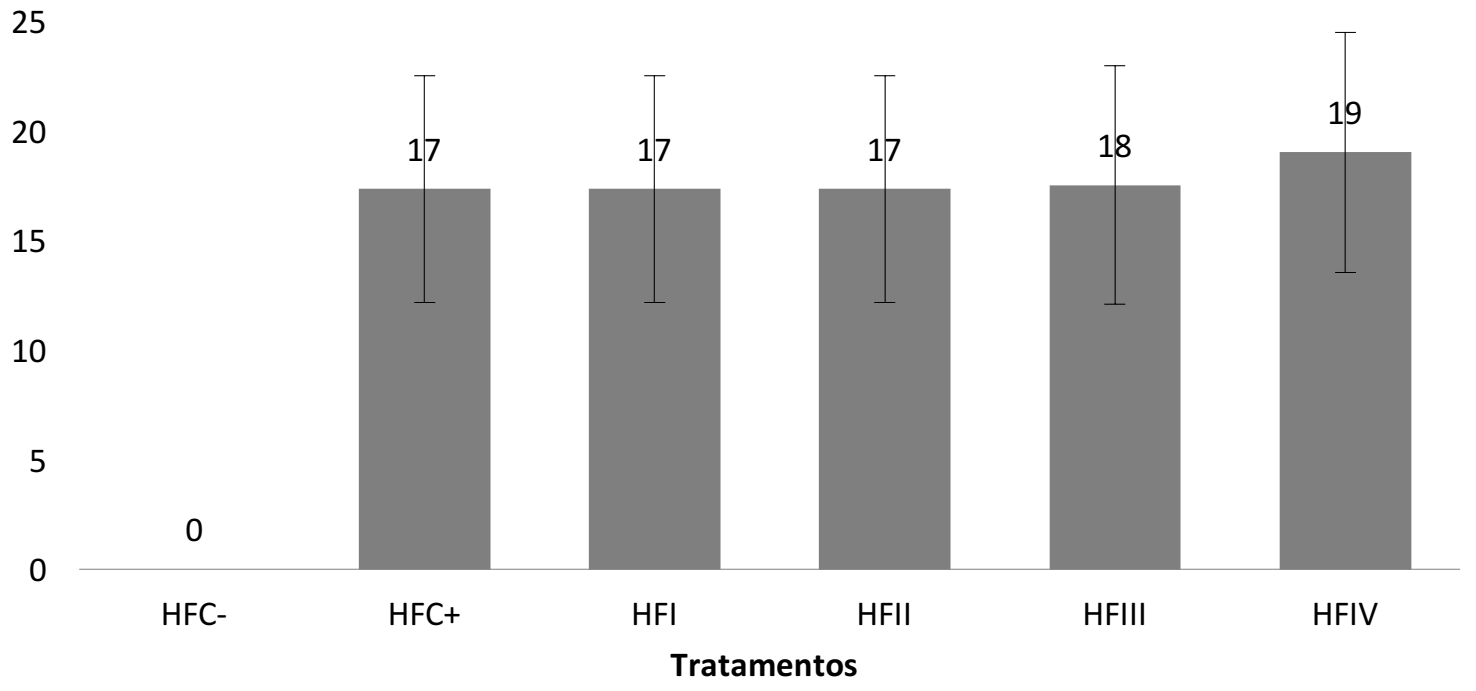

Tabela 16 - Índices de Alterações Histológicas para fígados no período chuvoso.

\begin{tabular}{ll}
\hline Grupo de & Definição \\
Tratamento & Órgão funcionalmente normal \\
\hline HFC- & Órgão com alterações de leves a moderadas \\
HFC+ & Órgão com alterações de leves a moderadas \\
HFI & Órgão com alterações de leves a moderadas \\
HFII & Órgão com alterações de leves a moderadas \\
HFIII & Órgão com alterações de leves a moderadas \\
\hline
\end{tabular}

O IAH hepático no período chuvoso apresentou diferenças significativas para as medianas no teste de Kruskal-Wallis $(\mathrm{P}<0,05)$. Seguido do teste de comparações múltiplas de 
Dunn $(\mathrm{P}<0,05)$ que mostrou diferenças significativas para os valores de IAH entre o controle e todos os grupos de tratamento. Este resultado coincide com o teste-t $(\mathrm{P}<0,05)$ que também apresentou diferenças significativas entre o controle e os tratamentos (Gráfico 6).

O IAH do fígado não apresentou alterações no grupo controle. No entanto, foram observadas alterações leves a moderadas em todos os demais grupos, isto coincide com o observado nos testes estatísticos (Tabela 16).

Gráfico 7 - Comprimento da lamela por grupo de tratamento e controles em micrómetros no período chuvoso (média e desvio padrão).

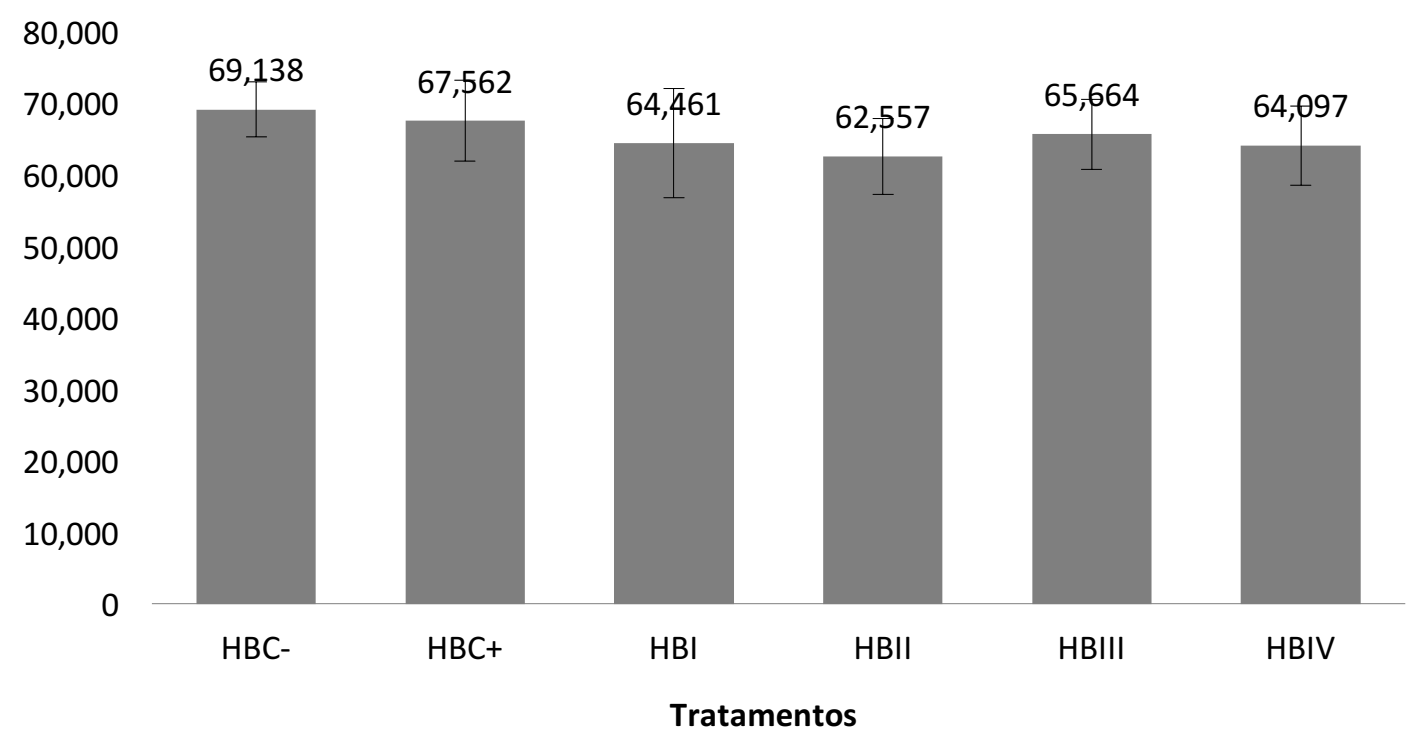

Gráfico 8 - Área das células de muco por grupo de tratamento e controles em micrómetros quadrados no período chuvoso (média e desvio padrão).

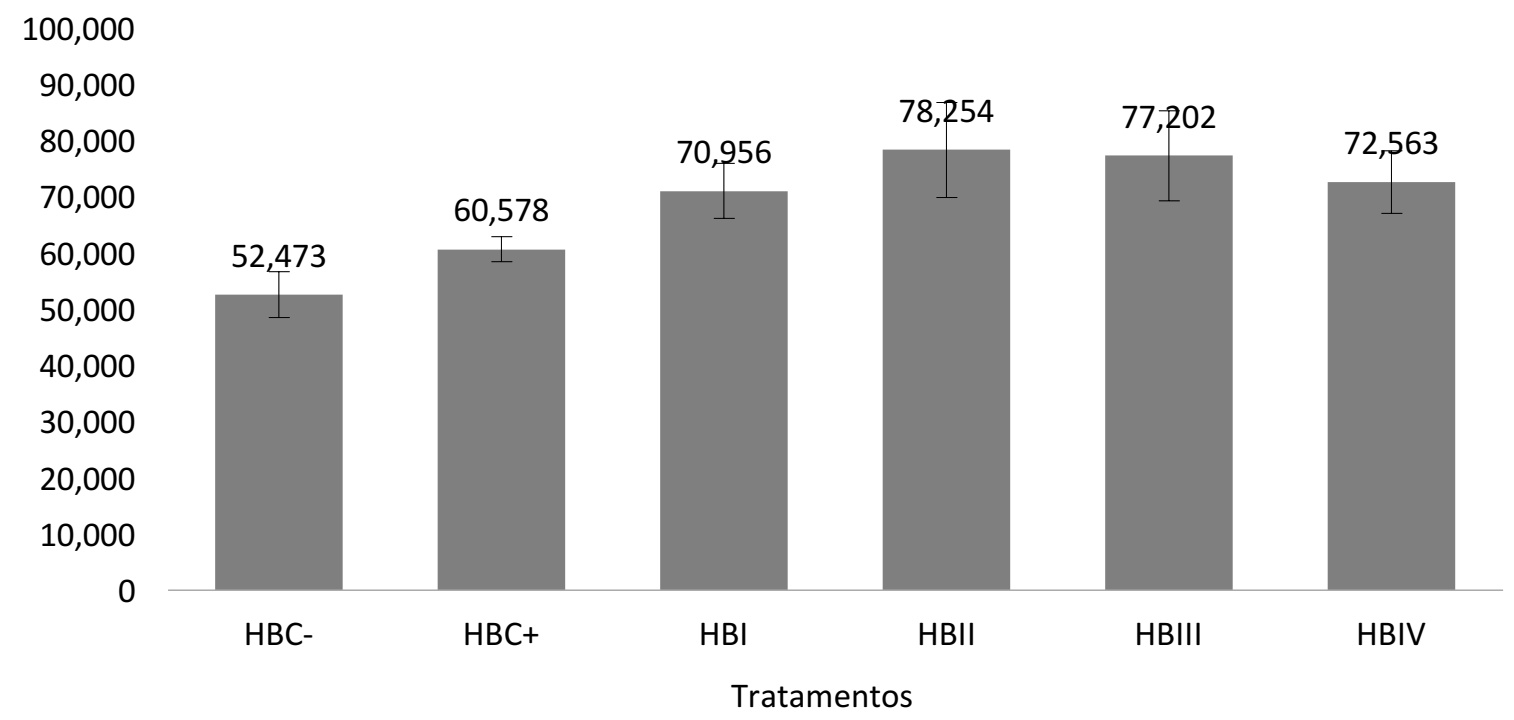


Na comparação dos resultados dos IAH do fígado e das brânquias entre os dois períodos, não foram observadas diferenças significativas entre as médias dos tecidos avaliados (Gráficos 9 e 10), conforme teste-t $(\mathrm{P}<0,05)$.

Gráfico 9 - Comparação das médias do IAH Branquial no período de Seca vs Chuva.

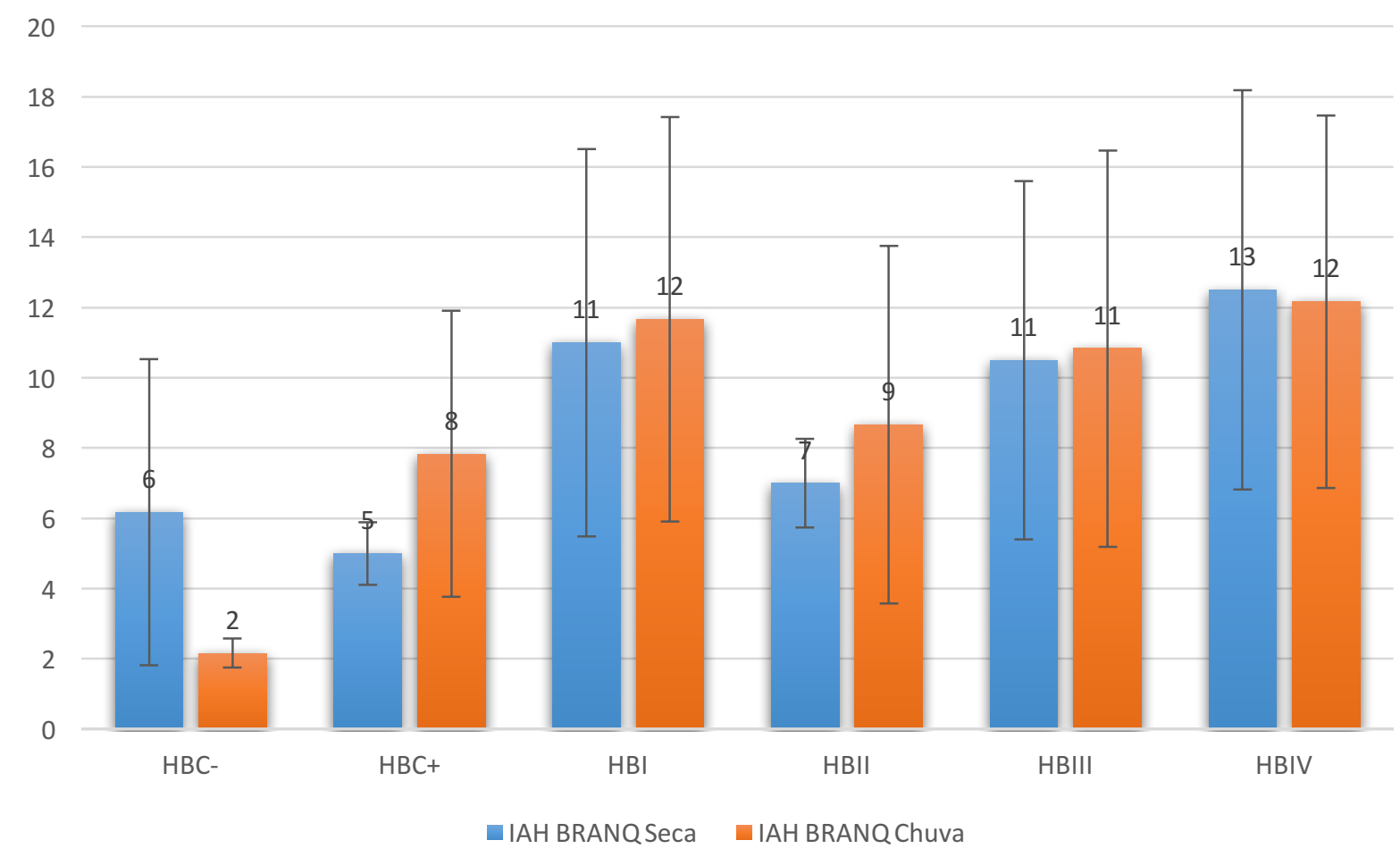

Gráfico 10 - Comparação das médias do IAH Fígado no período de Seca vs Chuva.

30

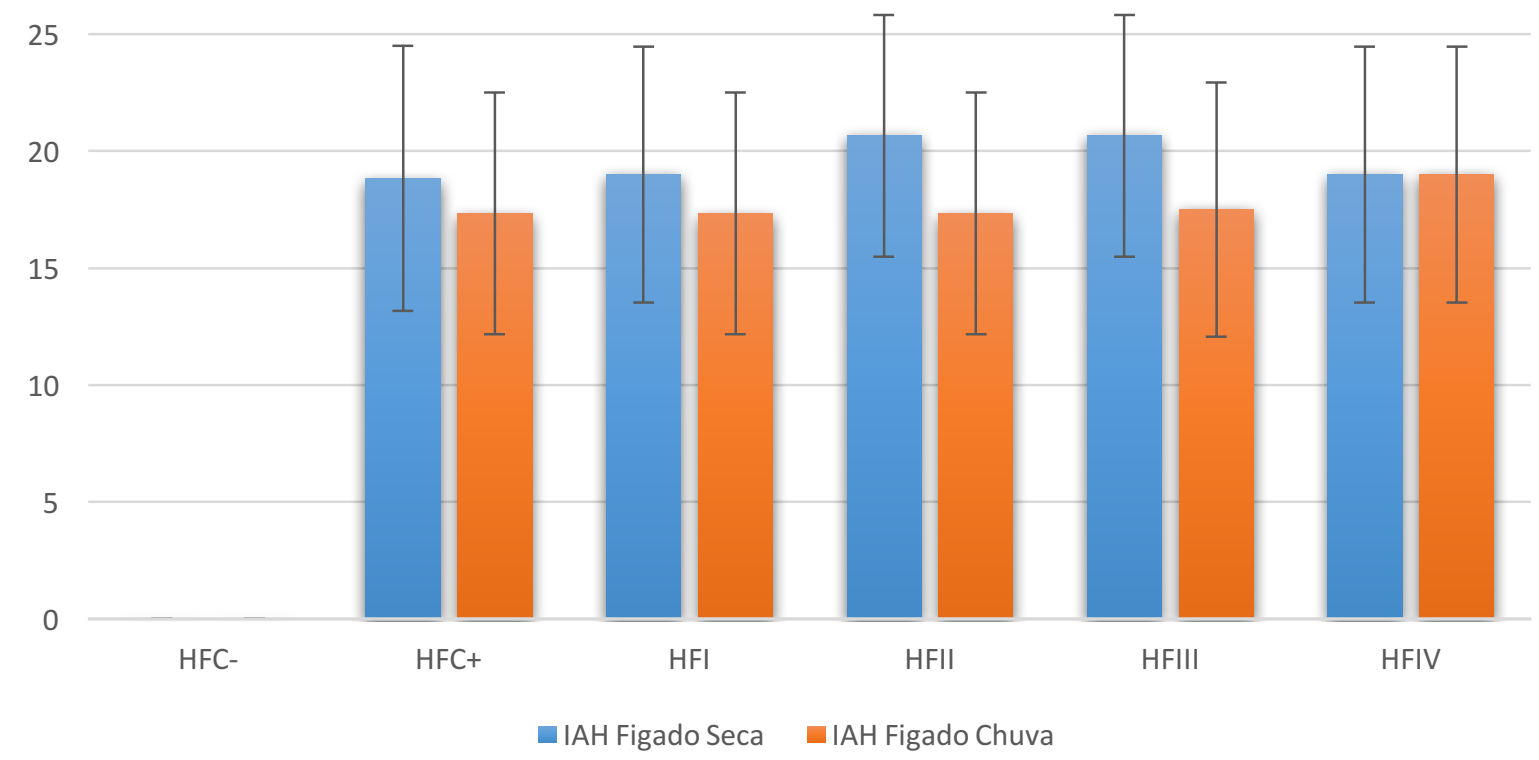




\subsection{Bioacumulação de Cu nas Brânquias e Fígado, Cálculo Fator de Bioacumulação}

Nas tabelas 17, 18, 19 e 20 podemos observar os resultados das concentrações de $\mathrm{Cu}$ nos tecidos coletados dos peixes expostos a água no período seco e chuvoso, respectivamente. Os resultados dos fatores de bioacumulação podem ser verificados nos gráficos 17 e 18 .

Observando os resultados do período chuvoso, as amostras de fígado foram grandes acumuladores de $\mathrm{Cu}$ com valores de até $10,525 \mathrm{mg} / \mathrm{L}$. Isto pode ser explicado, pelo fato de que mesmo que as concentrações instantâneas não sejam muito altas, o tempo de exposição no caso do fígado provocam efeito acumulativo. Isto resultou em concentrações mais elevadas que as medidas na água, o maior valor encontrado atingiu os $10,526 \mathrm{mg} / \mathrm{L}$ no peixe 2 do grupo III (Tabelas 17 e 18).

Tabela 17 - Bioacumulação de Cu nas brânquias (mg/L) no período chuvoso.

\begin{tabular}{crrrrrr}
\hline \multirow{2}{*}{ PEIXES } & CUTBC & CUTBC + & CUTBI & CUTBII & CUTBIII & CUTBIV \\
\cline { 2 - 7 } & \multicolumn{5}{c}{$\mathbf{m g} / \mathbf{L}$} \\
\hline $\mathbf{1}$ & 0,075 & 0,270 & 0,167 & 0,133 & 0,076 & 0,071 \\
$\mathbf{2}$ & 0,063 & 0,211 & 0,450 & 0,117 & 0,091 & 0,071 \\
$\mathbf{3}$ & 0,072 & 0,218 & 0,173 & 0,239 & 0,084 & 0,082 \\
$\mathbf{4}$ & 0,071 & 0,170 & 0,098 & 0,094 & 0,112 & 0,089 \\
$\mathbf{5}$ & 0,048 & 0,255 & 0,199 & 0,069 & 0,077 & 0,066 \\
$\mathbf{6}$ & 0,077 & - & 0,148 & 0,59 & 0,077 & 0,079 \\
\hline MÉDIA & $\mathbf{0 , 0 6 8}$ & $\mathbf{0 , 2 2 4 8}$ & $\mathbf{0 , 2 0 6}$ & $\mathbf{0 , 2 0 7}$ & $\mathbf{0 , 0 8 6}$ & $\mathbf{0 , 0 7 6 3}$ \\
\hline
\end{tabular}

Tabela 18 - Bioacumulação de Cu nos fígados (mg/L) no período chuvoso.

\begin{tabular}{ccccrrr}
\hline \multirow{2}{*}{ PEIXES } & CUTFC- & CUTFC+ & CUTFI & CUTFII & CUTFIII & CUTFIV \\
\cline { 2 - 7 } & \multicolumn{5}{c}{$\mathbf{m g} / \mathbf{L}$} \\
\hline $\mathbf{1}$ & 0,352 & 3,903 & 3,674 & 5,067 & 4,347 & 2,876 \\
$\mathbf{2}$ & 0,896 & 2,027 & 5,470 & 4,080 & 10,526 & 1,881 \\
$\mathbf{3}$ & 1,994 & 5,693 & 5,951 & 4,389 & 3,066 & 2,297 \\
$\mathbf{4}$ & 4,304 & 1,667 & 3,938 & 5,500 & 5,272 & 4,282 \\
$\mathbf{5}$ & 2,867 & 2,916 & 8,336 & 3,005 & 6,108 & 5,058 \\
$\mathbf{6}$ & 1,855 & - & 8,251 & 3,285 & 1,969 & 4,320 \\
\hline MÉDIA & $\mathbf{2 , 0 4 5}$ & $\mathbf{3 , 2 4 1}$ & $\mathbf{5 , 9 3 7}$ & $\mathbf{4 , 2 2 1}$ & $\mathbf{5 , 2 1 5}$ & $\mathbf{3 , 4 5 2}$ \\
\hline
\end{tabular}

Os resultados de bioacumulação nas brânquias e nos fígados no período chuvoso foram processados estatisticamente mediante ANOVA, seguido de teste de Tukey $(\mathrm{P}<0,05)$, para determinar as diferencias significativas entre as médias de cada grupo entre si. Para os valores 
das brânquias, os resultados da ANOVA apresentaram diferenças entre as médias. O teste de Tukey não mostrou diferenças. Os resultados da ANOVA para o fígado apresentaram diferenças entre as médias, e no teste de Tukey a diferença significativa ocorreu entre o grupo controle e CUTFC-; e o grupo 1 CUTFI (Gráficos 11 e 12).

Gráfico 11 - Médias de bioacumulação com os desvios padrões na brânquia para o período chuvoso.

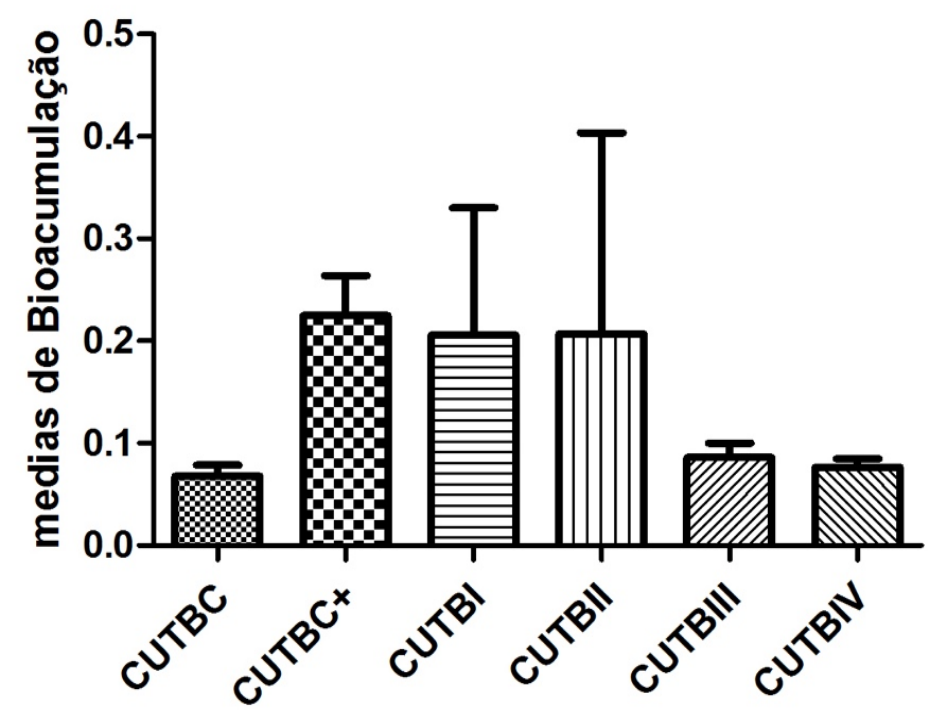

Gráfico 12 - Médias de bioacumulação com os desvios padrões no fígado para o período chuvoso.

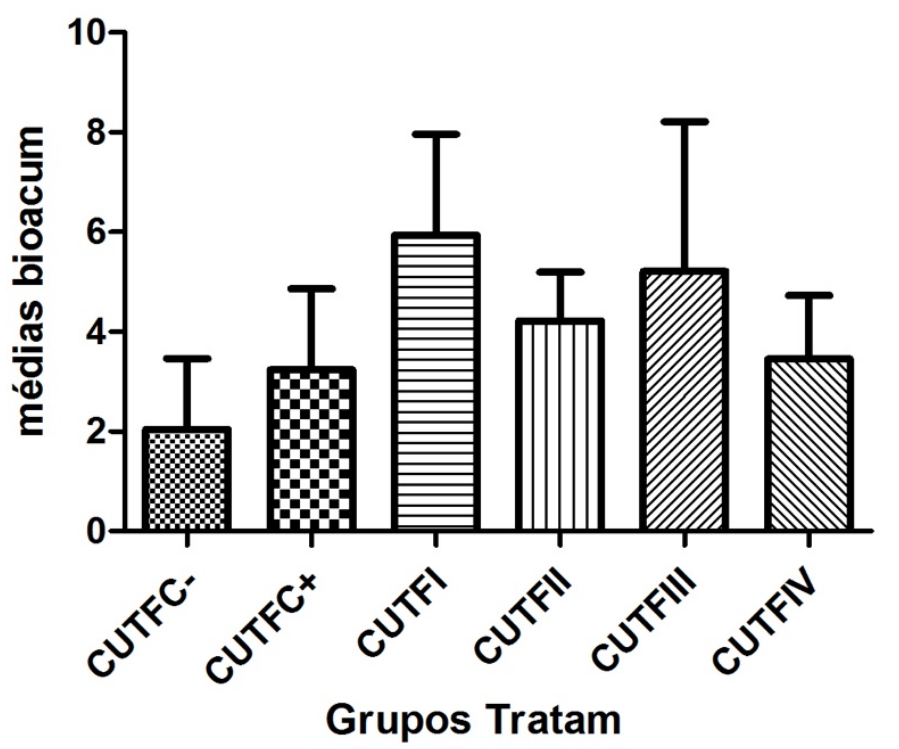


Seguindo o mesmo comportamento do período chuvoso, no período seco as amostras de fígado foram grandes acumuladores de $\mathrm{Cu}$, com valores de até 1,5560 mg/L. Corroborando o comportamento de órgão acumulador do $\mathrm{Cu}$ sempre em concentrações maiores que no meio. Os valores encontrados foram menores que no período de chuva, devido à menor disponibilidade do metal no período seco (Tabelas 19 e 20).

Tabela 19 - Bioacumulação de Cu nas brânquias (mg/L) no período seco.

\begin{tabular}{cccllll}
\hline \multirow{2}{*}{ PEIXES } & CUTBC & CUTBC + & CUTBI & CUTBII & CUTBIII & CUTBIV \\
\cline { 2 - 7 } & \multicolumn{7}{c}{$\mathrm{mg} / \mathrm{L}$} \\
\hline 1 & 0,0090 & 0,1200 & 0,0270 & 0,0540 & 0,0240 & 0,1920 \\
2 & 0,0090 & 0,2130 & 0,1110 & 0,0630 & 0,1170 & 0,0450 \\
3 & 0,0360 & 0,3450 & 0,0780 & 0,0270 & 0,0270 & 0,0600 \\
4 & 0,0190 & 0,1560 & 0,0160 & 0,0570 & 0,0230 & 0,0800 \\
5 & 0,0110 & 0,1320 & 0,0270 & 0,0480 & 0,1260 & 0,0690 \\
6 & 0,0140 & 0,1380 & 0,0210 & 0,0270 & 0,1060 & 0,0680 \\
\hline MÉ.DIA & $\mathbf{0 , 1 6 3 3}$ & $\mathbf{0 , 1 8 4 0}$ & $\mathbf{0 , 0 4 6 7}$ & $\mathbf{0 , 0 4 6 0}$ & $\mathbf{0 , 0 7 0 5}$ & $\mathbf{0 , 0 8 5 7}$ \\
\hline
\end{tabular}

Tabela 20 - Bioacumulação de $\mathrm{Cu}$ nos fígados (mg/L) no período seco.

\begin{tabular}{ccccccc}
\hline \multirow{2}{*}{ PEIXES } & CUTFC- & CUTFC + & CUTFI & CUTFII & CUTFIII & CUTFIV \\
\cline { 2 - 7 } & \multicolumn{5}{c}{$\mathbf{m g} / \mathbf{L}$} \\
\hline 1 & 0,0970 & 1,5990 & 0,8030 & 1,0300 & 0,5550 & 0,4200 \\
2 & 0,1750 & 0,5010 & 0,8250 & 1,1500 & 0,9290 & 0,2220 \\
3 & 0,4270 & 1,5420 & 1,3110 & 0,4990 & 0,6430 & 0,1500 \\
4 & 0,2730 & 1,1220 & 0,7730 & 0,6300 & 0,5230 & 0,3090 \\
5 & 0,7190 & 0,6080 & 0,0180 & 1,5560 & 0,6750 & 0,6910 \\
6 & 0,8060 & 1,0710 & 0,5910 & 1,3540 & 0,8760 & 0,7270 \\
MÉDIA & $\mathbf{0 , 4 1 6 2}$ & $\mathbf{1 , 0 7 3 8}$ & $\mathbf{0 , 7 2 0 2}$ & $\mathbf{1 , 0 3 6 5}$ & $\mathbf{0 , 7 0 0 2}$ & $\mathbf{0 , 4 1 9 8}$ \\
\hline
\end{tabular}

Os resultados de bioacumulação nas brânquias e nos fígados foram processados estatisticamente mediante ANOVA, seguido de teste múltiplo de Bonferroni $(\mathrm{P}<0,05)$ para verificar diferenças significativas entre as médias de cada grupo e entre si. Para os resultados das brânquias, a ANOVA apresentou diferenças significativas entre as médias. No teste de Bonferroni as diferenças foram entre o grupo controle positivo e todos os outros grupos. Resultados similares foram obtidos nas amostras do período chuvoso. No caso do fígado, a ANOVA mostrou diferenças entre as médias, repetindo o resultado do período chuvoso. No teste de comparações múltiplas de Bonferroni as diferenças significativas foram entre o grupo 
controle e CUTFC-; e o grupo controle positivo e CUTFC+, novamente similar ao observado nos tratamentos do período chuvoso (Gráficos 13 e 14).

Gráfico 14 - Médias de bioacumulação de $\mathrm{Cu}$ com os desvios padrões nas brânquias no período seco.

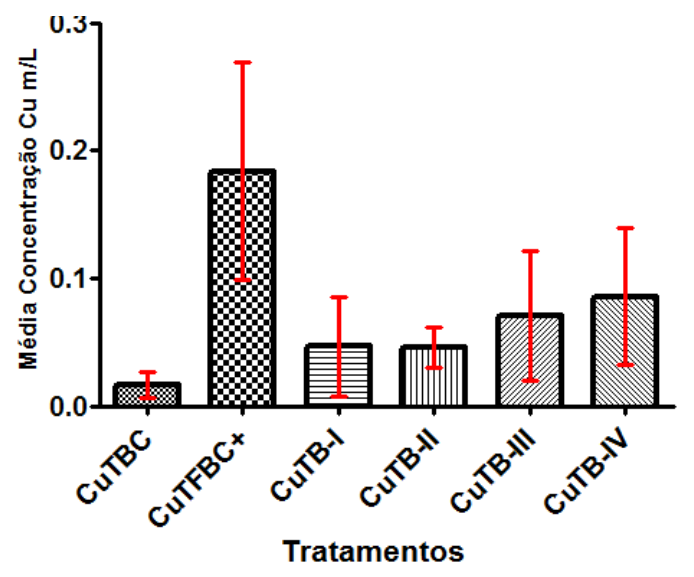

Gráfico 13 - Médias de bioacumulação de $\mathrm{Cu}$ com os desvios padrões nos fígados no período seco

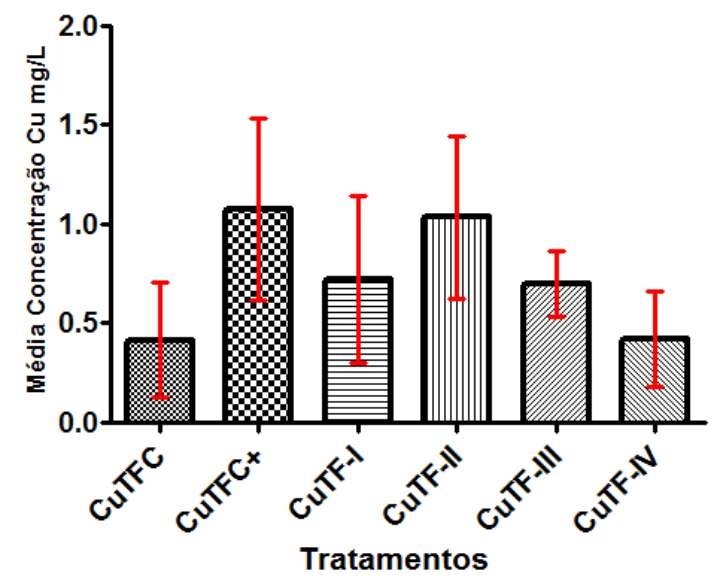

$\mathrm{Na}$ comparação dos resultados de bioacumulação de $\mathrm{Cu}$ no fígado, foi possível observar que maiores valores foram no período da chuva, corroborando com os resultados do fracionamento de $\mathrm{Cu}$ nos diferentes períodos e pontos de coleta. Em ambos períodos avaliados, os fígados apresentaram maiores valores nas concentrações de $\mathrm{Cu}$. Os resultados para ambos órgãos e períodos foram submetidos a tratamento estatístico, ANOVA e teste múltiplo de Bonferroni, apresentando diferenças significativas tanto para brânquias, quanto para os fígados. Isto corrobora a hipótese de que dependendo do período do ano, a dinâmica das águas na represa se alteram afetando a biodisponibilidade do $\mathrm{Cu}$ (Gráficos 15 e 16).

Gráfico 15 - Médias de bioacumulação de $\mathrm{Cu}$ com os desvios padrões nos fígados nos períodos Seca vs Chuva.

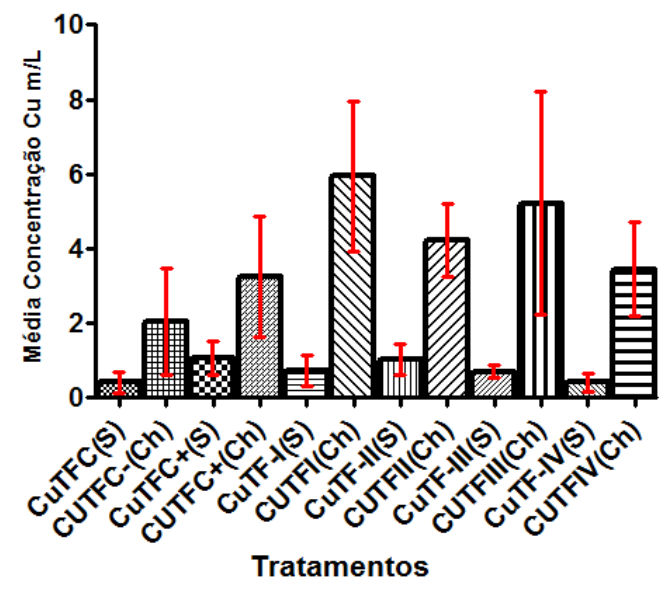

Gráfico 16 - Médias de bioacumulação de $\mathrm{Cu}$ com os desvios padrões nas brânquias nos períodos Seca vs Chuva.

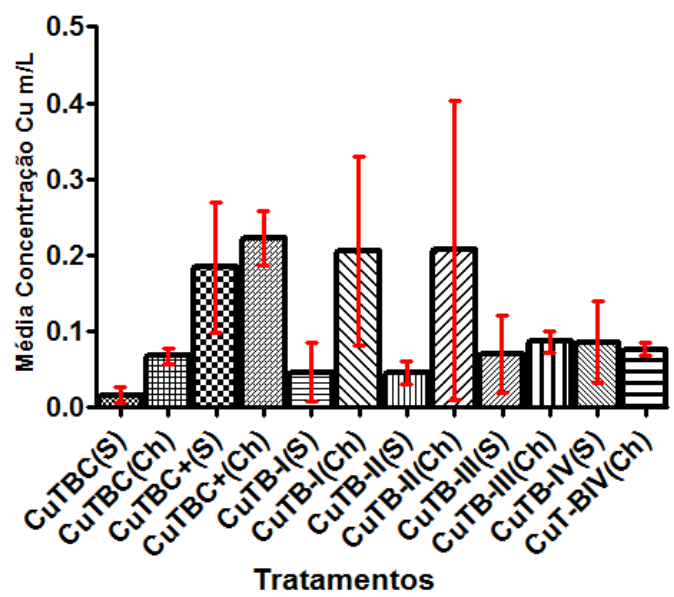


As maiores concentrações de $\mathrm{Cu}$ corresponderam com os peixes expostos aos pontos de maiores concentrações de $\mathrm{Cu}$ na água.

Gráfico 17 - Médias do fator de bioacumulação para as brânquias nos períodos seco e chuvoso.

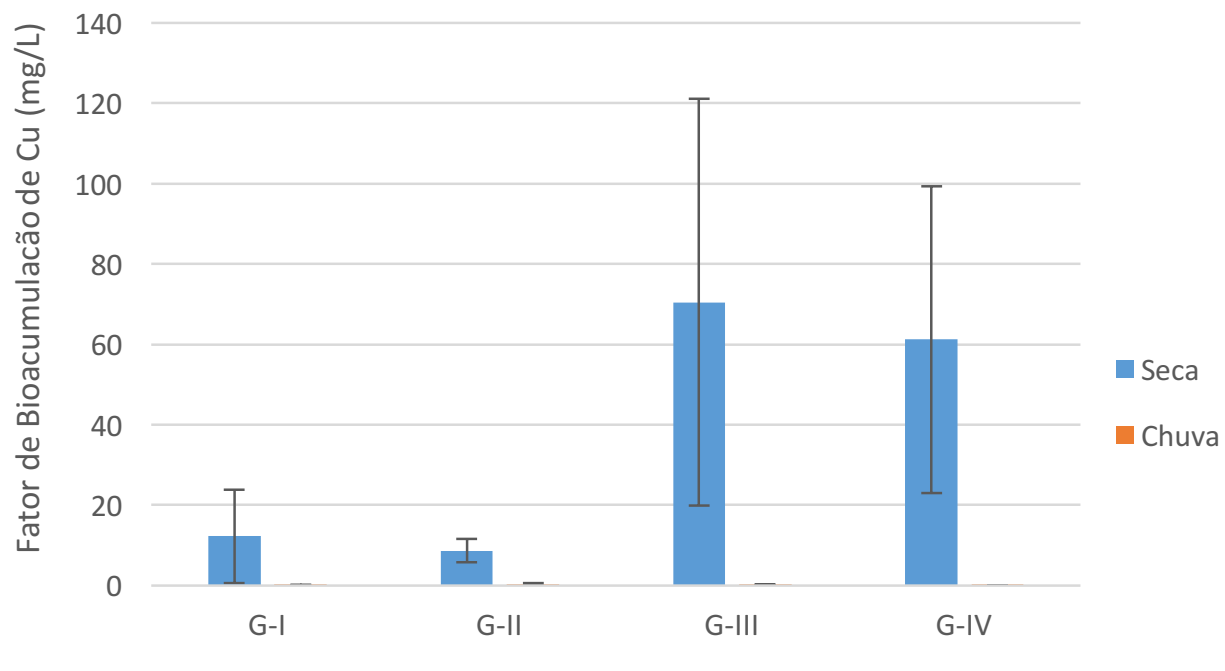

Grupos de Tratamentos

Gráfico 18 - Médias do fator de bioacumulação para fígados nos períodos seco e chuvoso.

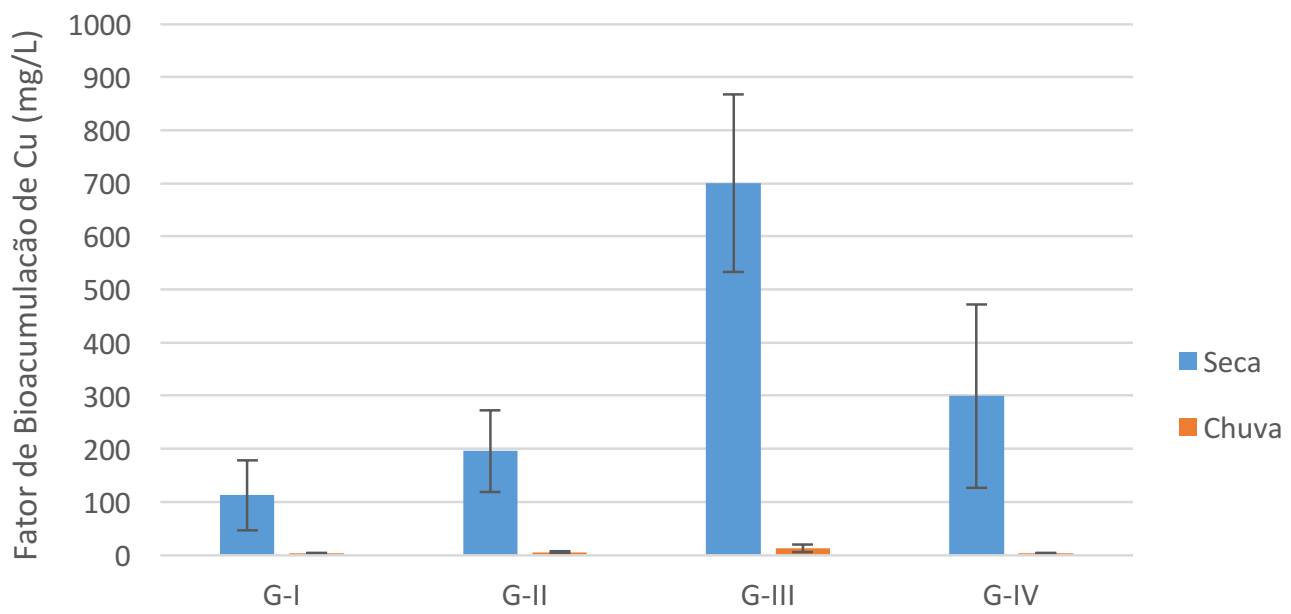

Grupos de Tratamentos 
Gráfico 19 - Médias do fator de bioacumulação para as brânquias e fígados no período chuvoso.

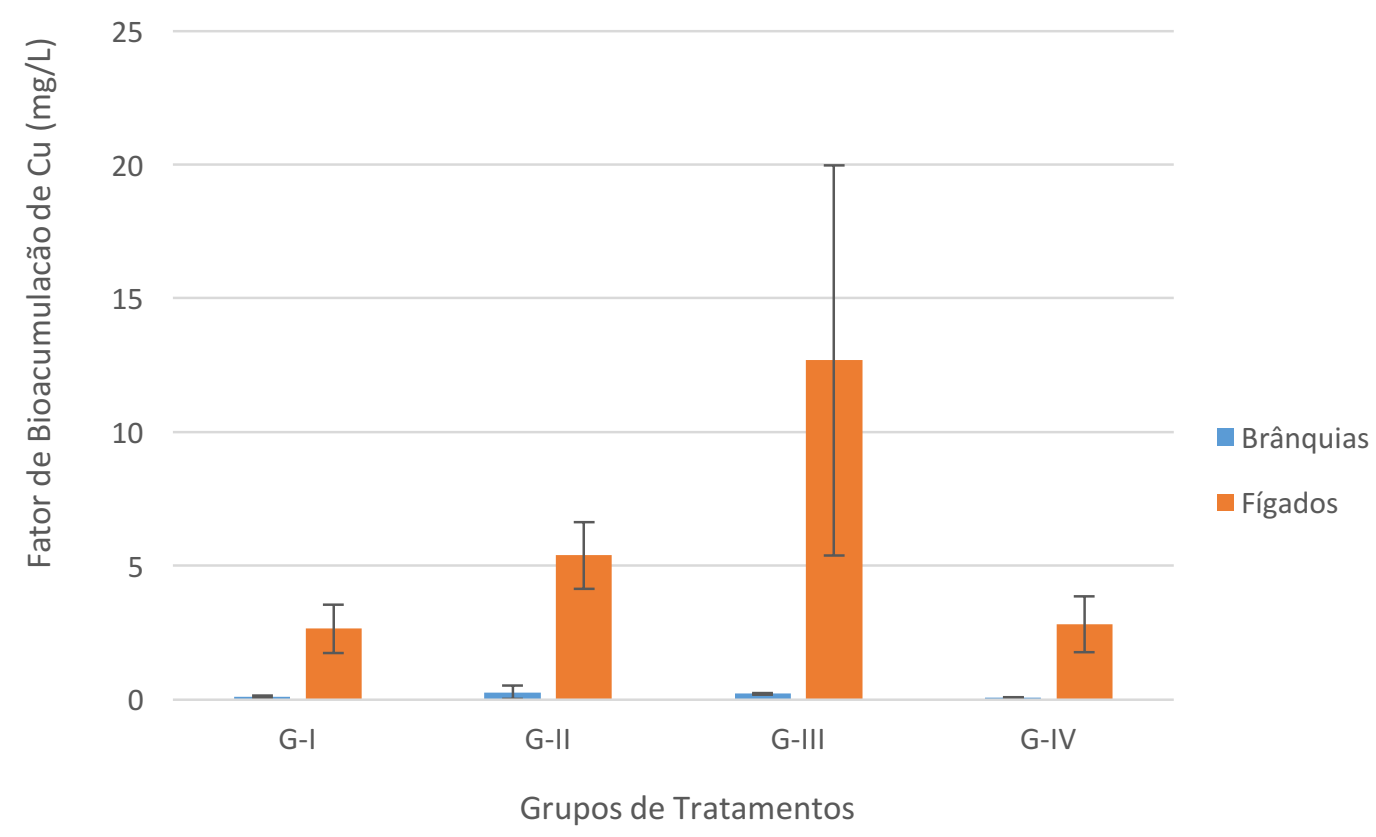

Gráfico 20 - Médias do fator de bioacumulação para as brânquias e fígados no período de seca.

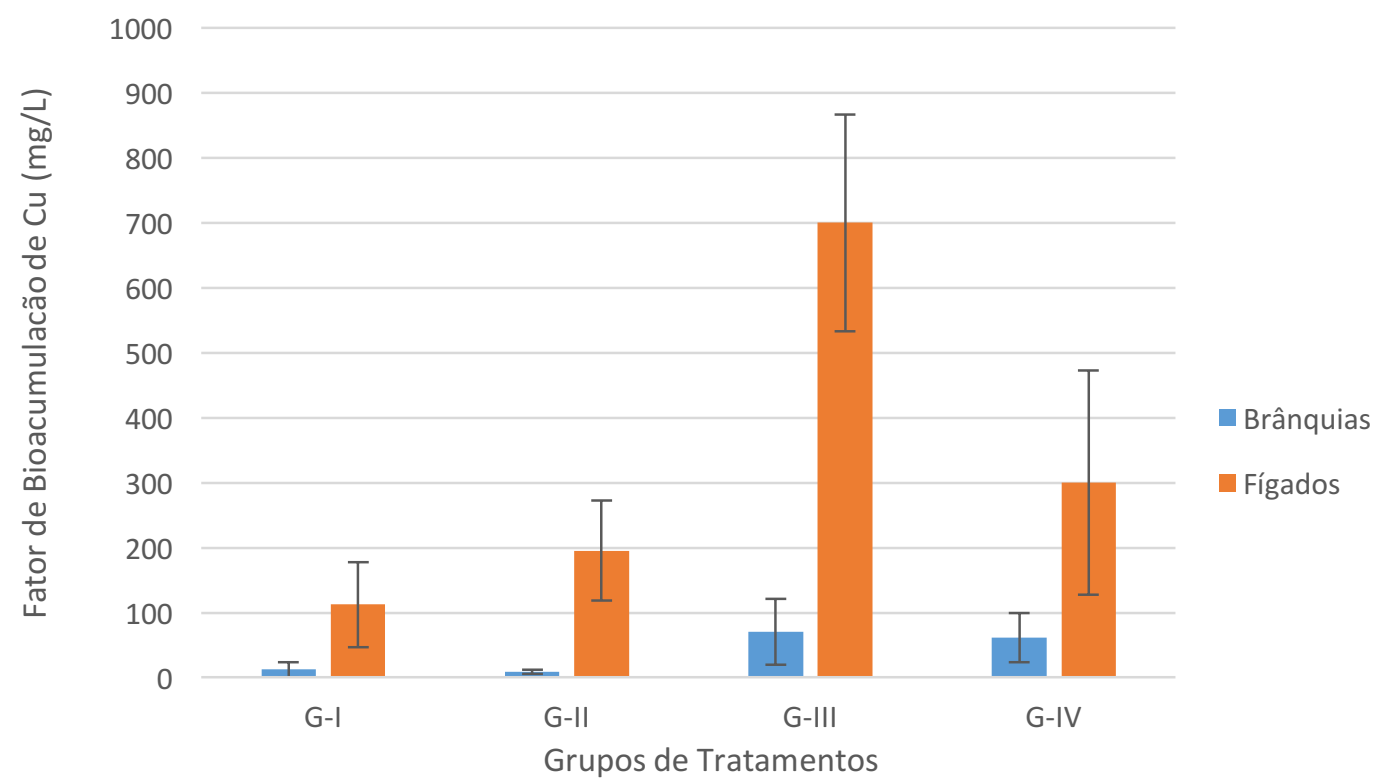




\subsection{Cálculo do Î́ndice Hepatosomático (IHS)}

Com os dados do peso dos peixes e dos respectivos fígados foi calculado o IHS, que expressa a porcentagem do peso do fígado em relação ao peso total do peixe (Tabelas 21 e 22). Os valores oscilaram entre $0,670 \%$ e $3,925 \%$ nos peixes para o período seco e $0,062 \%$ e $1,88 \%$ nos peixes do período chuvoso.

Tabela 21 - Valores em \% dos IHS para os peixes por tratamento no período seco.

\begin{tabular}{lrrrrrr}
\hline \multirow{2}{*}{ PEIXES } & CONTROLE & CONTROLE + & PONTO 1 & PONTO 2 & PONTO 3 & PONTO 4 \\
\cline { 2 - 7 } & \multicolumn{7}{c}{ \% } & & & \\
\hline $\mathbf{1}$ & 1,909 & 1,871 & 2,436 & 1,600 & 1,250 & 1,346 \\
$\mathbf{2}$ & 1,021 & 1,277 & 1,355 & 0,806 & 1,152 & 1,408 \\
$\mathbf{3}$ & 1,281 & 1,578 & 1,748 & 1,434 & 1,164 & 1,228 \\
$\mathbf{4}$ & 1,253 & 1,718 & 1,776 & 1,237 & 1,210 & 1,250 \\
$\mathbf{5}$ & 1,220 & 1,745 & 1,276 & 1,821 & 1,523 & 1,346 \\
$\mathbf{6}$ & 1,267 & 1,244 & 1,352 & 1,306 & 1,026 & 1,312 \\
$\mathbf{7}$ & 1,091 & 2,194 & 3,925 & 3,089 & 1,393 & 1,127 \\
$\mathbf{8}$ & 1,384 & 2,158 & 2,061 & 2,390 & 1,799 & 1,155 \\
$\mathbf{9}$ & 1,677 & 1,618 & 1,319 & 1,142 & 1,130 & 0,939 \\
$\mathbf{1 0}$ & 1,224 & 1,347 & 1,048 & 1,214 & 0,807 & 1,122 \\
$\mathbf{1 1}$ & 1,224 & 1,493 & 3,547 & 1,211 & 1,328 & 1,133 \\
$\mathbf{1 2}$ & 1,176 & 1,401 & 1,888 & 1,146 & 1,232 & 2,333 \\
$\mathbf{1 3}$ & 1,115 & 1,568 & 1,494 & 0,838 & 1,489 & 1,187 \\
$\mathbf{1 4}$ & 1,519 & 1,418 & 1,223 & 0,954 & 1,146 & 0,990 \\
$\mathbf{1 5}$ & 1,406 & 1,588 & 1,605 & 1,094 & - & 0,670 \\
$\mathbf{1 6}$ & 1,294 & 0,540 & 1,378 & 0,870 & - & 1,398 \\
$\mathbf{1 7}$ & 1,325 & 1,016 & 1,454 & 1,176 & - & 1,343 \\
$\mathbf{1 8}$ & 1,409 & 1,582 & 1,351 & 1,882 & - & 1,368 \\
\hline MÉyIA & $\mathbf{1 , 3 2 2}$ & $\mathbf{1 , 5 2 0}$ & $\mathbf{1 , 7 9 1}$ & $\mathbf{1 , 4 0 1}$ & $\mathbf{1 , 2 6 1}$ & $\mathbf{1 , 2 5 9}$ \\
\hline
\end{tabular}


Tabela 22 - Valores em \% dos IHS para os peixes por tratamento no período chuvoso.

\begin{tabular}{lrrrrrr}
\hline \multirow{2}{*}{ PEIXE } & CONTROLE & CONTROLE + & PONTO 1 & PONTO 2 & PONTO 3 & PONTO 4 \\
\cline { 2 - 7 } & \multicolumn{5}{c}{$\mathbf{\%}$} \\
\hline $\mathbf{1}$ & 1,280 & 1,153 & 1,200 & 1,164 & 1,198 & 1,281 \\
$\mathbf{2}$ & 1,214 & 1,173 & 1,167 & 1,271 & 1,196 & 1,276 \\
$\mathbf{3}$ & 1,233 & 1,171 & 1,211 & 1,187 & 1,219 & 1,187 \\
$\mathbf{4}$ & 1,240 & 1,189 & 1,132 & 1,187 & 1,196 & 1,250 \\
$\mathbf{5}$ & 1,243 & 1,147 & 1,267 & 1,168 & 1,291 & 1,247 \\
$\mathbf{6}$ & 1,180 & 1,132 & 1,142 & 1,183 & 1,212 & 1,238 \\
$\mathbf{7}$ & 0,446 & 1,086 & 0,624 & 1,091 & 0,300 & 0,062 \\
$\mathbf{8}$ & 0,361 & 0,446 & 0,964 & 0,598 & 0,726 & 0,523 \\
$\mathbf{9}$ & 0,351 & 1,089 & 1,404 & 0,947 & 0,491 & 0,695 \\
$\mathbf{1 0}$ & 0,725 & 1,012 & 1,824 & 1,170 & 1,630 & 0,636 \\
$\mathbf{1 1}$ & 0,584 & 1,024 & 1,000 & 1,093 & 0,874 & 0,412 \\
$\mathbf{1 2}$ & 0,505 & 0,525 & 1,117 & 1,155 & 0,899 & 0,507 \\
$\mathbf{1 3}$ & 0,698 & 1,140 & 1,552 & 1,177 & 1,219 & 1,219 \\
$\mathbf{1 4}$ & 1,593 & 1,164 & 1,023 & 1,174 & 0,731 & 0,858 \\
$\mathbf{1 5}$ & 0,813 & 1,187 & 1,189 & 1,078 & 1,001 & 1,001 \\
$\mathbf{1 6}$ & 1,889 & 1,156 & 0,831 & 1,054 & 1,502 & 1,502 \\
$\mathbf{1 7}$ & 0,929 & 1,151 & 1,639 & 1,109 & 1,139 & 1,139 \\
$\mathbf{1 8}$ & 0,541 & - & 1,170 & 1,229 & 1,359 & 1,359 \\
\hline MÉyIA & $\mathbf{1 , 0 1 3}$ & $\mathbf{1 , 0 5 5}$ & $\mathbf{1 , 1 9 2}$ & $\mathbf{1 , 1 1 3}$ & $\mathbf{1 , 0 6 6}$ & $\mathbf{0 , 9 6 6}$ \\
\hline
\end{tabular}

No período seco, a ANOVA e o teste de Tukey $(\mathrm{P}<0,05)$ apresentaram diferenças significativas nas médias; entre os pontos controle vs ponto 1 ; ponto 1 vs ponto 3 e ponto 4 . No entanto, no período chuvoso não foi verificado diferenças significativas (Gráficos 21 e 22). $\mathrm{Na}$ comparação com teste-t $(\mathrm{P}<0,005)$ das médias entre os períodos seco e chuvoso foram verificadas diferenças significativas $\mathrm{P}=0,036$ (Gráfico 23). No grupo controle, no período da chuva foi observado o menor IHS (Gráfico 22). 
Gráfico 21 - Médias de IHS com os desvios padrões por grupo de tratamento no período seco.

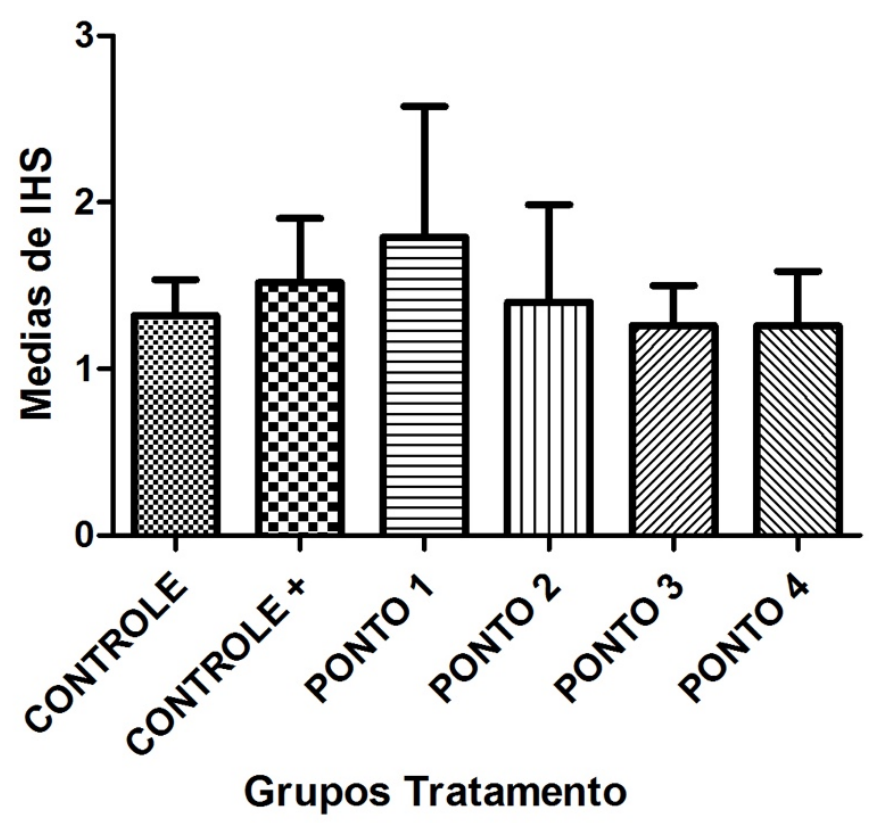

Gráfico 22 - Médias de IHS com os desvios padrões por grupo de tratamento no período chuvoso.

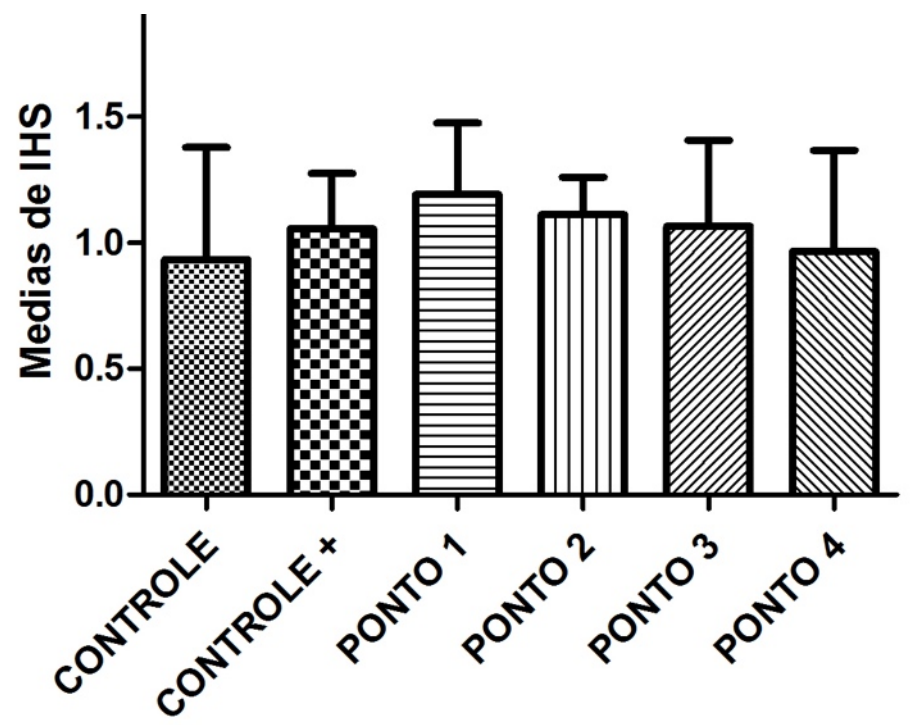

Grupos Tratamento 
Gráfico 23 - Comparação das médias de IHS no período de Seca vs Chuva.

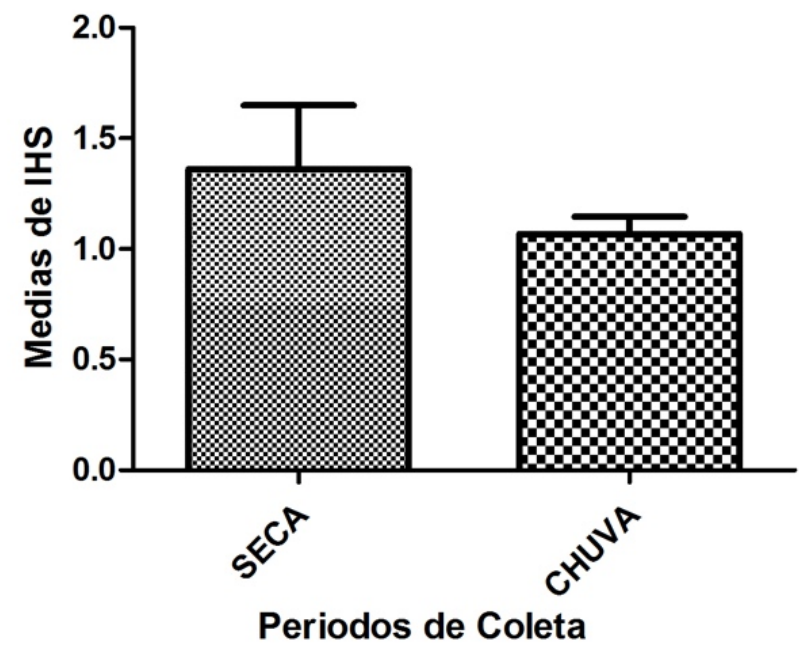

\subsection{Marcadores de estresse oxidativo: Catalase (CAT), Superóxido dismutase (SOD) e Glutationa peroxidase (GPX)}

A contaminação por metais pesados possui características de serem bioacumulativos, não biodegradáveis e tóxicos para a biota aquática.

$\mathrm{O} \mathrm{Cu}$ liberado de uma ampla variedade de fontes antropológicas como, mineração, emissão de lixo e aplicação de pesticidas e fertilizantes, tem sido amplamente detectado nos ambientes aquáticos com concentrações maiores que $152 \mu \mathrm{g} / \mathrm{L}$ (IRWIN, 1997; MANSOUR; SIDKY, 2002). Funcionando como cofator de muitas enzimas envolvidas em processos biológicos vitais, $\mathrm{Cu}$ é conhecido como um micronutriente essencial para os organismos vivos (JIANG et al., 2014). Entretanto, ele pode ser inibitório ou tóxico em altas concentrações (EYCKMANS et al., 2011; SANCHEZ et al., 2005).

A atividade da CAT não apresentou diferenças significativas para ANOVA $(\mathrm{P}<0.05)$, após 5 dias de exposição à água da Represa coletada no período seco. O teste de Bonferroni não mostrou diferenças significativas entre o grupo controle e os grupos de tratamentos. No Gráfico 24 é possível observar que os maiores resultados foram no grupo de tratamento II, correspondendo com o maior valor de bioacumulação de $\mathrm{Cu}$ verificado para o período seco. Na Tabela 23, os dados demostram uma leve tendência a aumentar a atividade da CAT quando 
ocorre um aumento da concentração de $\mathrm{Cu}$. A ordem das atividades da CAT por grupo de tratamento foram: II $>$ III $>I>I V>$ Controle. (Gráfico 24).

Tabela 23 - Atividade da catalase $(\mathrm{U} / \mathrm{mL})$ no período da seca.

\begin{tabular}{rrrrrrr}
\hline \multirow{2}{*}{ PEIXES } & ECAT-C & ECAT-C+ & ECAT-I & ECAT-II & ECAT-III & ECAT-IV \\
\cline { 2 - 7 } & \multicolumn{5}{c}{$\mu \mathrm{M}$} \\
\hline $\mathbf{1}$ & 8,4444 & 6,7778 & 21,2222 & 9,0000 & 5,1111 & 7,3333 \\
$\mathbf{3}$ & 7,8889 & 6,7778 & 7,3333 & 26,2222 & 11,2222 & 7,8889 \\
$\mathbf{4}$ & 5,1111 & 9,5556 & 6,2222 & 9,55560 & 12,8889 & 11,7778 \\
$\mathbf{5}$ & 6,7778 & 27,8889 & 4,5556 & 23,4444 & 10,6667 & 6,2222 \\
$\mathbf{6}$ & 9,5556 & 14,5556 & 33,4444 & 32,3333 & 47,8889 & 4,0000 \\
\hline MÉDIA & 5,1111 & 4,5556 & 7,33330 & 19,0000 & 10,1111 & 7,8889 \\
\hline
\end{tabular}

Gráfico 24 - Média da atividade da catalase $(\mathrm{U} / \mathrm{mL})$ no período da seca.

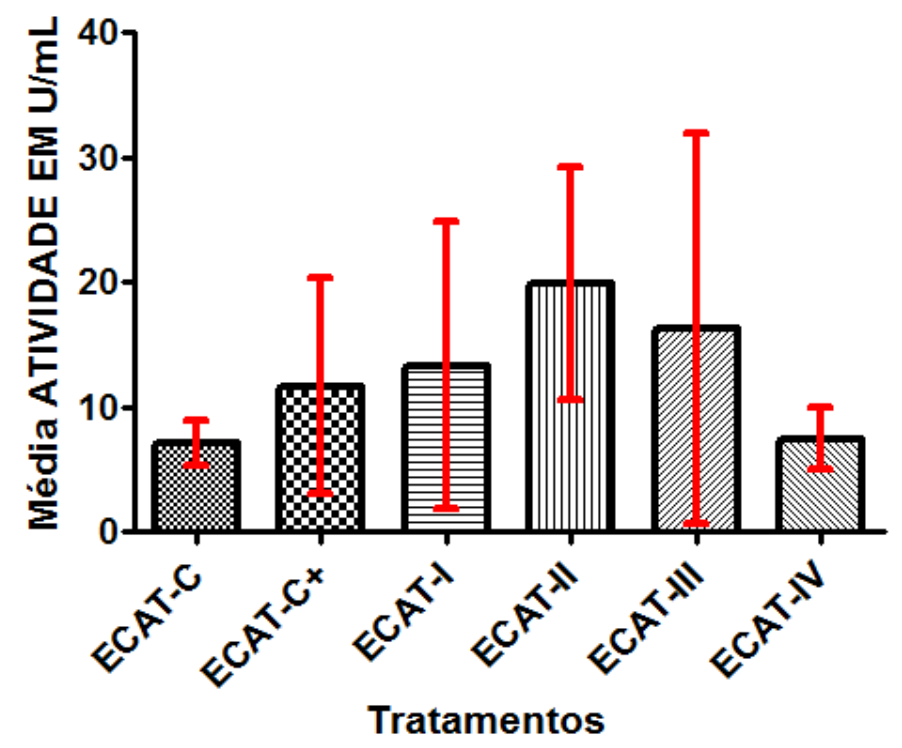

No período chuvoso os testes estatísticos apresentaram diferenças significativas para ANOVA $(\mathrm{P}<0.05)$ e o teste de Bartlett para as atividades da CAT. No teste de Bonferroni as diferenças significativas ocorreram entre o grupo controle e todos os grupo de tratamentos. A ordem das atividades da CAT (Tabela 24) por grupo de tratamento foram: II $>$ IV $>$ III $>$ I $>$ Controle (Gráfico 25). 
Tabela 24 - Atividade da catalase $(\mathrm{U} / \mathrm{mL})$ no período chuvoso.

\begin{tabular}{lcccccc}
\hline \multirow{2}{*}{ PEIXES } & ECAT-C & ECAT-C + & \multicolumn{1}{c}{ ECAT-I } & ECAT-II & ECAT-III & ECAT-IV \\
\cline { 2 - 7 } & \multicolumn{5}{c}{ U/mL } \\
\hline $\mathbf{1}$ & 6,4556 & 46,7778 & 97,6667 & 55,1111 & 60,1111 & 97,3333 \\
$\mathbf{2}$ & 4,3333 & 88,1111 & 72,8889 & 74,0231 & 89,5556 & 15,1111 \\
$\mathbf{3}$ & 1,7778 & 39,5556 & 51,7778 & 39,5556 & 57,8889 & 40,1111 \\
$\mathbf{4}$ & 5,1111 & 86,8889 & 30,1111 & 60,6667 & 27,3333 & 35,1111 \\
$\mathbf{5}$ & 4,0153 & 25,6667 & 20,6667 & 90,8889 & 36,2222 & 45,7778 \\
$\mathbf{6}$ & 1,2222 & 18,4444 & 14,5556 & 16,2222 & 27,8889 & 70,6667 \\
\hline MÉDIA & $\mathbf{3 , 8 1 9 2}$ & $\mathbf{5 0 , 9 0 7 4}$ & $\mathbf{4 7 , 9 4 4 5}$ & $\mathbf{5 6 , 0 7 7 9}$ & $\mathbf{4 9 , 8 3 3 3}$ & $\mathbf{5 0 , 6 8 5 2}$ \\
\hline
\end{tabular}

Gráfico 25 - Média da atividade da catalase $(\mathrm{U} / \mathrm{mL})$ no período chuvoso.

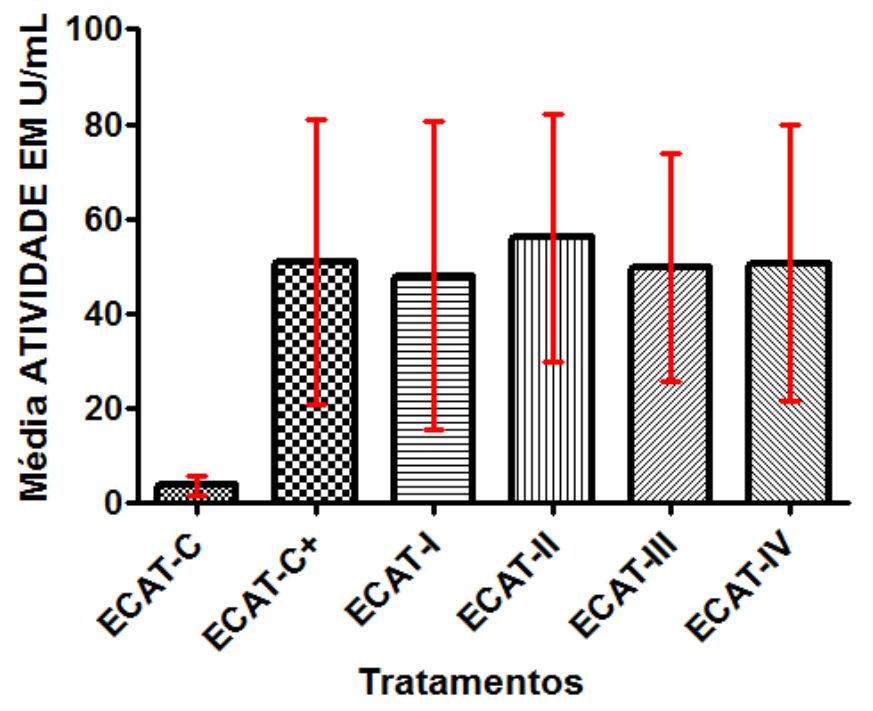

Nos gráficos 15 e 18, observa-se que a bioacumulação e o fator de bioacumulação de $\mathrm{Cu}$ no fígado durante o período chuvoso foi consideravelmente mais elevado que no período seco. Este mesmo comportamento ocorreu na atividade da CAT (Gráfico 26). A comparação do período chuvoso com o seco para a atividade da CAT nos peixes, mostraram diferenças significativas para ANOVA $(\mathrm{P}<0.05)$. No teste de Bartlett $(\mathrm{P}<0.05)$ foi possível verificar as diferenças significativas para as variâncias. E no teste de Bonferroni as diferenças significativas foram entre os grupos. O período chuvoso apresentou as maiores atividades da CAT, assim a CAT aumentou seus níveis de atividades ante as maiores concentrações de $\mathrm{Cu}$ no tecido e no meio ambiente, no período chuvoso (Gráfico 26). 
Gráfico 26 - Média da atividade da Catalase (U/mL) no período chuvoso e seco.

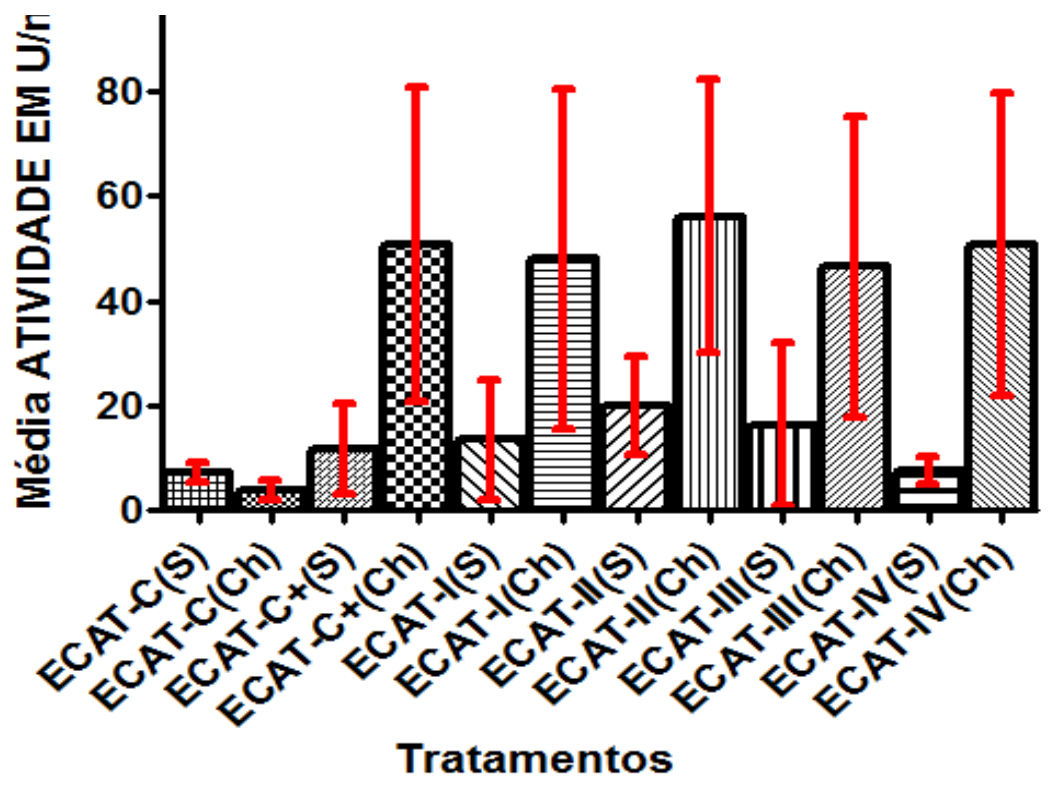

Os resultados para a SOD no período seco não apresentaram diferenças significativas quando utilizado o teste ANOVA $(\mathrm{P}<0.05)$ (Tabela 25). O teste de Bonferroni não apresentou diferenças significativas (Gráfico 27). No Gráfico 27 podemos observar que mesmo sem diferenças significativas a ordem das atividades nos tratamentos e controle foram: $\mathrm{III}>\mathrm{IV}>\mathrm{I}>\mathrm{II}=$ Controle. Estes valores de maiores atividades estão relacionados com os menores índices de bioacumulação neste período. Desta forma, podemos relacionar que no período seco com uma maior concentração de $\mathrm{Cu}$ houve uma diminuição da atividade da SOD, mesmo que não significativa.

Tabela 25 - Atividade SOD (U/mL) no período seco.

\begin{tabular}{ccccccc}
\hline \multirow{2}{*}{ PEIXES } & ESOD-C & ESOD-C + & ESOD-I & ESOD-II & ESOD-III & ESOD-IV \\
\cline { 2 - 7 } & \multicolumn{5}{c}{ U/mL } \\
\hline 1 & 2,6811 & 2,1042 & 2,2324 & 1,8189 & 9,8606 & 2,9535 \\
2 & 1,9920 & 2,4087 & 2,5208 & 2,5048 & 2,3285 & 5,8221 \\
3 & 2,4247 & 2,4087 & 2,3766 & 2,4087 & 2,3926 & 2,9375 \\
4 & 1,7196 & 2,5208 & 2,6170 & 2,4407 & 2,5689 & 2,4407 \\
5 & 2,3766 & 2,5529 & 2,3446 & 2,4728 & 2,4728 & 2,5849 \\
6 & 2,5369 & 2,6330 & 2,9054 & 2,2324 & 2,3285 & 2,2804 \\
\hline MÉDIA & $\mathbf{2 , 2 8 8 5}$ & $\mathbf{2 , 4 3 8 1}$ & $\mathbf{2 , 4 9 9 5}$ & $\mathbf{2 , 3 1 3 1}$ & $\mathbf{3 , 6 5 8 7}$ & $\mathbf{3 , 1 6 9 9}$ \\
\hline
\end{tabular}


Gráfico 27 - Média da atividade SOD (U/mL) no período seco.

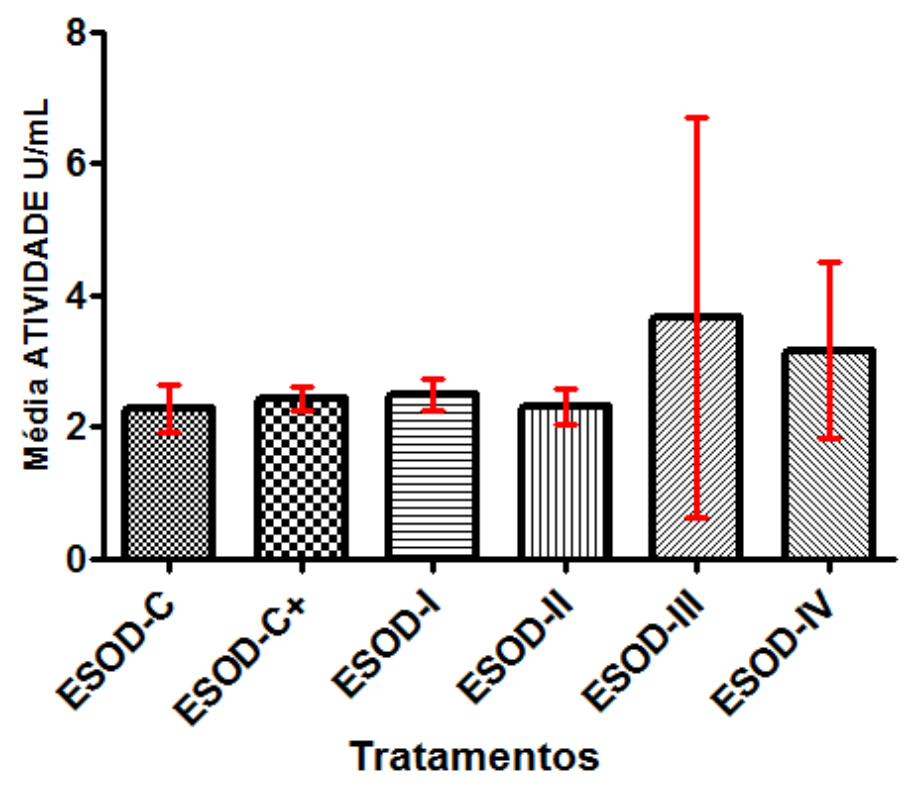

No período chuvoso a SOD, não apresentou diferenças significativas para nenhum dos testes estatísticos (Tabela 26 e Gráfico 28). Neste caso a ordem dos valores das atividades foram: $\mathrm{C}=\mathrm{IV}>\mathrm{III}>\mathrm{II}>\mathrm{I}$ (Gráfico 28). Ressalta-se que mesmo não havendo diferenças significativas no tratamento controle, ocorreu um comportamento de relação inversa com os valores da bioacumulação do $\mathrm{Cu}$ nos fígados no período. O que inclina a pensar que a resposta ante o $\mathrm{Cu}$ foi de diminuição da atividade.

Tabela 26 - Atividade SOD (U/mL) no período chuvoso.

\begin{tabular}{|c|c|c|c|c|c|c|}
\hline \multirow{2}{*}{ PEIXES } & ESOD-C & ESOD-C+ & ESOD-I & ESOD-II & ESOD-III & ESOD-IV \\
\hline & \multicolumn{6}{|c|}{$\mathrm{U} / \mathrm{mL}$} \\
\hline 1 & 1,3958 & 2,4087 & 1,3349 & 2,633 & 2,3606 & 2,5208 \\
\hline 2 & 3,4247 & 2,4888 & 0,9824 & 2,5529 & 2,4567 & 2,5208 \\
\hline 3 & 2,649 & 2,4407 & 2,5849 & 2,4087 & 2,5048 & 2,601 \\
\hline 4 & 2,2965 & 2,5849 & $-0,1554$ & 2,601 & 2,3285 & 2,5529 \\
\hline 5 & 3,1715 & 2,4567 & $-0,2356$ & 2,5689 & 2,5369 & 2,5369 \\
\hline 6 & 2,4728 & 2,4728 & 0,5657 & 1,0946 & 2,2484 & 2,5369 \\
\hline MÉDIA & 2,5684 & 2,4754 & 0,8462 & 2,3099 & 2,4060 & 2,5449 \\
\hline
\end{tabular}


Gráfico 28 - Média da atividade SOD (U/mL) no período chuvoso.

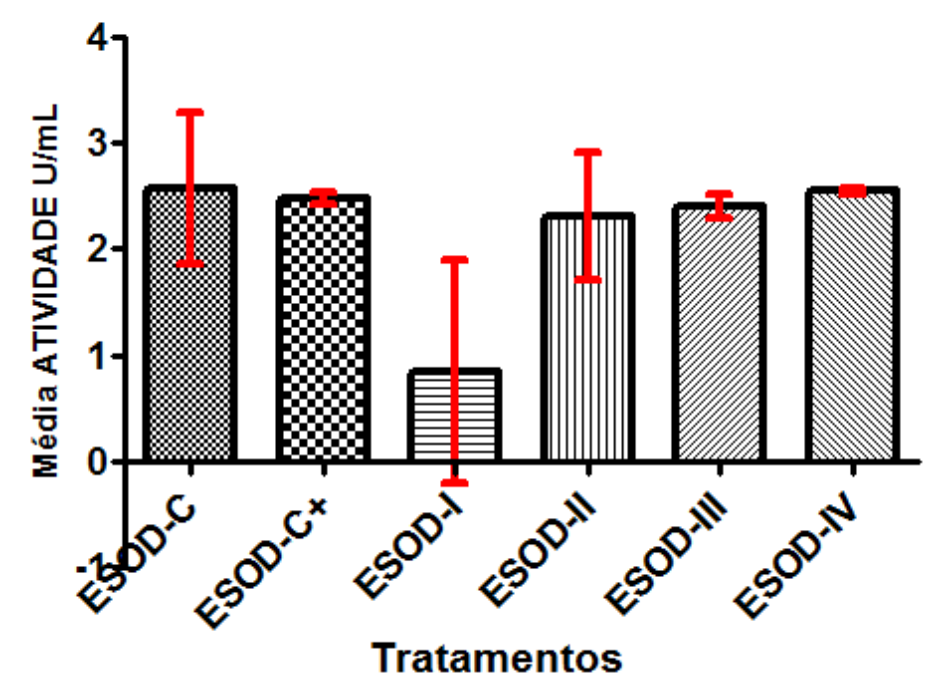

Na comparação entre os períodos de chuva e seca os testes com ANOVA $(\mathrm{P}<0.05)$ apresentaram diferenças significativas entre as médias, mas ao aplicar o teste de Bonferroni estas diferenças não ocorreram entre os grupos homólogos dos períodos seco e chuva, respectivamente (Gráfico 29).

Gráfico 29 - Média da atividade SOD (U/mL) no período chuvoso vs seco.

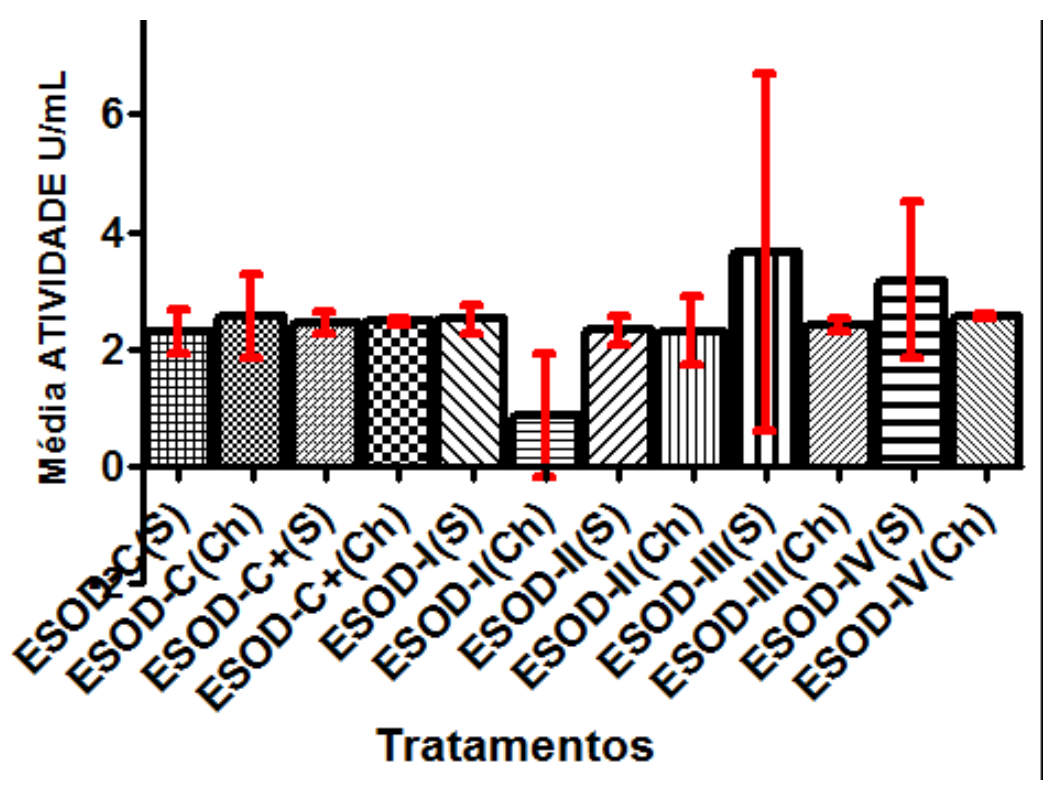


A GPX tem um papel crucial na proteção intracelular contra componentes tóxicos como o Cu e o Zn (MOSLEH et al., 2005). A GPX é responsável pela defesa enzimática ante $\mathrm{H}_{2} \mathrm{O}_{2}$, e é estritamente relacionada com a concentração de GSH, porque ela catalisa a reação entre a glutationa e o $\mathrm{H}_{2} \mathrm{O}_{2}$, tendo como resultado a formação de dissulfeto de glutationa (GSSG) (ALKALADI; MOSLEH; AFIFI, 2013; PAGLIA; VALENTINE, 1967).

No período seco as atividades de GPx (Tabela 27) não apresentaram diferenças significativas com o teste de ANOVA $(\mathrm{P}<0.05)$, porém ao aplicar o teste de Bartlett as variâncias apresentaram diferenças significativas $(\mathrm{P}<0.05)$. O teste de Bonferroni não apresentou diferenças significativas entre o grupo controle e os grupos de tratamentos. No Gráfico 30 observa-se que as médias mesmo sem diferenças significativas apresentaram diferenças numéricas. O maior valor foi no grupo de tratamento II, em que os valores de bioacumulação do $\mathrm{Cu}$ foram maiores no período.

No Gráfico 30, observa-se ainda que as atividades da GPx nos grupos de tratamentos foram maiores quando comparados ao grupo controle, com exceção do grupo III. Observando todos os grupos para o período não foi verificado variações significativas quando comparado com o controle, nem entre os diferentes tratamentos.

Tabela 27 - Atividade GPx (U/L) no período seco.

\begin{tabular}{crrrrrr}
\hline \multirow{2}{*}{ PEIXES } & EGPX-C & EGPX-C + & \multicolumn{1}{c}{ EGPX-I } & EGPX-II & EGPX-III & EGPX-IV \\
\cline { 2 - 7 } & \multicolumn{7}{c}{$\mathbf{( U / L )}$} \\
\hline 1 & 10,8333 & 17,5000 & 8,4167 & 16,8056 & 11,0417 & 10,5556 \\
2 & 8,9583 & 2,2917 & 14,4583 & 12,7083 & 14,0972 & 6,5278 \\
3 & 9,7222 & 2,9861 & 14,4444 & 14,7917 & 1,2500 & 6,7361 \\
4 & 11,0417 & 14,7917 & 9,0278 & 14,6528 & 5,0000 & 14,3750 \\
5 & 14,1250 & 11,1111 & 10,9722 & 15,9028 & 7,5694 & 16,3194 \\
6 & 12,4306 & 14,3750 & 8,8194 & 15,7639 & 15,9028 & 13,9583 \\
\hline MÉDIA & $\mathbf{1 1 , 1 8 5 2}$ & $\mathbf{1 0 , 5 0 9 3}$ & $\mathbf{1 1 , 0 2 3 1}$ & $\mathbf{1 5 , 1 0 4 2}$ & $\mathbf{9 , 1 4 3 5}$ & $\mathbf{1 1 , 4 1 2 0}$ \\
\hline
\end{tabular}


Gráfico 30 - Média da atividade GPx (U/L) no período seco.

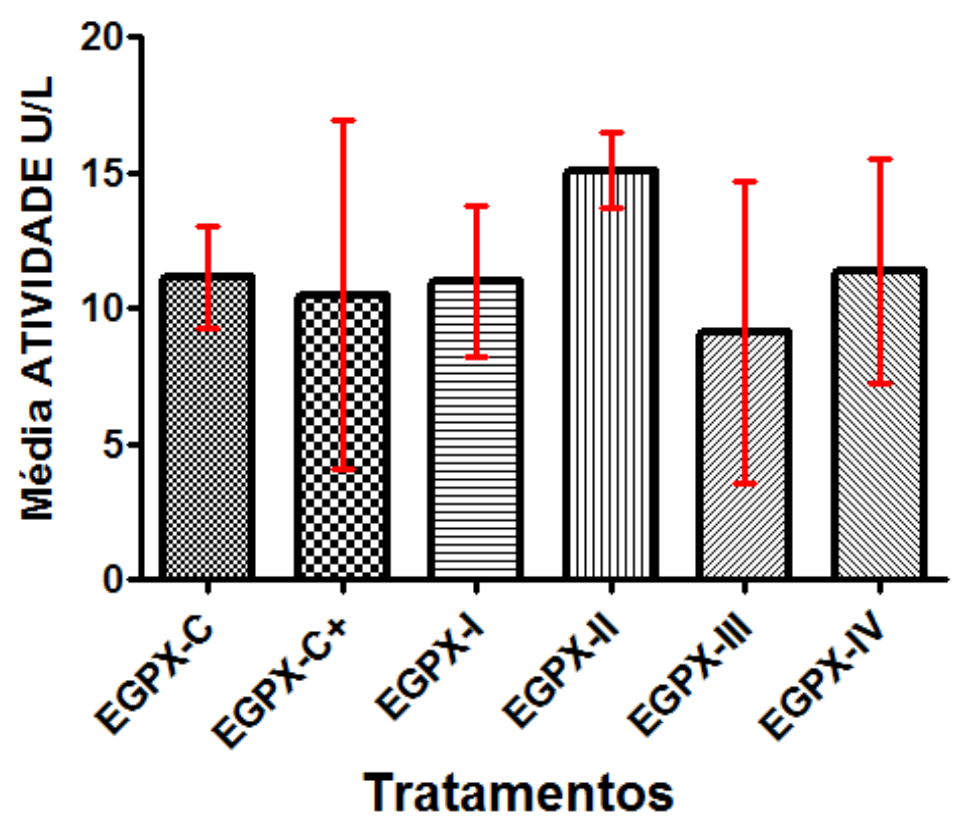

Para o período chuvoso, o tratamento estatístico para a atividade da GPx também não apresentou diferenças significativas para ANOVA e o teste de Bonferroni, entre os tratamentos e o controle. Neste período, o valor mais elevado para a atividade da GPx foi no grupo de tratamento IV seguido por II $>$ III $>$ I $>$ C (Tabela 28 e Gráfico 31 ).

Tabela 28 - Atividade GPx (U/L) no período chuvoso.

\begin{tabular}{lrrrrrr}
\hline \multirow{2}{*}{ PEIXES } & EGPX-C & EGPX-C + & EGPX-I & EGPX-II & EGPX-III & EGPX-IV \\
\cline { 2 - 7 } & \multicolumn{5}{c}{$\mathbf{( U / L )}$} \\
\hline 1 & 7,3611 & 9,2361 & $-3,2639$ & 15,0000 & 8,7500 & 12,0833 \\
3 & 5,2083 & 13,7500 & 15,4167 & 16,9444 & 12,1528 & 15,1389 \\
4 & 3,8194 & 8,8194 & 15,2778 & 18,0556 & 9,0972 & 13,2639 \\
5 & 10,1389 & 14,2361 & 13,9583 & 15,7639 & 14,5139 & 16,1806 \\
6 & 9,9306 & 5,8333 & 12,2917 & $-3,3333$ & 14,8611 & 10,2778 \\
\hline MÉDIA & 13,7500 & 7,2917 & 9,7917 & 16,2500 & 14,0278 & 15,6944 \\
\hline & $\mathbf{8 , 3 6 8 1}$ & $\mathbf{9 , 8 6 1 1}$ & $\mathbf{1 0 , 5 7 8 7}$ & $\mathbf{1 3 , 1 1 3 4}$ & $\mathbf{1 2 , 2 3 3 8}$ & $\mathbf{1 3 , 7 7 3 2}$ \\
\hline
\end{tabular}


Gráfico 31 - Média da atividade GPx (U/L) no período chuvoso.

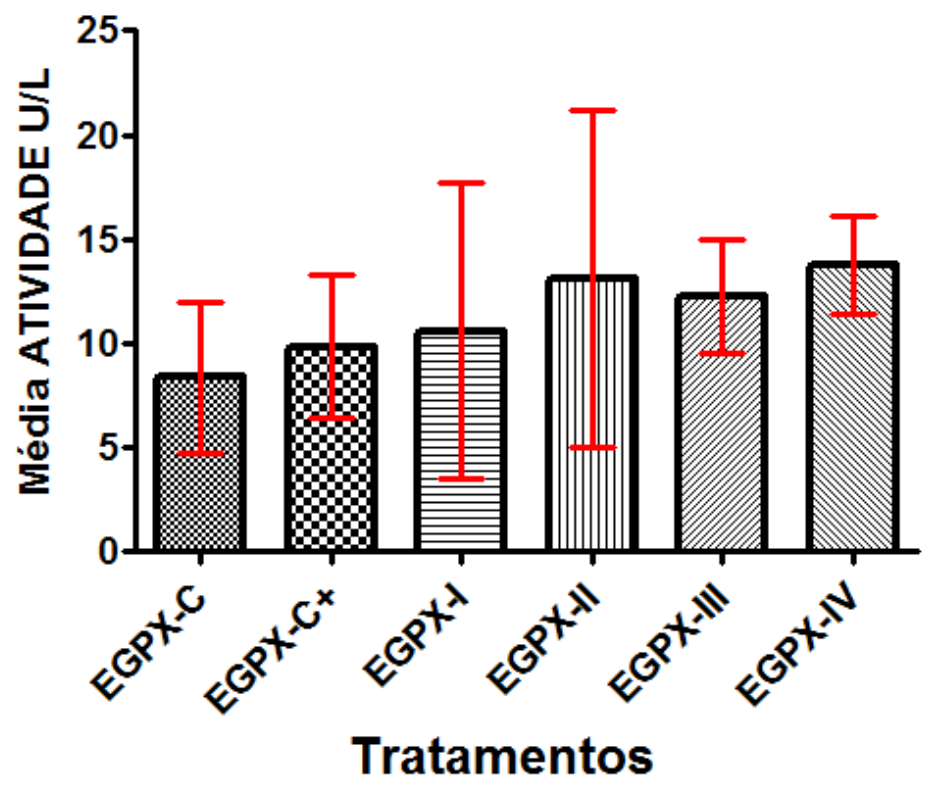

Na comparação entre os períodos seco e chuvoso (Tabelas 27 e 28 e Gráfico 32) foi observado que na maioria dos tratamentos os valores das atividades da GPx foram maiores no período chuvoso. Os tratamentos estatísticos para os valores da seca vs chuva para ANOVA $(\mathrm{P}<0.05)$ e o teste de Bonferroni não apresentaram diferenças significativas. No teste de Bartlett $(\mathrm{P}<0.05)$ ocorreu diferenças significativas para as medianas.

Gráfico 32 - Média da atividade GPx (U/L) no período seco vs chuvoso.

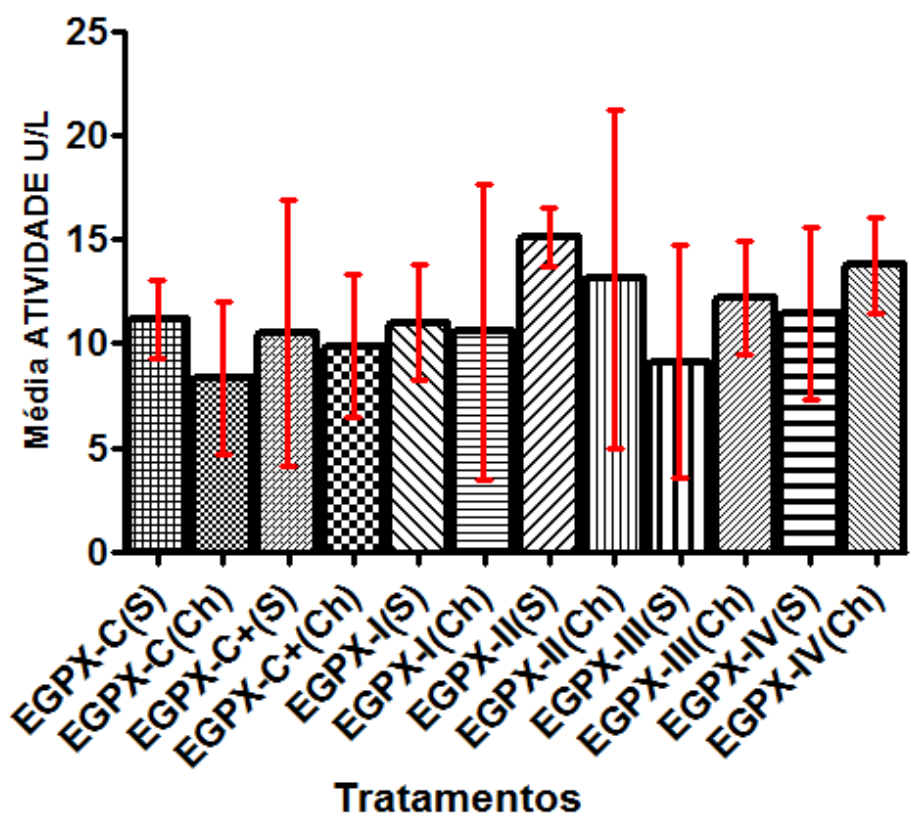


Neste trabalho não foram observadas diferenças significativas entre os valores das atividades de GPx para nenhum dos períodos ou concentrações analisadas. Também nas diferenças numéricas das médias das atividades não foi possível estabelecer um padrão de hierarquia. 


\section{DISCUSSÃO}

No ambiente aquático, a temperatura está relacionada com a variação da temperatura no ambiente terrestre, com a sazonalidade, vazão, condições climáticas, autodepuração das águas, largura e profundidade do leito, entre outras. Nesta pesquisa as temperaturas no período seco oscilaram entre 18 e $23{ }^{\circ} \mathrm{C}$. No período chuvoso se mantiveram praticamente estável em torno de $22{ }^{\circ} \mathrm{C}$ em todos os pontos analisados. Isto pode ser explicado pela incidência das chuvas e a subida do nível da Represa, pois estas condições aumentam o movimento das correntezas criando regiões com temperaturas mais dinâmicas.

Os IET obtidos estavam diretamente relacionados com o aumento da quantidade de clorofila-a, que foi maior no período seco, causado pelo florescimento de algas que é comum na estiagem, corroborando com os resultados encontrados pela CETESB nos relatórios correspondentes dos anos 2012 e 2013, períodos em que foram realizadas as coletas de dados na Represa Guarapiranga. Os valores mais elevados encontrados para o IET foram justamente onde as menores concentrações de $\mathrm{Cu}$ foram determinadas. Como o $\mathrm{Cu}$ é utilizado para eliminação de parte dos fitoplânctons e zooplânctons existentes na Represa, quando o $\mathrm{Cu}$ estava em altas concentrações a clorofila estava baixa.

Os valores mais elevados observados nas concentrações de $\mathrm{Cu}$ nas frações, no período de chuva, podem ser explicados pelo grande volume de água que entra na Represa proveniente dos rios e córregos que vão coletando no seu curso todo material e insumos de origem diversas. Assim como, os insumos provenientes das comunidades das margens da Represa que a cada dia são invadidas por construções irregulares. Estas águas trazem para dentro da Represa todo tipo de contaminantes, seja de origem doméstica, industrial ou agrícola. Por outro lado, a mudança do volume da Represa, aumenta a dinâmica das águas, criando correntezas e misturando os diferentes estratos do corpo d'água. Dessa forma, as grandes quantidades de $\mathrm{CuSO}_{4}$ depositadas na Represa pela SABESP para o controle das algas e cianobactérias, podem estar presos no sedimento podendo ser incorporados com esta nova dinâmica ao corpo da água. O que pode explicar os resultados encontrados.

As alterações histológicas mais severas, como aneurisma, hiperplasia das células mucosas, foram encontradas no período chuvoso onde as concentrações de $\mathrm{Cu}$ foram maiores segundo resultados desta pesquisa. $\mathrm{O}$ aneurisma observado indica a morte das células basais, o que provoca a perda da integridade estrutural da lamela secundária e a acumulação de células sanguíneas, o que por sua vez afetam o fluxo sanguíneo (HEATH, 1995; REZENDE et al., 2014b; VAN DEN HEUVEL et al., 2000). Os pesquisadores Jiraungkoorskul et al. (2003), 
observaram aneurismas em $O$. niloticus que foram expostos a glifosfato, o mesmo foi verificado por Rezende et al. (2014b) em O. niloticus coletadas nas águas poluídas da Represa Billings no Estado de São Paulo. Karan et al. (1998) também observaram estas alterações em peixes expostos a metais pesados, como o $\mathrm{Cu}$. $\mathrm{O}$ descolamento do epitélio branquial observado, pode ser caracterizado pela separação do epitélio lamelar na lamela secundária, formando um espaço que pode ser preenchido pela água podendo levar a formação de edema. Esta alteração pode funcionar como um mecanismo de defesa, aumentando a distância de difusão entre o sangue e a água. Entretanto, isto interfere com a eficiência da troca de gases e o transporte iônico (MALLATT, 1985; THOPHON et al., 2003). Outra alteração encontrada nos peixes analisados incluso em algum dos controles é a hiperplasia das células epiteliais. Devido à sobrecarga funcional de algumas estruturas do tecido, a hiperplasia destas células podem ser uma forma de crescimento adaptativo (TAKASHIMA; HIBIYA, 1995).

As análises desta pesquisa de tese foram referentes ao $\mathrm{Cu}$ e os peixes foram expostos as concentrações do metal na água da Represa, porém outros poluentes poderiam estar presentes, já que a água utilizada nos aquários era oriunda da própria Represa.

O descolamento epitelial, a hiperplasia e a fusão lamelar são alterações inespecíficas, que podem ser provocadas por diversos estressores, incluindo amônia, fenóis, infeções por microrganismos e a presença de ectoparasitas (HINTON et al., 1992). Danos nas células basais podem ter como resultado um aumento de sangue dentro da lamela, provocando uma dilatação dos canais marginais, congestão sanguínea ou mesmo aneurismas (ABDEL-MONEIM et al., 2012; ROSETY-RODRÍGUEZ et al., 2002; TAKASHIMA; HIBIYA, 1995). A formação de um aneurisma está relacionado a ruptura das células basais, devido a um alto fluxo de sangue ou mesmo aos diferentes efeitos dos poluentes nas células (ABDEL-MONEIM et al., 2012). Um aneurisma é um tipo grave de lesão da qual é possível a recuperação, mas com maior dificuldade do que a recuperação de uma alteração epitelial (POLEKSIC; MITROVICTUTUNDZIC, 1994). Aneurismas são menos frequentemente associados a exposição à metais (MALLATT, 1985). Contudo, estudos experimentais tem revelado que a exposição ao cádmio (GARCIA-SANTOS et al., 2007; THOPHON et al., 2003), chumbo (MARTINEZ et al., 2004) e ao cobre (OLIVA et al., 2009) podem induzir este tipo de lesão no epitélio branquial. Estudos de campo também tem observado a presença de aneurismas (CAMARGO; MARTINEZ, 2007; FIGUEIREDO-FERNANDES et al., 2007; LUKIN et al., 2011; SYASINA; SOKOLOVSKII, 2001).

Resultados similares foram observados por Song et al. (2015), quando trataram trutas com nanopartículas de $\mathrm{Cu}$ a $1 \mathrm{mg} / \mathrm{L}$ e $0.5 \mathrm{mg} / \mathrm{L}$. Os pesquisadores observaram fusão das 
lamelas secundárias e descolamento das células epiteliais na base das lamelas secundárias. As principais alterações observadas por Figueiredo-Fernandes et al. (2007) nas Tilápias expostas a diferentes concentrações de $\mathrm{Cu}$ foram: edema, elevação do epitélio lamelar e intensa vasodilatação de eixo lamelar, embora menos frequente também observaram fusão lamelar. Para duas espécies de peixes capturados no lago Jansen no Estado de Maranhão, Santos et al. (2014) observaram alterações similares nas brânquias dos peixes. Estas alterações também foram observadas por Abdel-Moneim; Al-Kahtani; Elmenshawy, (2012); Flores-Lopes; Thomaz, (2011) e Monteiro et al. (2008). A hiperplasia das células de muco, que foi verificada com mais frequência no período chuvoso, pode ser explicada pelo fato do muco no epitélio das brânquias agir como um ligante que forma complexos com o $\mathrm{Cu}$. Por esta razão, a produção de muco tem sido considerado como uma resposta compensatória para evitar a entrada do $\mathrm{Cu}$ pelas brânquias (CARVALHO; ALINE; NARCISO, 2015; TAO et al., 2001). Metais pesados como $\mathrm{Cd}$, Zn e Cu estimulam a secreção de muco destas células (HEATH, 1995; REZENDE et al., 2014a).

Os fígados também apresentaram maiores alterações no período chuvoso, onde as concentrações de $\mathrm{Cu}$ nos tecidos e na água foram mais elevadas. A vacuolização do citoplasma foi frequente nas amostras analisadas, isto pode ser sinal de processos degenerativos resultantes de problemas metabólicos, provavelmente provocado pelos contaminantes (PACHECO; SANTOS, 2002). No trabalho de Figueiredo-Fernandes et al. (2007), ao expor as Tilápias do Nilo a diferentes concentrações de $\mathrm{Cu}$, observaram diversas alterações nos fígados quando comparados com os controles. As alterações observadas foram vacuolização e necrose, também verificaram uma diminuição do número de núcleos por $\mathrm{mm}^{2}$ ao aumentar a concentração do $\mathrm{Cu}$. Alterações também foram encontradas em estudos de Abdel-Moneim; Al-Kahtani; Elmenshawy (2012); Flores-Lopes; Malabarba (2007); Rezende et al. (2014b) e Van Dyk; Cochrane; Wagenaar (2012). A congestão dos vasos sanguíneos hepáticos foi outra alteração que ocorreu. Congestão indica um aumento da circulação sanguínea no tecido hepático, o que poderia facilitar o transporte dos nutrientes e também melhorar a oxigenação destas áreas atuando como um mecanismo auxiliar na desintoxicação. De acordo com Anderson; Zeeman (1995) e Rezende et al. (2014b), a congestão pode ser considerada um indicador de estresse nos peixes devido a presença de substâncias xenobióticas. Alterações morfológicas significantes foram observadas nos fígados do jundiá (Rhamdia quelen) ante a exposição aguda ao $\mathrm{Cu}$ (MELA et al., 2013). De fato, também foi reportado que a longa exposição ao Cu foi responsável pelo aumento de alterações morfológicas no fígado do peixe Synechogobius hasta (CHEN et al., 2013). 
Os IAH para as brânquias mostraram alterações leves a moderadas em todos os grupos de tratamento. $\mathrm{O}$ que indica que as alterações mesmo que afetando o funcionamento do órgão, podem ter os danos revertidos. As maiores diferenças encontraram foram nos peixes do grupo IV. Já no caso dos fígados, foram observadas alterações moderadas a grave em vários indivíduos e grupos de tratamento, indicando que este órgão foi mais afetado.

A acumulação de metais nos peixes pode ser utilizada como bioindicadores, pois podem afetar diretamente o comportamento e o estado destes. Ou ainda podem ser transferidos para os consumidores mediante a cadeia alimentar, incluindo os seres humanos. Os íons dissolvidos de metais na água entram no corpo do peixe mediante as brânquias, outra parte destes metais que se encontram no sedimento entram pelo trato digestivo (JAYAPRAKASH et al., 2015). A bioacumulação de metais nos peixes dependem de propriedades físico-químicas da água e de fatores ecológicos (FARKAS; SALÁNKI; SPECZIÁR, 2003).

Os pesquisadores Maceda-Veiga; Monroy; De Sostoa (2012), obtiveram as maiores bioacumulações de $\mathrm{Cu}$ nos fígados dos peixes nos pontos de maior poluição. A concentração dos metais nos tecidos dos peixes pode não estar diretamente relacionada as concentrações na água. Nem todos os metais ingeridos são acumulados e os peixes podem em certo grau regular a concentração de metais nos tecidos após a bioacumulação (ALLEN; LUTHER; GARRISON, 1997; BERVOETS; BLUST; VERHEYEN, 2001; POURANG et al., 2005; YAMAZAKI; TANIZAKI; SHIMOKAWA, 1996). O presente estudo de tese, apresentou uma relação entre a concentração das frações biodisponíveis do $\mathrm{Cu}$ e a sua bioacumulação no fígado. Isto também foi observado nos resultados de Maceda-Veiga; Monroy; De Sostoa (2012), para o caso do Cu.

Vale mencionar o risco do conteúdo de metais no fígado para os predadores, que usualmente ingerem a presa inteira (BARATA et al., 2010; GUPTA et al., 2009; SUÁREZSERRANO et al., 2010; UYSAL et al., 2009). O Cu é um metal essencial na atividade enzimática e proteica durante os momentos de grande atividade alimentar e ovo-posição (FILIPOVIĆ MARIJIĆ; VARDIĆ SMRZLIĆ; RASPOR, 2014). As concentrações de Cu encontradas em Tilápias por Jayaprakash et al. (2015) apresentaram semelhanças com as verificadas no presente trabalho, no período chuvoso.

$\mathrm{O} \mathrm{Cu}$ na forma dissolvida é altamente tóxico para os organismos aquáticos, adquiridos pelas brânquias se encontram numa concentração média de 1,721 $\mu \mathrm{g} / \mathrm{g}$. O Cu que é um elemento importante nas sínteses da hemoglobina pode levar a toxicidade se adquirido em altas concentrações (VELUSAMY et al., 2014).

Jayaprakash et al. (2015) analisaram o fator de bioacumulação de vários metais incluindo $\mathrm{Fe}, \mathrm{Mn}, \mathrm{Cr}, \mathrm{Cu}, \mathrm{Ni}, \mathrm{Co}, \mathrm{Pb}, \mathrm{Zn}$. Neste estudo o Ni, Pb, Mn, Co, Cr e Fe apresentaram maior 
fator de bioacumulação nas brânquias, enquanto $\mathrm{o} C \mathrm{Cu}$ apresentou $\mathrm{o}$ maior fator de bioacumulação no fígado junto ao $\mathrm{Zn}$. O Cu o que foi verificado neste estudo de tese apresentou alto grau de bioacumulação. O lento nível de liberação gera potencial efeitos crónicos nos peixes e sua transferência na cadeia alimentar (DEFOREST; BRIX; ADAMS, 2007; KWOK et al., 2014).

Correspondendo também com os atuais resultados de Islam et al. (2015) que mediram concentrações de diversos metais em diferentes espécies de peixes. $\mathrm{O} \mathrm{Cu}$ foi encontrado em todas as amostras com concentrações entre 1,1 a $7,2 \mathrm{mg} / \mathrm{kg}$, sendo que a maior concentração de $\mathrm{Cu}$ na água também ocorreu no período chuvoso com média de $22 \mu \mathrm{g} / \mathrm{L}$.

O fator de bioacumulação calculado apresentou maiores valores nos fígados, tanto no período da chuva como na seca (Gráficos 19 e 20). O fígado se mostrou um órgão altamente acumulador (Gráfico 18) e resultados similares foram obtidos por Jayaprakash et al. (2015). Como podemos observar nos gráficos 17 e 18, em ambos órgãos os maiores índices de bioacumulação foram no período da seca, isto porque neste período as concentrações na água foram bem menores. No caso das brânquias, os valores do FB encontrados no período chuvoso acima de 1, indicam alta tendência a bioacumulação. Já no período seco todos os valores das médias estiveram abaixo de 1 . No fígado os valores das médias mostraram alta bioacumulação, tanto na chuva como na seca. No caso das brânquias, pode estar associado a maior formação de muco no tecido, o que poderia dificultar a incorporação do metal.

Os valores de IHS refletem o estado do fígado e está associado com a exposição a contaminantes (DETHLOFF et al., 1999). IHS foi correlacionado negativamente com os níveis de metais na água e nos tecidos. Os valores de IHS foram menores nos períodos de maior concentração de metais, resultados similares foram obtidos por Maceda-Veiga; Monroy; De Sostoa (2012).

A mobilização das reservas hepáticas de energia podem contribuir no intercâmbio de metais entre o fígado e outros tecidos (ex. músculo, gónadas, etc) (DI GIULIO; HINTON, 2008). A diminuição do IHS pode estar relacionada ao gasto das reservas de energia hepáticas, como resposta à exposição dos contaminantes (ALMEIDA; MELETTI; MARTINEZ, 2005). Coincidindo com as alterações histológicas observadas neste trabalho, outros estudos reportam que a vacuolização nos hepatócitos foram verificadas junto à alterações no metabolismo energético do fígado nos indivíduos do mesmo estudo (MACEDA-VEIGA; MONROY; DE SOSTOA, 2012). Contrastando estes resultados Figueiredo-Fernandes et al. (2007) verificaram um aumento do IHS quando as Tilápias foram expostas as maiores concentrações de $\mathrm{Cu}$ $(2,5 \mathrm{mg} / \mathrm{L})$. 
O estrese oxidativo acontece quando espécies reativas de oxigênio (ROS), tais como o íon superóxido $\left(\mathrm{O}_{2}{ }^{-}\right)$, peróxido de hidrogênio $\left(\mathrm{H}_{2} \mathrm{O}_{2}\right)$, radical hidroxilo $\left({ }^{-} \mathrm{OH}\right)$ e o oxigênio simples $\left(\mathrm{O}_{1}\right)$ reagem com lipídios, proteínas, carboidratos ou ácidos nucleicos, provocando um mal funcionamento e respostas derivadas com danos bioquímicos graves (BASTOS et al., 2007). Alguns xenobióticos podem liberar ROS na célula, estas são continuamente desintoxicadas por sistemas de defesa dos organismos formados por enzimas como a superóxido dismutase (SOD), catalase (CAT) e glutationa peroxidase (GPx). O estresse oxidativo é um parâmetro útil para medir a toxicidade e ecotoxicidade, devido a propriedade das células de responder ao estresse oxidativo criando uma série de mecanismos de respostas que podem ser facilmente medidos, como a alteração da expressão enzimática e genética (ABDEL-KHALEK et al., 2015; KOVOCHICH et al., 2007).

A catalase (CAT), é um componente da linha de defensa antioxidante primária, protege os peixes do estrese oxidativo convertendo o peróxido de hidrogênio em água e oxigênio.

Coincidindo também com nossos resultados Atli et al. (2006) obtiveram aumento na atividade da CAT com diferenças significativa em concentrações in vivo de 0,1 e $1 \mathrm{mg} / \mathrm{L}$ de $\mathrm{Cu}$. No mesmo estudo, a maior atividade da CAT foi observada no fígado referente a outros órgãos, intestino, rim, cérebro e brânquias. Neste estudo foram testados outros metais como $\mathrm{Zn}, \mathrm{Cd}$ e $\mathrm{Cr}$ e todos menos Ag tiveram o mesmo efeito de aumentar a atividade da CAT. Meng et al. (2014) obtiveram aumentos progressivos da atividade da CAT ao expor a Tilápia do Nilo à 2,20 e $200 \mu \mathrm{g} / \mathrm{L}$ do pesticida methomyl, sendo o maior aumento de $355,67 \%$ referente ao controle aos $200 \mu \mathrm{g} / \mathrm{L}$. Jin et al. (2010) reportaram aumento da atividade da CAT no fígado do peixe paulistinha após 14 dias de exposição a atrazina. O $\mathrm{Cu}$ também aumentou significativamente a atividade da CAT para todos os tecidos nos peixes de água doce nos estudos desenvolvidos por Ransberry et al. (2015). Quando exposta à concentrações de $\mathrm{CuO}$, o fígado da Tilápia do Nilo também apresentou aumento significativo na atividade da CAT (ABDEL-KHALEK et al., 2015). Um aumento na atividade da CAT representa uma resposta direta as ROS (RANSBERRY et al., 2015). O aumento na atividade da CAT pode estar associado ao aumento do estresse oxidativo causado pelos metais. Contrário ao observado neste estudo de tese, os pesquisadores Eyckmans et al. (2011) não encontraram diferenças na atividade da CAT nas brânquias de trutas quando expostas a diferentes concentrações de $\mathrm{Cu}$ $(20,50,65 \mu \mathrm{g} / \mathrm{L})$. Por outro lado no mesmo trabalho, a carpa comum mostrou aumentos de 256\% depois de 24 h. Atli e Canli (2007) expuseram indivíduos de Oreochromis niloticus a 5, 10 e $20 \mu \mathrm{M}$ de $\mathrm{Cu}, \mathrm{Cd}$ e $\mathrm{Zn}$, e não verificaram diferenças significativas na atividade da CAT 
em nenhuma das concentrações de $\mathrm{Cu}$. A maior diferença e atividade foram para $10 \mu \mathrm{M}$ de $\mathrm{Cd}$ e o Zn que provocaram inibição da atividade da CAT. Os mesmos autores Atli e Canli (2010a) obtiveram uma diminuição na atividade da CAT no fígado, quando a Tilápia do Nilo foi exposta a $\mathrm{Cu}$. Resultados semelhantes com diminuição da inibição da CAT em relação ao $\mathrm{Cu}$ também foram observados por Feng et al. (2015) e Simonato et al. (2016). A estimulação a atividade da CAT pode estar associada com uma efetiva resposta antioxidante, atuando contra o estresse oxidativo e/ou compensando a diminuição de outras enzimas como a SOD e GPX (ATLI; CANLI, 2010b).

Referente a exposição do $\mathrm{Cu}$, a inibição da atividade da SOD no fígado após 5 dias foi de acordo com os resultados prévios de Wang et al. (2014) para Epinephelus coioides e Gasterosteus aculeatus. Após 4 dias de exposição à 0,79 e 3,15 $\mu \mathrm{mol} / \mathrm{L}$ de $\mathrm{Cu}$, os pesquisadores Feng et al. (2015) observaram diminuição significativa da atividade da SOD no fígado, já a exposição ao PFOS e PFOA não foi observado alterações significativas. Ao expor o killifish (Fundulus heteroclitus) ao $\mathrm{Cu}$, a atividade da SOD diminuiu nas brânquias e não ocorreu mudanças significativas no fígado e no intestino (RANSBERRY; BLEWETT; MCCLELLAND, 2016).

A razão da inibição pode estar relacionada ao importante papel do $\mathrm{Cu}$ para disparar o estresse oxidativo nos peixes, seja provocando danos diretos ou esgotando as defesas antioxidantes. Especificamente o $\mathrm{Cu}$ é conhecido como um metal REDOX ativo e pode participar na reação de Fenton, catalisando a conversão do ânion superóxido e $\mathrm{H}_{2} \mathrm{O}_{2}$ ao radical hidroxilo, o mais reativo entre os ROS, sendo o principal responsável pelo estresse oxidativo (SEVCIKOVA et al., 2011). Além disso, níveis elevados do Cu podem se ligar a moléculas contendo tiol como a GSH, provocando seu esgotamento. E finalmente mudando o balanço redox celular para um estado mais oxidante, que por sua vez pode causar mais estresse e dano oxidativo (SEVCIKOVA et al., 2011).

Interessantemente os resultados deste estudo de tese apresentaram um comportamento diferente dos observados para a paulistinha (CRAIG; WOOD; MCCLELLAND, 2007); para o Pacu (GARCIA SAMPAIO et al., 2008); para Tilápia do Nilo (ABDEL-KHALEK et al., 2015); para três espécies diferentes de peixes (EYCKMANS et al., 2011); para Prochilodus lineatus (SIMONATO et al., 2016) e para Tilápia do Nilo exposta ao pesticida methomyl (MENG et al., 2014). Os autores Sanchez et al. (2005) mostraram que a exposição ao Cu inicialmente induz a atividade da SOD aos 4 dias, seguida de uma diminuição após 21 dias. No killifish exposto a concentrações sub-letais de Zn por 96 horas foi observado uma diminuição da atividade da SOD em todos os tecidos (LORO et al., 2012). Este comportamento, da 
atividade da SOD nos nossos resultados pode estar relacionado a ligação direta do $\mathrm{Cu}$ a enzima e por consequência inibindo a sua atividade; como sugerido previamente em peixes (PEDRAJAS; PEINADO; LÓPEZ-BAREA, 1995).

A GPx catalisa a redução do $\mathrm{H}_{2} \mathrm{O}_{2}$ ou peróxidos orgânicos em água ou os correspondentes álcoois, usando geralmente a GSH como fator de redução (BRIGELIUS-FLOHÉ; MAIORINO, 2013). Neste estudo de tese a atividade da GPx não apresentou alterações significativas em nenhum dos grupos de tratamento. No presente estudo só a CAT teve uma resposta significativa em relação a exposição ao $\mathrm{Cu}$, aumentando nos fígados dos peixes expostos a maiores concentrações. Este efeito pode estar relacionado com a habilidade do $\mathrm{Cu}$ em promover a geração de ROS pela reação de Fenton (DI GIULIO; HINTON, 2008; HERMES-LIMA, 2005). Em particular, o Cu induz ciclos REDOX pela reação de Fenton, os quais podem acelerar a formação de radicais hidroxila e causar graves danos oxidativos a membranas celulares (EYCKMANS et al., 2011). Estudos prévios demonstram que a exposição ao $\mathrm{Cu}$ pode tanto ativar, quanto inibir a atividade das enzimas antioxidantes nos peixes, dependendo da concentração do metal, da espécie e da rota de exposição (SANCHEZ et al., 2005; SIMONATO et al., 2016). De modo geral, a resposta da defesa antioxidante nos peixes é resultado de uma combinação de fatores bióticos e abióticos (MARTíNEZÁLVAREZ; MORALES; SANZ, 2005).

Peixes expostos ao Cu não tiveram diferenças significativas na atividade da GPx, quando comparados aos tratamentos com os peixes mantidos nas condições do controle (SIMONATO et al., 2016). Abdel-Moneim et al. (2012) não encontraram diferenças significativas na atividade da GPx nas brânquias das Tilápias do Nilo, quando comparados com os controles. Diferentemente dos resultados encontrados neste estudo de tese, após 4 dias de exposição ao $\mathrm{Cu}$, as atividades da GPx nos fígados do peixe Carassius auratus diminuíram significativamente no estudo de Feng et al. (2015). As funções da SOD e da CAT estão relacionadas. A SOD catalisa a dismutação do radical superóxido em $\mathrm{H}_{2} \mathrm{O}_{2}$, que é desintoxicado pela atividade da CAT e da GPx. Aumentos das atividades da SOD e da CAT são normalmente encontrados na presença de poluentes, já que o sistema SOD-CAT representam a primeira linha de defesa contra o estresse oxidativo (PANDEY et al., 2008). Contudo a atividade destas enzimas nos peixes podem também diminuir após a exposição a xenobióticos, como reportado por Feng et al. (2015); Livingstone (2001); Pandey et al. (2008).

Em exemplares de Tilápia do Nilo tratadas com $\mathrm{CuO}$ após 30 dias de exposição foram observadas diferenças significativas (ABDEL-KHALEK et al., 2015). Em experimentos Orun et al. (2008), observaram alterações significativas na atividade da GPx, nos tecidos do peixe 
Onchorhynchus mykiss, após tratamentos com Cd e Cr. (ATLI; CANLI, 2010b) Exemplares de Tilápia do Nilo foram tratadas com diversos metais entre eles $\mathrm{Cu}$, os resultados mostraram que a atividade da GPX no fígado, aumentaram significativamente quando exposto a $\mathrm{Cu}$ e $\mathrm{Zn}$. Já nos rins, o aumento ocorreu quando exposto ao $\mathrm{Cu}$ e $\mathrm{Cd}$, sendo que o $\mathrm{Cu}$ provocou o maior aumento da atividade da GPX entre os metais. A atividade da SOD diminuiu 54\% e as atividades da CAT, GPX e GR aumentaram em 30 à 60\% (CARVALHO; ALINE; NARCISO, 2015). 


\section{CONCLUSÃO}

$\mathrm{O}$ fracionamento do $\mathrm{Cu}$ nas amostras de água coletadas, mostrou que o estado das variáveis físico - químicas apresentaram maiores concentrações de $\mathrm{Cu}$ na fração dissolvida $(0,22 \mu \mathrm{m})$. Neste estado o metal apresenta sua maior disponibilidade e, portanto, com maiores chances de provocar efeitos toxicológicos nos organismos. Aparentemente existe uma relação entre a concentração do Cu e a clorofila-a. Neste trabalho, esta relação foi inversa entre o Cu e clorofila-a, e da mesma forma entre as concentrações do $\mathrm{Cu}$ e o índice de estado trófico.

As alterações histológicas observadas nas brânquias e nos fígados ante a exposição ao $\mathrm{Cu}$, corroboraram com o encontrado por diversos autores. Estas alterações se apresentaram frente ao $\mathrm{Cu}$ e outros metais, assim como diversos xenobióticos. Isto faz reflexionar sobre a eficácia destas alterações provocadas pelo $\mathrm{Cu}$ e assim serem utilizados como biomarcadores de toxicidade em peixes. Estes elementos servem para suportar a toxicidade do $\mathrm{Cu}$ em conjunto com outros indicadores, como o caso da bioacumulação nos tecidos e o índice hepatosomático (IHS).

Os altos valores de bioacumulação do $\mathrm{Cu}$ achados neste trabalho nos fígados das Tilápias indicam o perigo do consumo deste peixe proveniente do reservatório Guarapiranga, pois o $\mathrm{Cu}$ tem a capacidade da biomagnificação na cadeia alimentar, sendo assim o consumo de este peixe ou de algum outro organismo que consuma o peixe pode terminar afetando os seres humanos.

O conjunto dessas análises junto a determinação das atividades enzimáticas podem fornecer um resultado mais específico. As atividades das enzimas antioxidantes podem ser utilizadas como um método mais efetivo para biomarcadores do estresse causado pelo $\mathrm{Cu}$ e outros metais. Observamos neste estudo que o $\mathrm{Cu}$ é capaz de gerar estresse oxidativo em peixes, mesmo antes que uma bioacumulação significativa aconteça no fígado. Isto atribuído ao envolvimento de diferentes mecanismos na incorporação do $\mathrm{Cu}$ e seu metabolismo.

De forma geral as atividades das enzimas antioxidantes CAT, SOD e GPX, foram alteradas de alguma forma depois de 120 horas de exposição ao $\mathrm{Cu}$, proveniente de 4 pontos de coleta da Represa Guarapiranga. Este efeito pode estar relacionado com a habilidade do $\mathrm{Cu}$ em provocar ROS via reação de Fenton. Podemos concluir que realmente o estudo das atividades das enzimas antioxidantes respondem a exposição da Tilápia do Nilo ao $\mathrm{Cu}$. Corroborado com outros resultados auxiliares que podem ser usados como biomarcadores da toxicidade do $\mathrm{Cu}$. 
Pode-se inferir que o uso de $\mathrm{CuSO}_{4}$ como algicida e a entrada de $\mathrm{Cu}$ por lixiviação no reservatório Guarapiranga estão provocando a existência de níveis deste metal no meio aquático que podem alterar e provocar estresse nos peixes. Recomendamos uma revisão detalhada do uso deste produto no tratamento dos florescimentos de algas no reservatório.

Para obter resultados mais apurados, recomendamos que sejam realizadas mais amostragens na Represa por um período de tempo maior. E também realizadas análises de PCR em tempo real para verificar os efeitos a nível genético. 


\section{REFERÊNCIAS $*^{1}$}

ABDEL-KHALEK, A. A. et al. Comparative toxicity of copper oxide bulk and nano particles in Nile Tilapia; Oreochromis niloticus: Biochemical and oxidative stress. The Journal of Basic \& Applied Zoology, v. 72, p. 43-57, 2015.

ABDEL-MONEIM, A. M. et al. Gill oxidative stress and histopathological biomarkers of pollution impacts in Nile tilapia from Lake Mariut and Lake Edku, Egypt. Journal of aquatic animal health, v. 24, n. 3, p. 148-160, 2012.

ABDEL-MONEIM, A. M.; AL-KAHTANI, M. A.; ELMENSHAWY, O. M.

Histopathological biomarkers in gills and liver of Oreochromis niloticus from polluted wetland environments, Saudi Arabia. Chemosphere, v. 88, n. 8, p. 1028-1035, 2012.

AHMAD, I. et al. Anguilla anguilla L. oxidative stress biomarkers responses to copper exposure with or without $\beta$-naphthoflavone pre-exposure. Chemosphere, v. 61, n. 2, p. 267$275,2005$.

ALKALADI, A.; MOSLEH, Y.; AFIFI, M. Biochemical And Histological Biomarkers Of Zn Pollution In Nile Tilapia,(Oreochromis niloticus). Archives Des Sciences, 2013.

ALLEN, H. E.; LUTHER, G. W.; GARRISON, W. Metals in Surface Waters. [s.1.] CRC Press, 262 p. 1997.

ALMEIDA, J. S.; MELETTI, P. C.; MARTINEZ, C. B. R. Acute effects of sediments taken from an urban stream on physiological and biochemical parameters of the neotropical fish Prochilodus lineatus. Comparative Biochemistry and Physiology - C Toxicology and Pharmacology, v. 140, n. 3-4, p. 356-363, 2005.

ANDERSON, D. P.; ZEEMAN, M. G. Immunotoxicology in fish. p. 371-404, 1995.

ARUOMA, O. I. et al. Copper-ion-dependent damage to the bases in DNA in the presence of hydrogen peroxide. The Biochemical journal, v. 273 ( Pt 3, p. 601-604, 1991.

Associação Brasileira de Normas Técnicas. NBR 13373: ecotoxicologia aquática toxicidade crônica - método de ensaio com Ceriodaphnia spp (Crustacea, Cladocera). Rio de Janeiro: ABNT, 2003. 12 p.

ATLI, G. et al. Response of catalase activity to $\mathrm{Ag}+, \mathrm{Cd} 2+, \mathrm{Cr} 6+, \mathrm{Cu} 2+$ and $\mathrm{Zn} 2+$ in five tissues of freshwater fish Oreochromis niloticus. Comparative biochemistry and physiology. Toxicology \& pharmacology : CBP, v. 143, n. 2, p. 218 - 224, jun. 2006.

ATLI, G.; CANLI, M. Enzymatic responses to metal exposures in a freshwater fish Oreochromis niloticus. Comparative biochemistry and physiology. Toxicology \& pharmacology : CBP, v. 145, n. 2, p. 282 - 287, mar. 2007.

ATLI, G.; CANLI, M. Responses of metallothionein and reduced glutathione in a freshwater fish Oreochromis niloticus following metal exposures. Environmental Toxicology and

\footnotetext{
1 * De acordo com: ASSOCIAÇÃO BRASILEIRA DE NORMAS TÉCNICAS. NBR 6023: informação e documentação: referências: elaboração, Rio de Janeiro, 2002
} 
Pharmacology, v. 25, n. 1, p. 33-38, 2008.

ATLI, G.; CANLI, M. Response of antioxidant system of freshwater fish Oreochromis niloticus to acute and chronic metal $(\mathrm{Cd}, \mathrm{Cu}, \mathrm{Cr}, \mathrm{Zn}, \mathrm{Fe})$ exposures. Ecotoxicology and Environmental Safety, v. 73, n. 8, p. 1884-1889, 2010a.

ATLI, G.; CANLI, M. Response of antioxidant system of freshwater fish Oreochromis niloticus to acute and chronic metal $(\mathrm{Cd}, \mathrm{Cu}, \mathrm{Cr}, \mathrm{Zn}, \mathrm{Fe})$ exposures. Ecotoxicology and environmental safety, v. 73 , n. 8 , p. $1884-1889,1$ nov. $2010 \mathrm{~b}$.

ATSDR - Agency for Toxic Substances and Disease Registry 1990. Toxicological profile for copper, Division of Toxicology/Toxicology Information Branch - Atlanta/ US. 364 p.

BALDWIN, D. H. et al. Sublethal effects of copper on coho salmon: impacts on nonoverlapping receptor pathways in the peripheral olfactory nervous system.

Environmental toxicology and chemistry / SETAC, v. 22, n. 10, p. 2266-2274, 2003.

BARATA, C. et al. Blood biomarkers and contaminant levels in feathers and eggs to assess environmental hazards in heron nestlings from impacted sites in Ebro basin (NE Spain). Environmental pollution (Barking, Essex : 1987), v. 158, n. 3, p. 704-710, mar. 2010.

BASTOS, V. L. F. C. et al. Cytosolic glutathione peroxidase from liver of pacu (Piaractus mesopotamicus), a hypoxia-tolerant fish of the Pantanal. Biochimie, v. 89, p. 1332-1342, 2007.

BENOIT, G.; ROZAN, T. F. The influence of size distribution on the particle concentration effect and trace metal partitioning in rivers. Geochimica et Cosmochimica Acta, v. 63, n. 1, p. 113-127, 1999.

BERVOETS, L.; BLUST, R.; VERHEYEN, R. Accumulation of metals in the tissues of three spined stickelback (Gasterosteus aculeatus) from natural fresh waters. Ecotoxicology and environmental safety, v. 48, n. 2, p. 117-127, fev. 2001.

BIDINOTTO, P. M.; MORAES, G.; SOUZA, R. H. S. Hepatic glycogen and glucose in eight tropical freshwater teleost fish: A procedure for field determinations of microsamples. Boletim Técnico do CEPTA, Pirassununga, v. 10: p. 53-60. 1997.

BIGAGLI, E. et al. Extremely low copper concentrations affect gene expression profiles of human prostate epithelial cell lines. Chemico-Biological Interactions, v. 188, n. 1, p. 214 $219,2010$.

BONNE HERNÁNDEZ, R.; OLIVEIRA, E.; ESPÓSITO, B. P. Distribution and behavior of manganese in the Alto do Paranapanema Basin. Journal of environmental monitoring : JEM, v. 11, n. 6, p. 1236-1243, 2009.

BOPP, S. K.; ABICHT, H. K.; KNAUER, K. Copper-induced oxidative stress in rainbow trout gill cells. Aquatic toxicology (Amsterdam, Netherlands), v. 86, n. 2, p. 197-204, 31 jan. 2008 .

BOUGATEF, A. et al. Purification and characterization of trypsin from the viscera of sardine (Sardina pilchardus). Food Chemistry, v. 102, n. 1, p. 343-350, 2007. 
BRASIL. ANA - AGENNCIA NACIONAL AGUA. Panorama da qualidade das águas superficiais no Brasil. Brasília: ANA/MMA, 2005. 179 p

BRIGELIUS-FLOHÉ, R.; MAIORINO, M. Glutathione peroxidases. Biochimica et Biophysica Acta - General Subjects, v. 1830, n. 5, p. 3289-3303, 2013.

BRITTON, R. S. Metal-induced hepatotoxicity. Seminars in liver disease, v. 16, n. 1, p. 3$12,1996$.

BRULAND, K. W.; DONAT, J. R.; HUTCHINS, D. A. Interactive influences of bioactive trace metals on biological production in oceanic waters. Limnology and Oceanography, v. 36, n. 8, p. 1555-1577, 1991.

BUI, T.-K. L. et al. Copper toxicity and the influence of water quality of Dongnai River and Mekong River waters on copper bioavailability and toxicity to three tropical species.

Chemosphere, v. 144, p. 872-878, 2016.

BURKHEAD, J. L. et al. Copper homeostasis. The New phytologist, v. 182, n. 4, p. 799816, jun. 2009.

BUNCE, N. Environmental Chemistry, 2ed. Wuerz Publishing Ltd, Winnipeg, 1994.

CAMARGO, M. M. P.; MARTINEZ, C. B. R. Histopathology of gills, kidney and liver of a Neotropical fish caged in an urban stream. Neotropical Ichthyology, v. 5, n. 3, p. 327-336, set. 2007.

CAO, L. et al. Accumulation and oxidative stress biomarkers in Japanese flounder larvae and juveniles under chronic cadmium exposure. Comparative Biochemistry and Physiology - C Toxicology and Pharmacology, v. 151, n. 3, p. 386-392, 2010.

CARVALHO, S.; ALINE, V.; NARCISO, M. Copper levels and changes in pH induce oxidative stress in the tissue of curimbata (Prochilodus lineatus ). Aquatic Toxicology, v. 167, p. 220-227, 2015.

CAVAS, T.; GARANKO, N. N.; ARKHIPCHUK, V. V. Induction of micronuclei and binuclei in blood, gill and liver cells of fishes subchronically exposed to cadmium chloride and copper sulphate. Food and Chemical Toxicology, v. 43, n. 4, p. 569-574, 2005.

CERQUEIRA, C. C. C.; FERNANDES, M. N. Gill tissue recovery after copper exposure and blood parameter responses in the tropical fish Prochilodus scrofa. Ecotoxicology and environmental safety, v. 52, n. 2, p. 83-91, 2002.

CETESB, Companhia de Tecnologia de Saneamento Ambiental. 1990. Avaliação da qualidade das águas para consumo humano no Estado de São Paulo - 1990. São Paulo, Secretaria do Meio Ambiente, 1991, p. 268 (Série/Relatórios).

CETESB, Companhia de Tecnologia de Saneamento Ambiental. Qualidade das águas interiores do Estado de São Paulo 2001, São Paulo: CETESB, Secretaria de Estado do Meio Ambiente, 2002. p.475. (Série/Relatórios).

CETESB. Companhia de Tecnologia de Saneamento Ambiental. Qualidade das águas interiores do Estado de São Paulo. 2004. São Paulo: CETESB, 2005, p. 486. 
(Série/Relatórios).

CETESB. Companhia de Tecnologia de Saneamento Ambiental. Qualidade das águas interiores do estado de São Paulo 2007, São Paulo: CETESB, Secretaria de Estado do Meio Ambiente, 2008, p.536. (Série/Relatórios).

CETESB. Companhia de Tecnologia de Saneamento Ambiental. Qualidade das águas superficiais no estado de São Paulo 2012 [recurso eletrônico] / CETESB. - - São Paulo: CETESB, 2013. p. 370: il. Color. (Série/Relatórios).

CETESB. Companhia de Tecnologia de Saneamento Ambiental. Qualidade das águas superficiais no estado de São Paulo 2013 [recurso eletrônico] / CETESB. - São Paulo: CETESB, 2014.1 p. 340: il. Color. (Série/Relatórios).

CHEN, Q. L. et al. Effects of waterborne chronic copper exposure on hepatic lipid metabolism and metal-element composition in Synechogobius hasta. Archives of Environmental Contamination and Toxicology, v. 64, n. 2, p. 301-315, 2013.

ÇOĞUN, H. Y.; KARGIN, F. Effects of pH on the mortality and accumulation of copper in tissues of Oreochromis niloticus. Chemosphere, v. 55, n. 2, p. 277-282, 2004.

ÇOĞUN, H. Y.; YÜZEREROĞLU, T. A.; KARGIN, F. Accumulation of Copper and Cadmium in Small and Large Nile Tilapia Oreochromis niloticus. Bulletin of Environmental Contamination and Toxicology, v. 71, n. 6, p. 1265-1271, 2003.

COOMBS, S. et al. Avaliação da degradação ambiental na bacia do rio Mogi-Guaçu por meio de testes de toxicidade com sedimento e de análises histopatológicas em peixes.

Encyclopedia of Fish Physiology, v. 1, p. 476-488, 2011.

CRAIG, P. M.; WOOD, C. M.; MCCLELLAND, G. B. Oxidative stress response and gene expression with acute copper exposure in zebrafish (Danio rerio). American journal of physiology. Regulatory, integrative and comparative physiology, v. 293, n. 5, p. R1882R1892, 2007.

D'ARCY, B.; FROST, A. The role of best management practices in alleviating water quality problems associated with diffuse pollution. The Science of the total environment, v. 265, $\mathrm{n}$. $1-3$, p. 359-367, 2001.

DAVID, M. et al. Sodium cyanide-induced modulations in the activities of some oxidative enzymes and metabolites in the fingerlings of Cyprinus carpio (Linnaeus). Toxicological \& Environmental Chemistry, v. 92, n. 10, p. 1841-1849, 1 nov. 2010.

DAVIS, A. P.; SHOKOUHIAN, M.; NI, S. Loading estimates of lead, copper, cadmium, and zinc in urban runoff from specific sources. Chemosphere, v. 44, n. 5, p. 997-1009, 2001.

DE BOECK, G. et al. Copper toxicity in the spiny dogfish (Squalus acanthias): Urea loss contributes to the osmoregulatory disturbance. Aquatic Toxicology, v. 84, n. 2 SPEC. ISS., p. 133-141, 2007.

DEFOREST, D. K.; BRIX, K. V.; ADAMS, W. J. Assessing metal bioaccumulation in aquatic environments: The inverse relationship between bioaccumulation factors, trophic transfer factors and exposure concentration. Aquatic Toxicology, v. 84, n. 2, p. 236-246, 
2007.

DETHLOFF, G. M. et al. The effects of copper on blood and biochemical parameters of rainbow trout (Oncorhynchus mykiss). Archives of Environmental Contamination and Toxicology, v. 36, n. 4, p. 415-423, 1999.

DEWEZ, D. et al. Determination of photosynthetic and enzymatic biomarkers sensitivity used to evaluate toxic effects of copper and fludioxonil in alga Scenedesmus obliquus. Aquatic Toxicology, v. 74, n. 2, p. 150-159, 2005.

DI GIULIO, T. T.; HINTON, D. E. The toxicology of fishes. Boca Raton; CRC PRESS, 2008. $1071 \mathrm{p}$

EYCKMANS, M. et al. Exposure to waterborne copper reveals differences in oxidative stress response in three freshwater fish species. Aquatic Toxicology, v. 103, n. 1-2, p. 112-120, 2011.

FARKAS, A.; SALÁNKI, J.; SPECZIÁR, A. Age- and size-specific patterns of heavy metals in the organs of freshwater fish Abramis brama L. populating a low-contaminated site. Water Research, v. 37, n. 5, p. 959-964, 2003.

FEDELI, D.; CARLONI, M.; FALCIONI, G. Oxidative damage in trout erythrocyte in response to "in vitro" copper exposure. Marine environmental research, v. 69, n. 3, p. 172177, abr. 2010.

FENG, M. et al. Evaluation of single and joint toxicity of perfluorooctane sulfonate, perfluorooctanoic acid, and copper to Carassius auratus using oxidative stress biomarkers. Aquat. Toxicol., v. 161, p. 108-116, 2015.

FIGUEIREDO-FERNANDES, A. et al. Histopathological changes in liver and gill epithelium of Nile tilapia, Oreochromis niloticus, exposed to waterborne copper copper. Pesquisa Veterinaria Brasileira, v. 27, n. 3, p. 103-109, 2007.

FILIPOVIĆ MARIJIĆ, V.; VARDIĆ SMRZLIĆ, I.; RASPOR, B. Does fish reproduction and metabolic activity influence metal levels in fish intestinal parasites, acanthocephalans, during fish spawning and post-spawning period? Chemosphere, v. 112, p. 449-455, out. 2014.

FLORES-LOPES, F.; MALABARBA, L. R. ALTERAÇÕES HISTOPATOLÓGICAS OBSERVADAS NO FÍGADO DO LAMBARÍ Astyanax jacuhiensis ( COPE , 1894 ) ( TELEOSTEI , CHARACIDAE ) SOB INFLUÊNCIA DE EFLUENTES PETROQUÍMICOS. Biociências, v. 15, n. 2, p. 166-172, 2007.

FLORES-LOPES, F.; THOMAZ, A T. Histopathologic alterations observed in fish gills as a tool in environmental monitoring. Brazilian journal of biology $=$ Revista brasleira de biologia, v. 71, n. 1, p. 179-188, 2011.

FRIDOVICH, I. Oxygen toxicity: a radical explanation. J. Exp. Biol., v. 201, n. 8, p. 12031209, 1 abr. 1998.

GARCIA SAMPAIO, F. et al. Antioxidant defenses and biochemical changes in pacu (Piaractus mesopotamicus) in response to single and combined copper and hypoxia exposure. Comparative Biochemistry and Physiology - C Toxicology and Pharmacology, v. 147, n. 
020, p. 43-51, 2008.

GARCÍA-MUÑOZ, E.; GUERRERO, F.; PARRA, G. Intraspecific and interspecific tolerance to copper sulphate in five Iberian amphibian species at two developmental stages. Archives of environmental contamination and toxicology, v. 59, n. 2, p. 312-321, ago. 2010.

GARCIA-SANTOS, S. et al. Alterações histológicas em brânquias de tilápia nilotica Oreochromis niloticus causadas pelo cádmio. Arq. Bras. Med. Vet. Zootec, v. 59, n. 2, p. 376-381, 2007.

GEORGOPOULOS, P. G.; ROY, A.; YONONE-LIOY, M. J.J. Toxicol. Environ. Health, v 4, pp. 341-394, 2001.

GONÇALVES, A. C.; LUCHESE, E. B.; LENZI, E. Avaliação da fitodisponibilidade de cádmio, chumbo e crômio, em soja cultivada em latossolo vermelho escuro tratado com fertilizantes comerciais. Quimica Nova, v. 23, n. 2, p. 173-177, 2000.

GROSELL, M. et al. Effects of prolonged copper exposure in the marine gulf toadfish (Opsanus beta) I. Hydromineral balance and plasma nitrogenous waste products. Aquatic Toxicology, v. 68, n. 3, p. 249-262, 2004.

GROSELL, M.; NIELSEN, C.; BIANCHINI, A. Sodium turnover rate determines sensitivity to acute copper and silver exposure in freshwater animals Comparative Biochemistry and Physiology - C Toxicology and Pharmacology, v. 133, p. 287-303, 2002.

GROSELL, M.; WOOD, C. M. Copper uptake across rainbow trout gills: mechanisms of apical entry. The Journal of experimental biology, v. 205, n. Pt 8, p. 1179-1188, 2002.

GUPTA, A. et al. Analysis of some heavy metals in the riverine water, sediments and fish from river Ganges at Allahabad. Environmental monitoring and assessment, v. 157, n. 1-4, p. 449-458, out. 2009.

HAN, N.; THOMPSON, M. L. Copper-Binding Ability of Dissolved Organic Matter Derived from Anaerobically Digested Biosolids. Journal of Environment Quality, v. 28, n. 3, p. 939-944, 1999.

HARRISON, M. D.; JONES, C. J.; SOLIOZ, M.; DAMERON, C. T. Intracellular copper routing: The role of copper chaperonesTrends in Biochemical Sciences, v. 25, p. 29-32, 2000 .

HEATH, A. G. Water Pollution and Fish Physiology. 2. ed. Boca Raton: CRC Press; 1995. p. 384.

HERMES-LIMA, M. Oxygen in Biology and Biochemistry: Role of Free Radicals. In: Storey, K.B. (eds.) Functional Metabolism, Regulation and Adaptation, 2005. p. 319-368.

HOLT, M. . Sources of chemical contaminants and routes into the freshwater environment. Food and Chemical Toxicology, v. 38, n. SUPPL. 1, p. S21-S27, abr. 2000.

HUDSON, R. J. M. Which aqueous species control the rates of trace metal uptake by aquatic biota? Observations and predictions of non-equilibrium effects. Science of The Total 
Environment, v. 219, n. 2-3, p. 95-115, ago. 1998.

IRWIN, R. J. Environmental Contaminants Encyclopedia Copper Entry. Environmental Contaminants Encyclopedia, n. Copper, p. 6-39, 1997.

ISLAM, M. S. et al. Assessment of trace metals in fish species of urban rivers in Bangladesh and health implications. Environmental toxicology and pharmacology, v. 39, n. 1, p. 347$357,2015$.

JARDIM, W. F. A contaminação dos recursos hídricos por esgoto doméstico e industrial. Química Nova, v. 15, n. 2, p. 144-154, 1992.

JAYAPRAKASH, M. et al. Bioaccumulation of metals in fish species from water and sediments in macrotidal Ennore creek, Chennai, SE coast of India: A metropolitan city effect. Ecotoxicology and Environmental Safety, v. 120, p. 243-255, 2015.

JIANG, W.-D. et al. Copper exposure induces oxidative injury, disturbs the antioxidant system and changes the Nrf2/ARE (CuZnSOD) signaling in the fish brain: protective effects of myo-inositol. Aquatic toxicology (Amsterdam, Netherlands), v. 155, n. 46, p. 301-313, 2014.

JIN, Y. et al. Oxidative stress response and gene expression with atrazine exposure in adult female zebrafish (Danio rerio). Chemosphere, v. 78, n. 7, p. 846-852, 2010.

JIRAUNGKOORSKUL, W. et al. Biochemical and histopathological effects of glyphosate herbicide on Nile tilapia (Oreochromis niloticus). Environmental toxicology, v. 18, n. 4, p. 260-267, ago. 2003.

JO, H.-J. et al. Combined effects of water quality parameters on mixture toxicity of copper and chromium toward Daphnia magna. Chemosphere, v. 81, n. 10, p. 1301-1307, nov. 2010.

KARAN, V. et al. Functional enzymes activity and gill histology of carp after copper sulfate exposure and recovery. Ecotoxicology and environmental safety, v. 40, n. 1-2, p. 49-55, 1998.

KHANGAROT, B. S.; DAS, S. Effects of copper on the egg development and hatching of a freshwater pulmonate snail Lymnaea luteola L. Journal of hazardous materials, v. 179, n. $1-3$, p. $665-675,15$ jul. 2010.

KIPTON, H.; POWELL, J.; FENTON, E. Size fractionation of humic substances: Effect on protonation and metal binding properties. Analytica Chimica Acta, v. 334, n. 1-2, p. 27-38, 1996.

KNAUERT, S.; KNAUER, K. The role of reactive oxygen species in copper toxicity to two freshwater green algae. Journal of Phycology, v. 44, n. 2, p. 311-319, 2008.

$\mathrm{KOVOCHICH}, \mathrm{M}$. et al. Principles and procedures to assess nanomaterial toxicity.

Environmental Nanotechnology, p. 205-230, 2007.

KUZ'MINA, V. V; USHAKOVA, N. V. The dependence on temperature and $\mathrm{pH}$ of the effects of zinc and copper on proteolytic activities of the digestive tract mucosa in piscivorous fish and their potential preys. Fish physiology and biochemistry, v. 36, n. 3, p. 787-795, set. 
2010.

KWOK, C. K. et al. Bioaccumulation of heavy metals in fish and Ardeid at Pearl River Estuary, China. Ecotoxicology and environmental safety, v. 106, p. 62-67, ago. 2014.

LAUREN, D.; MCDONALD, D. G. Acclimation to Copper by Rainbow Trout, Salmo gairdneri: Biochemistry. Canadian Journal of Fisheries and Aquatic Sciences, v. 44, n. hZcLeese 1956, p. 105-111, 1987.

LI, J. et al. Effects of water-borne copper on branchial chloride cells and $\mathrm{Na}+\mathrm{K}+-\mathrm{ATPase}$ activities in Mozambique tilapia (Oreochromis mossambicus). Aquatic Toxicology, v. 43, n. 1, p. 1-11, set. 1998.

LIVINGSTONE, D. R. Contaminant-stimulated reactive oxygen species production and oxidative damage in aquatic organisms. Marine pollution bulletin, v. 42, n. 8, p. 656-666, ago. 2001.

LLOYD, D. R.; CARMICHAEL, P. L.; PHILLIPS, D. H. Comparison of the formation of 8hydroxy-2'-deoxyguanosine and single- and double-strand breaks in DNA mediated by fenton reactions. Chemical research in toxicology, v. 11, n. 5, p. 420-427, maio 1998.

LORO, V. L. et al. Oxidative stress parameters and antioxidant response to sublethal waterborne zinc in a euryhaline teleost Fundulus heteroclitus: protective effects of salinity. Aquatic toxicology (Amsterdam, Netherlands), v. 110-111, p. 187-193, abr. 2012.

LU, Y.; ALLEN, H. Characterization of copper complexation with natural dissolved organic matter (DOM) - link to acidic moieties of DOM and competition by $\mathrm{Ca}$ and $\mathrm{Mg}$. Water Research, v. 36, n. 20, p. 5083-5101, dez. 2002.

LUKIN, A. et al. Assessment of fish health status in the Pechora River: effects of contamination. Ecotoxicology and environmental safety, v. 74, n. 3, p. 355-365, mar. 2011.

MA, Y. et al. Cupric nitrilotriacetate induces oxidative DNA damage and apoptosis in human leukemia HL-60 cells. Free Radic Biol Med, v. 25, n. 4-5, p. 568-575, 1998.

MACEDA-VEIGA, A.; MONROY, M.; DE SOSTOA, A. Metal bioaccumulation in the Mediterranean barbel (Barbus meridionalis) in a Mediterranean River receiving effluents from urban and industrial wastewater treatment plants. Ecotoxicology and Environmental Safety, v. 76, p. 93-101, 2012.

MACINTYRE, C. M. et al. The Influences of Water Quality on the Welfare of Farmed Rainbow Trout: A Review. In: Branson, E. J (eds.). Fish Welfare. Ed. Wiley-Blackwell 2008, p. 150-184.

MALIK, N. et al. Bioaccumulation of heavy metals in fish tissues of a freshwater lake of Bhopal. Environmental Monitoring and Assessment, v. 160, n. 1-4, p. 267-276, 2010.

MALLATT, J. Fish Gill Structural Changes Induced by Toxicants and Other Irritants: A Statistical Review. Canadian Journal of Fisheries and Aquatic Sciences, v. 42, n. 4, p. 630-648, 1985.

MALMSTRÖM, B. G.; LECKNER, J. The chemical biology of copper. Current opinion in 
chemical biology, v. 2, n. 2, p. 286-292, 1998.

MANSOUR, S. A.; SIDKY, M. M. Ecotoxicological studies. 3. Heavy metals contaminating water and fish from Fayoum Governorate, Egypt. Food Chemistry, v. 78, n. 1, p. 15-22, 2002.

MARKICH, S. J.; BROWN, P. L. Relative importance of natural and anthropogenic influences on the fresh surface water chemistry of the Hawkesbury-Nepean River, southeastern Australia. Science of the Total Environment, v. 217, n. 3, p. 201-230, 1998.

MARTINEZ, C. B. R. et al. Acute morphological and physiological effects of lead in the neotropical fish Prochilodus lineatus. Brazilian journal of biology $=$ Revista brasleira de biologia, v. 64, n. 4, p. 797-807, nov. 2004.

MARTÍNEZ-ÁLVAREZ, R. M.; MORALES, A. E.; SANZ, A. Antioxidant Defenses in Fish: Biotic and Abiotic Factors. Reviews in Fish Biology and Fisheries, v. 15, n. 1-2, p. 75-88, fev. 2005.

MASINI, J. C. et al. Comparison of methodologies for determination of carboxylic and phenolic groups in humic acids. Analytica Chimica Acta, v. 364, n. 1-3, p. 223-233, 1998.

MAZON, A F.; CERQUEIRA, C. C. C.; FERNANDES, M. N. Gill cellular changes induced by copper exposure in the South American tropical freshwater fish Prochilodus scrofa.

Environmental research, v. 88, p. 52-63, 2002.

MCGEER, J. C. et al. A Physiologically Based Biotic Ligand Model for Predicting the Acute Toxicity of Waterborne Silver to Rainbow Trout in Freshwaters. Environmental Science \& Technology, v. 34, n. 19, p. 4199-4207, out. 2000.

MEHTA, R.; TEMPLETON, D. M.; O’BRIEN, P. J. Mitochondrial involvement in genetically determined transition metal toxicity. II. Copper toxicity. Chemico-Biological Interactions, v. 163, n. 1-2, p. 77-85, 2006.

MELA, M. et al. Risks of waterborne copper exposure to a cultivated freshwater Neotropical catfish (Rhamdia quelen). Ecotoxicology and environmental safety, v. 88, p. 108-116, fev. 2013.

MENEZES, A. C. Toxicidade do cobre sobre tambaqui Colossoma macropomum (Cuvier, 1818) em pH 4 e pH 8. (Tese de Mestrado). Universidade Federal do Amazonas. Manaus. 2005.

MENG, S. L. et al. Hepatic antioxidant enzymes SOD and CAT of nile tilapia (oreochromis niloticus) in response to pesticide methomyl and recovery pattern. Bulletin of Environmental Contamination and Toxicology, v. 92, n. 4, p. 388-392, 2014.

MITCHELL, G. Mapping hazard from urban non-point pollution: A screening model to support sustainable urban drainage planning. Journal of Environmental Management, v. 74, n. 1, p. 1-9, 2005.

MONTEIRO, S. M. et al. Quantitative histopathology of Oreochromis niloticus gills after copper exposure. Journal of Fish Biology, v. 73, n. 6, p. 1376-1392, 2008. 
MOSLEH, Y. Y. et al. Metallothionein induction, antioxidative responses, glycogen and growth changes in Tubifex tubifex (Oligochaete) exposed to the fungicide, fenhexamid. Environmental pollution (Barking, Essex : 1987), v. 135, n. 1, p. 73-82, maio 2005.

NEDER, LYANDRA MARA ZANATTA. Alterações bioquímicas e cardio-respiratórias de Tilápia do Nilo (Oreochromis niloticus) frente à exposição sub-letal ao sulfato de cobre. São Carlos: UFSCar, 66 p. 2006.

NELSON, D.L; COX, M. M. LEHNINGER - Principles of biochemistry. 3. ed. New York: Worth Publishers, 2000. 1152 p.

OLIVA, M. et al. Sublethal and lethal toxicity in juvenile Senegal sole (Solea senegalensis) exposed to copper: a preliminary toxicity range-finding test. Experimental and toxicologic pathology : official journal of the Gesellschaft für Toxikologische Pathologie, v. 61, n. 2, p. 113-121, mar. 2009.

OLIVEIRA, C.P.F. Efeito do cobre e do chumbo presentes na água de formação derivada da extração do petróleo da província petroleira do Urucu - Am, sobre o tambaqui Colossoma macropomum (Curvier, 1818). (Dissertação de Mestrado). Instituto de Pesquisas da Amazônia, Universidade Federal do Amazonas. Manaus, 2003.

OLIVEIRA, M. et al. European eel (Anguilla anguilla L.) metallothionein, endocrine, metabolic and genotoxic responses to copper exposure. Ecotoxicology and Environmental Safety, v. 70, n. 1, p. 20-26, 2008.

ORUN, I. et al. Antioxidative role of selenium on some tissues of $(\mathrm{Cd} 2+), \mathrm{Cr} 3+)$-induced rainbow trout. Ecotoxicol Environ Saf, v. 71, n. 1, p. 71-75, 2008.

OZCELIK, D.; UZUN, H. Copper intoxication; Antioxidant defenses and oxidative damage in rat brain. Biological Trace Element Research, v. 127, n. 1, p. 45-52, 2009.

PACHECO, M.; SANTOS, M. A. Biotransformation, genotoxic, and histopathological effects of environmental contaminants in European eel (Anguilla anguilla L.). Ecotoxicology and Environmental Safety, v. 53, n. 3, p. 331-347, nov. 2002.

PAGLIA, D. E.; VALENTINE, W. N. Studies on the quantitative and qualitative characterization of erythrocyte glutathione peroxidase. The Journal of laboratory and clinical medicine, v. 70, n. 1, p. 158-169, jul. 1967.

PANDEY, S. et al. Effects of exposure to multiple trace metals on biochemical, histological and ultrastructural features of gills of a freshwater fish, Channa punctata Bloch. Chemicobiological interactions, v. 174, n. 3, p. 183-192, 11 ago. 2008.

PEDRAJAS, J. R.; PEINADO, J.; LÓPEZ-BAREA, J. Oxidative stress in fish exposed to model xenobiotics. Oxidatively modified forms of $\mathrm{Cu}, \mathrm{Zn}$-superoxide dismutase as potential biomarkers. Chemico-biological interactions, v. 98, n. 3, p. 267-282, 1995.

PERRY, S. F. The chloride cell: structure and function in the gills of freshwater fishes. Annual review of physiology, v. 59, n. 1, p. 325-347, 1 jan. 1997.

POLEKSIC, V.; MITROVIC-TUTUNDŽIC, V. Fish gills as a monitor of sublethal and chronic effects of pollution. IN: MÜLLER, R.; LLOYD, R. Sublethal and chronic effects of 
pollutants on freshwater fish. Oxford: Fishing News Books, cap.30, pp. 339-352, 1994.

POURANG, N. et al. Trace elements accumulation in edible tissues of five sturgeon species from the Caspian Sea. Environmental monitoring and assessment, v. 100, n. 1-3, p. 89108, jan. 2005.

PRASHANTH, M. S. Acute toxicity, behavioral and nitrogen metabolism changes of sodium cyanide affected on tissues of Tilapia mossambica (Perters). Drug and chemical toxicology, v. 35, n. 2, p. 178-183, 17 abr. 2012.

PROUSEK, J. Fenton chemistry in biology and medicine. Pure and Applied Chemistry, v. 79, n. 12, p. 2325-2338, 1 jan. 2007.

QUABIUS, E. S.; BALM, P. H.; WENDELAAR BONGA, S. E. Interrenal stress responsiveness of tilapia (Oreochromis mossambicus) is impaired by dietary exposure to PCB 126. General and comparative endocrinology, v. 108, n. 3, p. 472-482, 1997.

RANSBERRY, V. E. et al. Oxidative stress and metabolic responses to copper in freshwaterand seawater-acclimated killifish, Fundulus heteroclitus. Aquatic Toxicology, v. 161, p. 242$252,2015$.

RANSBERRY, V. E.; BLEWETT, T. A.; MCCLELLAND, G. B. The oxidative stress response in freshwater-acclimated killifish (Fundulus heteroclitus) to acute copper and hypoxia exposure. Comparative Biochemistry and Physiology Part C: Toxicology \& Pharmacology, v. 179, p. 11-18, 2016.

BRASIL. Ministério do Meio Ambiente, Conselho Nacional de Meio Ambiente, CONAMA. Resolução CONAMA nº 357, de 17 de março de 2005. - In: Resoluções, 2005. Disponível em: < http://www.mma.gov.br/port/conama/res/res05/res35705.pdf > Acesso em: 12 abril 2015.

REZENDE, K. F. O. et al. Histopathological and genotoxic effects of pollution on Nile Tilapia ( Oreochromis niloticus, Linnaeus, 1758) in the Billings Reservoir (Brazil). Toxicology Mechanisms and Methods, v. 24, n. 6, p. 404-411, 2014a.

REZENDE, K. F. O. et al. Histopathological and genotoxic effects of pollution on Nile Tilapia (Oreochromis niloticus, Linnaeus, 1758) in the Billings Reservoir (Brazil).

Toxicology mechanisms and methods, v. 24, n. 6, p. 404-411, set. 2014 b.

ROMÉO, M. et al. Cadmium and copper display different responses towards oxidative stress in the kidney of the sea bass Dicentrarchus labrax. Aquatic Toxicology, v. 48, n. 2-3, p. 185$194,2000$.

ROSETY-RODRÍGUEZ, M. et al. Morpho-histochemical changes in the gills of turbot, Scophthalmus maximus L., induced by sodium dodecyl sulfate. Ecotoxicology and environmental safety, v. 51, n. 3, p. 223-228, mar. 2002.

SANCHEZ, W. et al. Copper-induced oxidative stress in three-spined stickleback: relationship with hepatic metal levels. Environmental toxicology and pharmacology, v. 19, n. 1, p. 177-183, jan. 2005.

SANTOS, D. M. S. et al. Histological changes in gills of two fish species as indicators of 
water Quality in Jansen Lagoon (S??o Lu??s, Maranh??o State, Brazil). International Journal of Environmental Research and Public Health, v. 11, n. 12, p. 12927-12937, 2014.

SARGENTINI JUNIOR, É. et al. Substâncias húmicas aquáticas: fracionamento molecular e caracterização de rearranjos internos após complexação com íons metálicos. Química Nova, v. 24, n. 3, p. 339-344, 1 jun. 2001.

SCHWAIGER, J. et al. The use of histopathological indicators to evaluate contaminantrelated stress in fish. Journal of Aquatic Ecosystem Stress and Recovery, v. 6, n. 1, p. 7586, 1997.

SEVCIKOVA, M. et al. Metals as a cause of oxidative stress in fish: a review. Vet Med. v. 56, n. 11, p. 537-546, 2011.

SEYMORE DU PREEZ, H.H., T.; VAN VUREN, J. H. J. Bioaccumulation of chromium and nickel in the tissues of Barbus marequensis A. Smith, 1841 from the Lower Olifants River, Mpumalanga. South African Journal of Zoology, v. 31, n. 3, p. 101-109, 1996.

SIKORSKA, J.; WOLNICKI, J. Cadmium and copper toxicity to tench Tinca tinca (L.) larvae after a short-term exposure. Reviews in Fish Biology and Fisheries, v. 20, n. 3, p. 417-423, 2010 .

SIMONATO, J. D. et al. Biomarkers of waterborne copper exposure in the Neotropical fish Prochilodus lineatus. Aquatic Toxicology, v. 170, p. 31-41, 2016.

SONG, L. et al. A comparative analysis on the in vivo toxicity of copper nanoparticles in three species of freshwater fish. Chemosphere, v. 139, p. 181-189, 2015.

SORENSEN, E. M. B. Metal Poisoning in Fish. [s.1.] CRC Press, 1991.

SU??REZ-SERRANO, A. et al. Procambarus clarkii as a bioindicator of heavy metal pollution sources in the lower Ebro River and Delta. Ecotoxicology and Environmental Safety, v. 73, n. 3, p. 280-286, 2010.

SYASINA, I. G.; SOKOLOVSKII, A. S. Assessment of the State of Flounders from Sivuch'ya Bight (Peter the Great Bay, Sea of Japan) Based on Histopathological Parameters. Russian Journal of Marine Biology, v. 27, n. 2, p. 80-86, 2001.

TAEBI, A.; DROSTE, R. L. Pollution loads in urban runoff and sanitary wastewater. Science of the Total Environment, v. 327, n. 1-3, p. 175-184, 2004.

TAKASHIMA, F.; HIBIYA, T. An atlas of fish histology : normal and pathological features. 2nd. ed. Tokyo: Tokyo : Stuttgart ; New York : Kodansha ; Gustav Fischer [distributor], 1995. $195 \mathrm{p}$.

TAO, S. et al. Simulation of acid-base condition and copper speciation in the fish gill microenvironment. Computers and Chemistry, v. 25, n. 3, p. 215-222, 2001.

TAO, S. Copper Speciation in the Gill Microenvironment of Carp (Cyprinus carpio) at Various Levels of pH. Ecotoxicology and Environmental Safety, v. 52, n. 3, p. 221-226, 2002 . 
TAO, Y. et al. Distribution and bioaccumulation of heavy metals in aquatic organisms of different trophic levels and potential health risk assessment from Taihu lake, China.

Ecotoxicology and environmental safety, v. 81, p. 55-64, jul. 2012.

TAYLOR, E. W. et al. Toxicology of Aquatic Pollution. Cambridge: Cambridge University Press, 1996. 283 p.

TEMPLETON, D. M. et al. Guidelines for terms related to chemical speciation and fractionation of elements. Definitions, structural aspects, and methodological approaches (IUPAC Recommendations 2000). Pure and Applied Chemistry, v. 72, n. 8, p. 1453-1470, 2000.

THOPHON, S. et al. Histopathological alterations of white seabass, Lates calcarifer, in acute and subchronic cadmium exposure. Environmental Pollution, v. 121, n. 3, p. 307-320, 2003.

UEDA, J. et al. Reactive oxygen species generated from the reaction of copper(II) complexes with biological reductants cause DNA strand scission. Archives of biochemistry and biophysics, v. 357, n. 2, p. 231-239, 1998.

UNSAL, T.; SOZUDOGRU OK, S. Description of characteristics of humic substances from different waste materials. Bioresource Technology, v. 78, n. 3, p. 239-242, 2001.

U.S.EPA, United States Environmental Protection Agency.

http://www.epa.gov/owow/nps/facts/point1.htm, acessado em junho de 2005.

UYSAL, K. et al. The comparison of heavy metal accumulation ratios of some fish species in Enne Dame Lake (Kütahya/Turkey). Environmental monitoring and assessment, v. 157, n. $1-4$, p. 355-362, out. 2009.

VAN DEN HEUVEL, M. R. et al. Disease and gill lesions in yellow perch (Perca flavescens) exposed to oil sands mining-associated waters. Ecotoxicology and environmental safety, v. 46, p. 334-341, 2000.

VAN DYK, J. C.; COCHRANE, M. J.; WAGENAAR, G. M. Liver histopathology of the sharptooth catfish Clarias gariepinus as a biomarker of aquatic pollution. Chemosphere, v. 87, n. 4, p. 301-311, 2012.

VEGA, M. et al. Assessment of seasonal and polluting effects on the quality of river water by exploratory data analysis. Water Research, v. 32, n. 12, p. 3581-3592, 1998.

VELASQUEZ, I. B.; JACINTO, G. S.; VALERA, F. S. The speciation of dissolved copper, cadmium and zinc in Manila Bay, Philippines. Marine Pollution Bulletin, v. 45, n. 1-12, p. 210-217, 2002.

VELUSAMY, A. et al. Bioaccumulation of heavy metals in commercially important marine fishes from Mumbai Harbor, India. Marine pollution bulletin, v. 81, n. 1, p. 218-224, 15 abr. 2014.

WANG, T. et al. The potential toxicity of copper nanoparticles and copper sulphate on juvenile Epinephelus coioides. Aquatic toxicology (Amsterdam, Netherlands), v. 152, p. 96-104, 2014. 
WARREN, L. A.; HAACK, E. A. Biogeochemical controls on metal behavior in freshwater environments. Earth-Sciences Reviews, v. 54, p. 261-320, 2001.

WHATELY, M.; CUNHA, P.M. Guarapiranga 2005: Como e por que São Paulo está perdendo este manancial: resultados do diagnóstico socioambiental participativo da bacia hidrográfica da Guarapiranga. São Paulo: Instituto Sócio Ambiental. 51pp. 2006.

WHO. “Copper.” World Health Organization, Geneva, 1998.

WENGER, K.; TANDY, S.; NOWACK, B. Effects of chelating agents on trace metal speciation and bioavailability. Biogeochemistry of chelating agents, v. 910, n. February, p. 204-224, 2005.

WILSON, R. W.; TAYLOR, E. W. The physiological responses of freshwater rainbow trout, Oncorhynchus mykiss, during acutely lethal copper exposure. Journal of Comparative Physiology B, v. 163, n. 1, p. 38-47, 1993.

WU, Y.-L. et al. Dry Deposition of Atmospheric Contaminants: The Relative Importance of Aerodynamic, Boundary Layer, and Surface Resistances. Aerosol Science and Technology, v. 16, n. 1, p. 65-81, 1992.

YAMAZAKI, M.; TANIZAKI, Y.; SHIMOKAWA, T. Silver and other trace elements in a freshwater fish, Carasius auratus langsdorfii, from the Asakawa River in Tokyo, Japan.

Environmental pollution (Barking, Essex : 1987), v. 94, n. 1, p. 83-90, jan. 1996. 